UNIVERSIDADE DE SÃO PAULO

ESCOLA DE ENFERMAGEM

MARCELA PADILHA FACETTO AZEVEDO

INFECÇÕES CIRÚRGICAS EM ORTOPEDIA CAUSADAS POR MICOBACTÉRIAS DE CRESCIMENTO RÁPIDO: REVISÃO INTEGRATIVA DA LITERATURA

SÃO PAULO 
MARCELA PADILHA FACETTO AZEVEDO

\section{INFECÇÕES CIRÚRGICAS EM ORTOPEDIA CAUSADAS POR MICOBACTÉRIAS DE CRESCIMENTO RÁPIDO: REVISÃO INTEGRATIVA DA LITERATURA}

Dissertação apresentada à Escola de Enfermagem da Universidade de São Paulo, para obtenção do título de Mestre em Enfermagem.

Área de Concentração:

Enfermagem na Saúde do Adulto

Orientadora:

Prof $^{a}$ Dr $^{\mathrm{a}}$ Ruth Natalia Teresa Turrini

SÃO PAULO

2012 
AUTORIZO A REPRODUÇÃO E DIVULGAÇÃO TOTAL OU PARCIAL DESTE TRABALHO, POR QUALQUER MEIO CONVENCIONAL OU ELETRÔNICO, PARA FINS DE ESTUDO E PESQUISA, DESDE QUE CITADA A FONTE.

Assinatura:

Data:

Catalogação na Publicação (CIP)

Biblioteca "Wanda de Aguiar Horta"

Escola de Enfermagem da Universidade de São Paulo

Azevedo, Marcela Padilha Facetto

Infecções cirúrgicas em ortopedia, causadas por micobactérias de crescimento rápido: revisão integrativa da literatura / Marcela Padilha

Facetto Azevedo. -- São Paulo, 2012.

$150 p$.

Dissertação (Mestrado) - Escola de Enfermagem da Universidade de São Paulo.

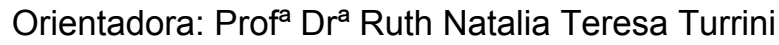

Área de concentração: Saúde do adulto

1. Infecção hospitalar 2. Micobacteriose 3. Cirurgia

ortopédica I. Título. 
FOLHA DE APROVAÇÃO

Nome: Marcela Padilha Facetto Azevedo

Título: Infecções cirúrgicas em ortopedia, causadas por Micobactérias de Crescimento Rápido: Revisão Integrativa da Literatura

Dissertação apresentada à Escola de Enfermagem da Universidade de São Paulo, para obtenção do título de Mestre em Enfermagem.

Área de Concentração: Enfermagem na Saúde do Adulto

Aprovado em:

\section{Banca Examinadora}

Profa $^{a}$. Dra ${ }^{\mathrm{a}}$. Instituição:

Julgamento: Assinatura:

Profa. ${ }^{a}{ }^{a}$. Instituição:

Julgamento: Assinatura:

Profa. Dra Instituição: Julgamento: Assinatura: 


\section{DEDICATÓRIA}

Ao meu pai, in memorian, pelo carinho, amor e incentivo aos estudos. A minha mãe, pela dedicação aos filhos, amor, compreensão e prontidão. Ao meu irmão, pelo companheirismo, amor e cumplicidade. Amo vocês.

Ao meu marido, pelos quinze anos de convivência, em que me ajudou a superar meus desafios. Obrigada por entender a minha ausência, durante o transcorrer deste trabalho. Sou grata, também, pelas valiosas contribuições, para conclusão da dissertação. Amo você. 


\section{AGRADECIMENTOS}

À minha orientadora, pelo conhecimento e competência. Sou grata por ter possibilitado uma convivência harmoniosa entre nós, obrigada pela paciência e por me receber nos seus horários de descanso; além do aprendizado pessoal;

Às Professoras $\mathrm{Dr}^{\mathrm{a}}$. Rúbia Aparecida Lacerda e $\mathrm{Dr}^{\mathrm{a}}$. Kazuko Uchikawa Graziano, pelo conhecimento transmitido na disciplina e também através da elaboração do artigo; além do grupo de pesquisa;

Aos professores da EEUSP e da Saúde Pública, que me ensinaram muito nas disciplinas;

À biblioteca e as secretarias do ENC e da pós-graduação;

Ao financiamento da CAPES pela concessão de bolsa de Mestrado;

À minha cunhada, em especial, que me ajudou muito no transcorrer desta pesquisa, obrigada pela amizade;

À minha sogra, que também ajudou bastante, na conclusão deste trabalho, obrigada pelo aprendizado;

Ao meu sogro pela paciência e compreensão;

Aos meus amigos que me apoiaram nos momentos mais exaustivos e tiveram compreensão nos meus períodos de ausência;

A Cristina, que conheci no mestrado e nos tornamos grandes amigas, obrigada pela ajuda de sempre;

Enfim, a todos aqueles que fizeram com que este trabalho fosse concluído. 
Azevedo MPF. Infecções Cirúrgicas em Ortopedia, causadas por Micobactérias de Crescimento Rápido: Revisão Integrativa da Literatura [dissertação]. São Paulo: Escola de Enfermagem, Universidade de São Paulo; 2012.

\section{RESUMO}

As micobacterioses são doenças causadas por micobactérias não tuberculosas pertencentes ao gênero Mycobacterium. As infecções por micobactéria de crescimento rápido (MCR) estão fortemente relacionadas às falhas nos processos de limpeza, desinfecção e esterilização de produtos médicos. Objetiva-se, analisar a ocorrência de infecções de sítio cirúrgico, por MCR, em pacientes submetidos a procedimentos ortopédicos, por meio de revisão integrativa; caracterizar as infecções de sítio cirúrgico (ISC) por MCR; verificar a presença de fatores que possam explicar as infecções de sítio cirúrgico por MCR. Como método utilizou-se a revisão integrativa, a qual contém as seguintes etapas: elaboração da questão da pesquisa; estabelecimento de critérios de inclusão e exclusão; definição das informações a serem extraídas do estudo; avaliação dos estudos incluídos; interpretação dos resultados e apresentação da revisão. No resultado foram encontrados 21 artigos, a maioria publicada no idioma inglês, e dois em francês, variando quanto ao continente e país de origem de edição. O tempo entre a cirurgia e o início dos sintomas foi mencionado para os 34 (100\%) pacientes, mas a análise foi feita para 33 pacientes, pois se considerou apenas o primeiro episódio de infecção por MCR. O tempo médio para o diagnóstico da ISC foi de 653,6 dias (93 semanas), desvio padrão \pm 1.343 dias (192 semanas), mediana de 80 dias (11,4 semanas) e moda de 90 dias (três meses). Quanto aos sinais e sintomas relatados pelos pacientes, os mais prevalentes foram: dor $(61,8 \%)$, secreção $(50,0 \%)$, edema $(41,2 \%)$, febre $(41,2 \%)$, eritema $(26,5 \%)$, fístula $(20,6 \%)$, calor $(14,7 \%)$, tremor $(5,9 \%)$, abscesso $(5,9 \%)$ e hematoma $(3,0 \%)$. Em relação às intervenções cirúrgicas efetuadas nos pacientes, após o diagnóstico de ISC, a mais frequente foi a antibioticoterapia (100\%), remoção de prótese total $(50,0 \%)$, drenagem $(41,2 \%)$, debridamento cirúrgico $(41,2 \%)$, irrigação $(23,5 \%)$, revisão cirúrgica 
$(17,6 \%)$ troca da prótese total $(8,8 \%)$, remoção de componentes da prótese $(8,8 \%)$ e reimplante da prótese (2,9\%). A identificação do(s) agente(s) etiológico(s) da(s) ISCs não seguiu uma metodologia de rotina, o que pode influenciar na confiabilidade do resultado, principalmente quanto à espécie do agente etiológico. Quanto à espécie de MCR isoladas dos sítios de infecção constatamos que M.fortuitum foi a mais prevalente; tendo sido isolados também M.chelonae, M.abscessus, M.goodii, M.smegmatis, M.farcinogenes e M.wolinskyi. Em relação às fontes investigadas, tem-se: provavelmente de origem iatrogênica, hábito do médico residente de ortopedia, presente nas cirurgias, de utilizar a hidromassagem antes de operar; componentes líquidos ou pó do cimento metilmetacrilato ou a prótese metálica; injeções de cortisona por sinovite crônica, durante cinco anos, antes da cirurgia; sistema de ar condicionado ou a solução de imersão para enxágue da prótese; sabão na água, onde foi realizada a imersão do pé (recomendação do podólogo); parafuso bioabsorvível utilizado na cirurgia; injeções intra-articulares de dexametasona; no entanto, nenhuma delas pode ser confirmada. Quando feito o teste de senbilidade observou-se que as cepas apresentavam em torno de $80 \%$ de sensibilidade à amicacina, claritromicina e ciprofloxacina.

PALAVRA-CHAVE: infecção hospitalar; micobacteriose; cirurgia ortopédica 
Azevedo M. P. F. Orthopedic surgical infections caused by rapidly growing mycobacteria: Integrative Review of Literature [dissertation]. São Paulo: School of Nursing, University of São Paulo; 2012.

\begin{abstract}
The mycobacteriosis is a disease caused by nontuberculous mycobacteria belonged to the Mycobacterium genus. Infections due to rapidly growing mycobacteria (RGM) are strongly related to failures in the processes of cleaning, disinfection and sterilization of medical products. The objective is to analyze the occurrence of surgical site infections by RGM in patients undergoing orthopedic procedures through integrative review; to characterize the surgical site infections (SSI) by RGM; and to verify the presence of factors that may explain the surgical site infections by RGM. The method was the integrative review, which includes the following steps: elaboration of the research question; establishment of inclusion and exclusion criteria; definition of information to be extracted from the study; assessment of the included studies; interpretation of results; and presentation of the review. 21 articles were found, mostly published in English and two in French, varying considering the continent and country of the origin of the article. The time between surgery and onset of symptoms was reported by 34 (100\%) patients, but the analysis was performed for 33 patients because it was considered only the first episode of infection by RGM. The average time to diagnosis of SSI was 653.6 days (93 weeks), standard deviation \pm 1343 days (192 weeks), median of 80 days (11.4 weeks) and mode of 90 days (three months). The most prevalent signs and symptoms reported by patients were: pain $(61.8 \%)$, secretion $(50.0 \%)$, edema $(41.2 \%)$, fever $(41.2 \%)$, erythema (26.5\%), fistula (20.6\%), heat (14.7\%), tremor $(5.9 \%)$, abscess $(5.9 \%)$ and hematoma (3.0\%). Regarding surgical interventions performed in patients after diagnosis of SSI, the most frequent was antibiotic therapy $(100 \%)$, removal of dentures $(50.0 \%)$, drainage $(41.2 \%)$, surgical debridement $(41.2 \%)$, irrigation $(23.5 \%)$, surgical revision $(17.6 \%)$, replacement of dentures $(8.8 \%)$, removal of the prosthetic components $(8.8 \%)$, and
\end{abstract}


reimplantation of the prosthesis $(2.9 \%)$. The identification of etiological agent(s) of SSI did not follow a routine methodology, which can influence the reliability of the results, especially regarding the kind of etiologic agent. Related to the kind of isolated RGM of the infection sites, it was found that M.fortuitum was the most prevalent; being also isolated the M.chelonae, M.abscessus, M.goodii, M.smegmatis, M.farcinogenes and M.wolinskyi. Regarding the sources investigated: probably from iatrogenic origin, it is habits of residents in orthopedics during surgeries to use hydromassage before operating; liquid components or cement powder of methylmethacrylate or metal prosthesis; cortisone injections for chronic synovitis during 5 years before surgery; air conditioning system or soaking solution to rinse the denture; soap in the water, where it was accomplished the immersion foot (podiatrist's recommendation); bioabsorbable screws used in surgery; intraarticular injections of dexamethasone; however, none of them can be confirmed. When the sensitivity test was done, it was observed that the strains had approximately $80 \%$ of sensitivity to amikacin, clarithromycin, ciprofloxacin. Quando feito o teste de senbilidade observou-se que as cepas apresentavam em torno de $80 \%$ de sensibilidade à amicacina, claritromicina e ciprofloxacina.

KEYWORDS: cross infection; mycobacteriosis; orthopedic surgery 


\section{LISTA DE FIGURAS}

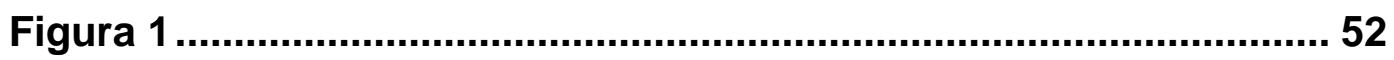

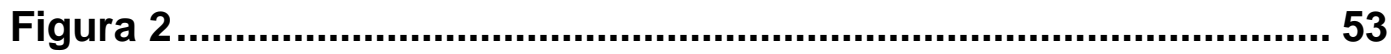

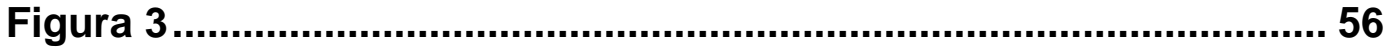

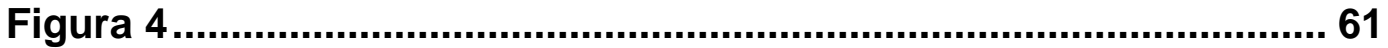

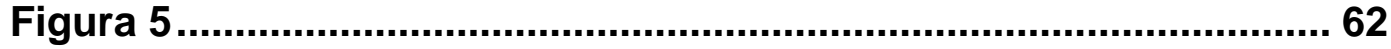

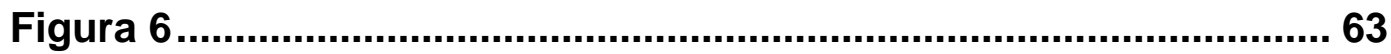

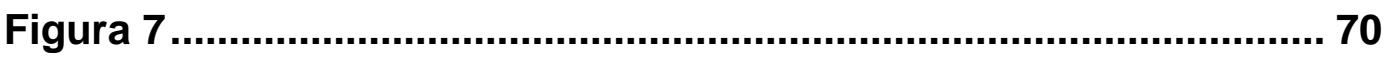




\section{LISTA DE TABELAS}

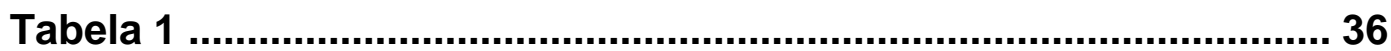

Tabela 2 ........................................................................................... 38

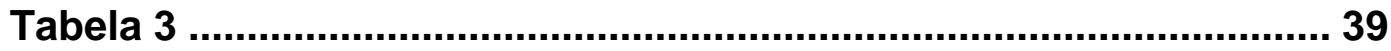

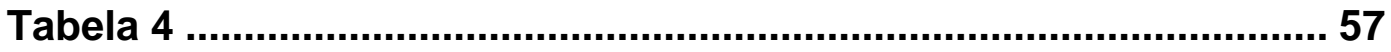

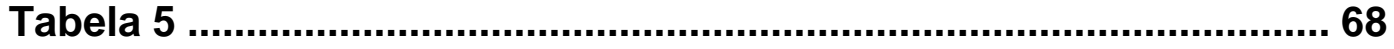

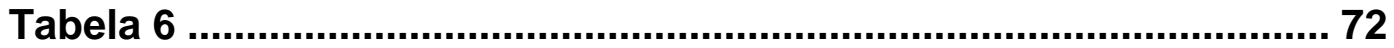

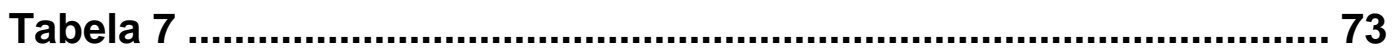

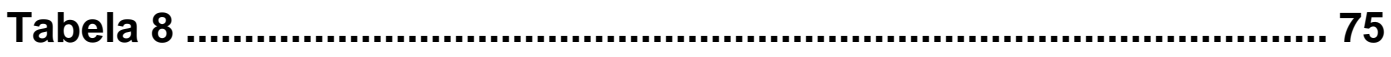




\section{LISTA DE QUADROS}

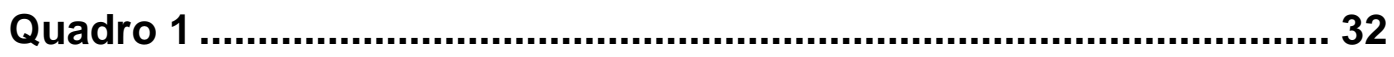

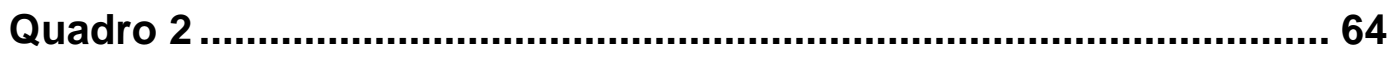

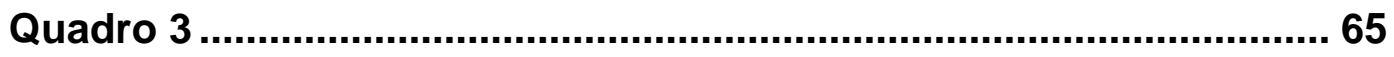


SIGLAS

\begin{tabular}{|l|l|}
\hline AIDS & Síndrome da Imunodeficiência Adquirida \\
\hline ANVISA & Agência Nacional de Vigilância Sanitária \\
\hline ASA & American Society of Anesthesiology \\
\hline ATS & American Thoracic Society \\
\hline BVS & Biblioteca Virtual em Saúde \\
\hline CCIH & Comissão de Controle de Infecção Hospitalar \\
\hline CDC & Center Disease Control \\
\hline CFT & Comissão de Farmácia e Terapêutica \\
\hline IH & Infecção Hospitalar \\
\hline INR & International Normalized Ratio \\
\hline IRAS & Infecção Relacionada à Assitência a Saúde \\
\hline ISC & Infecção de Sítio Cirúrgico \\
\hline MCR & Micobactérias de Crescimento Rápido \\
\hline MNT & Micobactérias Não Tuberculosas \\
\hline MS & Ministério das Saúde \\
\hline NNIS & National Nosocomial Infections Surveillance \\
\hline OMS & Organização Mundial da Saúde \\
\hline PBE & Prática Baseada em Evidências \\
\hline RENISS & $\begin{array}{l}\text { Rede Nacional de Investigação de Surtos e Eventos } \\
\text { Adversos em Serviços de Saúde }\end{array}$ \\
\hline SVS & Secretaria de Vigilância Sanitária \\
\hline
\end{tabular}




\section{SUMÁRIO}

2. INTRODUÇÃO 17

2.1. Infecção Hospitalar e Infecção de Sítio Cirúrgico ............................. 17

2.2. Infecção de Sítio Cirúrgico em Ortopedia ....................................... 21

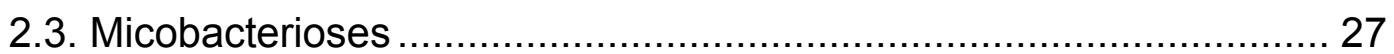

2.4. Características gerais de Mycobacterium spp. ............................. 37

2.5. Isolamento e Identificação de MNT / MCR ....................................... 39

2.6. Considerações sobre as infecções hospitalares por MCR ................ 41

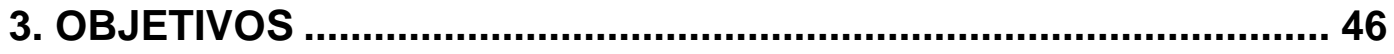

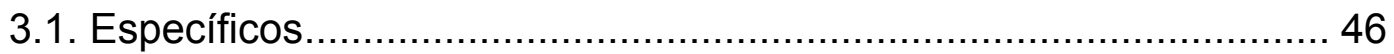

4. MATERIAL E MÉTODOS

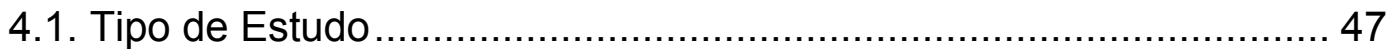

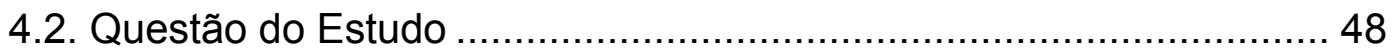

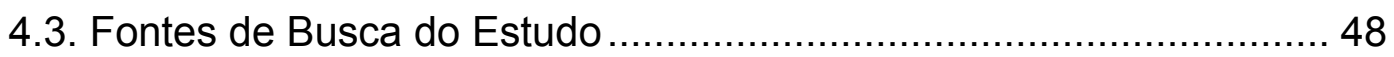

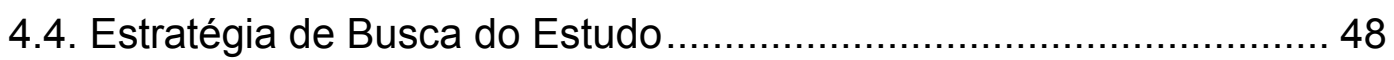

4.5. Critérios de Inclusão e Exclusão .................................................. 50

4.6. Procedimento de busca do material de análise .............................. 50

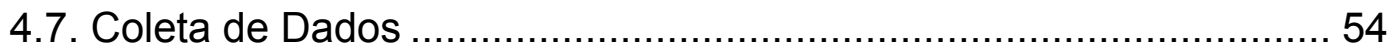

4.8. Síntese e Avaliação dos Artigos .................................................. 54

4.9. Interpretação e Discussão dos Resultados....................................... 54

4.10. Conclusão e Apresentação da Revisão Integrativa ........................ 54

5. RESULTADOS

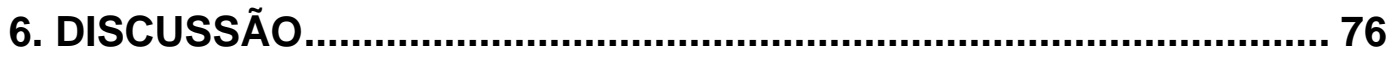


7. CONCLUSÕES.

8. REFERÊNCIAS

9. REFERÊNCIAS DOS ARTIGOS ANALISADOS............................ 124

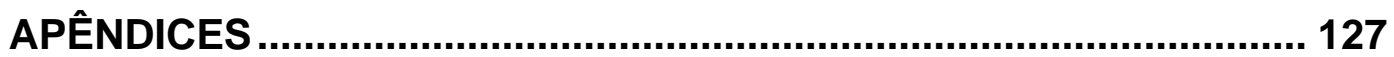

APÊNDICE A - Quadro 1 - Instrumento para coleta de dados................ 127

APÊNDICE B - Quadro 1 - Síntese do Estudo 1 - Estudo de Caso. São

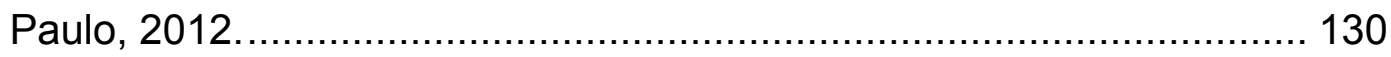




\section{IMPORTÂNCIA DO TEMA}

$\mathrm{Na}$ década de 1990, as Infecções Hospitalares (IH) por micobactérias atípicas acometiam, principalmente, pacientes imunodeprimidos, com predomínio de infecções pulmonares ou lesões localizadas (Falkinham, 1996). Na última década tem-se observado um aumento de infecções hospitalares por esses micro-organismos, em pacientes submetidos a procedimentos cirúrgicos, em particular, ortopédicos (Cheung, Wilson, 2007; Porat, Austin, 2008; Yinkey et al, 2010).

Em relação à ocorrência de Micobactérias Não Tuberculosas (MNT), o risco de infecção nos sítios cirúrgicos tornou-se uma problemática séria nos Serviços de Saúde. Ainda, é considerada, pela instância federal, emergência epidemiológica e sua investigação está sendo conduzida de modo articulado pela Agência Nacional de Vigilância Sanitária (ANVISA) e Ministério da Saúde, aliados as vigilâncias epidemiológicas e sanitárias, dos estados e municípios brasileiros (Brasil, 2008).

Fontana (2008) alerta que danos ao paciente, relacionados aos aspectos psicológicos e físicos, decorrentes de situações como dor, sofrimento e isolamento são variáveis importantes e de difícil avaliação econômica e financeira, o que implica, também, na necessidade de disponibilidade de recursos terapêuticos do Estado para seu tratamento.

As micobacterioses têm mobilizado os órgãos de vigilância epidemiológica e sanitária na avaliação dos surtos e das práticas hospitalares, mas algumas lacunas sobre a epidemiologia dessas infecções de origem hospitalar persistem, como por exemplo, como se explica que micro-organismos que infectavam pacientes imunodeprimidos ou com determinadas afecções crônicas passaram a infectar pacientes cirúrgicos?

Objetiva-se, com este estudo, apresentar uma revisão integrativa da literatura, acerca da $\mathrm{IH}$ causada por micobactérias de crescimento rápido (MCR), na tentativa de melhor compreender as mudanças epidemiológicas na ocorrência dessas infecções, no ambiente hospitalar. Esta revisão tem sua relevância científica, quando pretende aprofundar o conhecimento sobre um problema de Saúde Pública, no caso a micobacteriose atípica de origem 
hospitalar, capaz de provocar danos físicos e, consequentemente, emocionais ao paciente, principalmente quando deixa sequelas estéticas.

Desta forma, este estudo se desenvolverá a partir da seguinte questão: Há fatores em comum que explicam as infecções hospitalares por MCR, em procedimentos cirúrgicos ortopédicos? 


\section{INTRODUÇÃO}

\subsection{Infecção Hospitalar e Infecção de Sítio Cirúrgico}

A IH é conceituada como qualquer infecção adquirida ou transmitida após a internação do paciente, que se manifeste durante a mesma, ou após a alta, quando puder ser relacionada com a internação ou com os procedimentos realizados (Brasil, 1998).

O Center for Diseases Control and Prevention (CDC) é mais especifico, ao conceituar a $\mathrm{IH}$ como infecção local ou sistêmica, que ocorre após 48 horas da admissão hospitalar; em até 48 horas após a alta da Unidade de Terapia Intensiva; e em 30 dias após a cirurgia sem colocação de prótese ou em até um ano, se houver colocação de prótese (Garner et al., 1988).

Se a IH, contudo, pode ser conceituada desde a sua origem, quando foram criados os primeiros hospitais, na Idade Média, as suas características de manifestação não permaneceram as mesmas, assim como os seus fatores de risco e causalidades (Lacerda, Egry, 1997). As autoras consideram que a história da ocorrência de $\mathrm{IH}$ e de suas práticas de prevenção e controle mantém uma relação estreita com a própria história das concepções dominantes do processo saúde-doença na sociedade ocidental e de suas formas de inserção e de intervenção no hospital.

É preciso considerar que a $\mathrm{IH}$ não é uma doença infecciosa qualquer, mas decorrente da evolução das práticas de assistência à saúde, que culminaram na predominância do modelo clínico, de características eminentemente invasivas, desenvolvido, predominantemente, no hospital. Desse modo, a ocorrência de IH não é um fenômeno meramente biológico e universal e, sim, histórico-social (Lacerda, 2003).

A IH predispõe ao aumento da morbidade e mortalidade dos indivíduos, assim como determina o aumento dos custos diretos e indiretos, tais como aqueles ocasionados pelo hospital em decorrência dessa condição e aqueles advindos da descontinuidade do trabalho e da produção do paciente, respectivamente (Fontana, 2008). 
O termo $\mathrm{IH}$, atualmente, foi substituído por Infecção Relacionada à Assistência à Saúde (IRAS), no qual passa a incluir não apenas as infecções ocorridas nos hospitais, mas também, aquelas decorrentes de procedimentos terapêuticos realizados fora desse ambiente, como clínicas e domicílios. É uma das consequências decorrentes da invasão do hospedeiro e da multiplicação de micro-organismos de sua própria microbiota ou daqueles provenientes dos artigos médico-hospitalares, da equipe assistencial ou do ambiente e sua prevenção e controle são considerados passos fundamentais para a segurança e qualidade de assistência à saúde (Díaz-Agero-Pérez et al., 2011).

A maioria das IRAS manifesta-se como complicações naturais de pacientes debilitados, decorrente do desequilíbrio entre a microbiota endógena e os seus mecanismos de defesa. Esse desequilíbrio é provocado por determinadas doenças, procedimentos invasivos ou imunossupressivos a que o paciente foi submetido. Consequentemente, algumas infecções são evitáveis e outras não. Assim, as medidas de prevenção e controle não são capazes de evitar a IRAS, cuja ocorrência não indica que o hospital ou a sua equipe tenham cometido erros na assistência prestada ao paciente (Fernandes et al., 2000; Focaccia e Veronesi, 2004).

A vigilância epidemiológica das $\mathrm{IH}$, segundo a Portaria 2.616/98, do Ministério da Saúde (MS) recomenda a busca ativa, sistemática e continua da ocorrência de IH entre pacientes hospitalizados ou não e dos eventos e condições que podem ser trabalhados para a sua prevenção e controle (Brasil, 1998). Os principais objetivos da vigilância das IRAS são determinar taxas, detectar mudanças de padrões assistenciais e identificar as características dos micro-organismos causadores, bem como dos fatores de riscos envolvidos, visando determinar medidas para a redução de sua incidência (Pérez et al., 2009).

O Programa de Vigilância de IRAS (2004 a 2006), no Estado de São Paulo, Brasil, envolvendo as unidades de centro cirúrgico, terapia intensiva e berçário de alto risco e com a participação de $51,1 \%(n=457)$ dos hospitais credenciados no banco de dados nacional, apresentou resultados preliminares que já puderam ser utilizados na educação, vigilância e 
prevenção das infecções. O sucesso na coleta de dados e a maior adesão das instituições poderão contribuir na avaliação do impacto das intervenções e melhor distribuição de recursos no Estado (Padoveze et al., 2010).

Para as infecções em cirurgia, o CDC recomenda que se deve utilizar o termo infecção do sítio cirúrgico (ISC) em substituição à infecção da ferida cirúrgica, visto que "nem toda infecção relacionada à manipulação cirúrgica ocorre na ferida propriamente dita, mas também em órgãos ou espaços abordados durante a operação", e pode desenvolver-se de 30 dias a um ano após a realização do procedimento cirúrgico, como no implante de prótese ou retirada da mesma (Poveda et al., 2003).

Dados do Estudo Brasileiro da Magnitude das IH e Avaliação da Qualidade das Ações de Controle de $\mathrm{IH}$, realizado entre maio e agosto de 1994, no Brasil, apontam uma taxa de IH de $15,5 \%$, sendo que a ISC foi a segunda mais frequente, com 15,6\% desse montante (Prade et al., 1995).

O sistema de saúde, as instituições e os profissionais deveriam incluir em suas discussões para a qualificação da assistência, todos os aspectos envolvidos quando um indivíduo desenvolve ISC (Torres, 2011). Anderson et al. (2010), para minimizar o sofrimento decorrente das ISC, defende o emprego, em todas as fases do cuidado, de estratégias para a sua prevenção.

A classificação das ISC, divide-se em, incisionais superficiais ou profundas e infecções de órgãos e cavidades. As incisionais superficiais ocorrem até 30 dias após o procedimento e envolvem apenas pele e tecido subcutâneo; as incisionais profundas são identificadas até 30 dias após o procedimento, ou até um ano, quando houver implantes envolvendo as partes moles (fáscia e músculo); quando a ISC envolve órgãos ou espaços manipulados durante o procedimento cirúrgico, com exceção das infecções de pele e as partes moles, e ocorre até 30 dias após a sua realização ou até um ano, quando na presença de implantes, passa a ser denominada infecção de órgãos e cavidades (Mangram et al., 1999).

As infecções incisionais ou profundas podem ser classificadas como primárias ou secundárias, segundo o local do sítio cirúrgico, quando a cirurgia envolve uma ou mais incisões. As infecções primárias são identificadas na 
incisão primária, e as secundárias ocorrem nas demais incisões, por exemplo, em cirurgias de revascularização do miocárdio com pontes de safena. Nesse caso, o paciente tem a incisão cirúrgica primária no tórax e a(s) incisão(ões) secundária(s) nos membros inferiores (Mangram et al., 1999).

De acordo com Astagneau, L'Hériteau (2010), a ISC é uma das infecções que mais preocupa as instituições de saúde, apesar do amplo conhecimento dos fatores predisponentes, endógenos e exógenos; devido a questões relacionadas aos aspectos de vigilância e ao retorno de dados, os quais ainda são controversos. Além disso, a ocorrência de ISC pode significar prolongamento da internação e readmissões longas e de alto custo, com necessidade de novas intervenções cirúrgicas.

Inúmeros micro-organismos, normalmente, colonizam a pele, e são comumente responsáveis pela instalação de um processo infeccioso; portanto, diagnosticar uma infecção associada a um procedimento cirúrgico, requer, não apenas documentação microbiológica, mas também, manifestações clínicas (Torres, 2011)

Qualquer ato operatório tem como risco inerente, a ISC, que esta associada a uma complexa relação de fatores pertinentes ao próprio procedimento, assim como às condições físicas e clínicas do indivíduo (Culver et al., 1991). Desde a década de 1980, tem-se chamado à atenção para a relação entre procedimentos específicos e gerais, e riscos do paciente cirúrgico, mais especificamente sobre a infecção pós-operatória. Nos anos 1990, houve maior entendimento acerca de indivíduos com maior ou menor risco, de acordo com os procedimentos e, a partir daí até nossos dias, o enfoque é diferenciado para cada grupo de risco (Nichols, 2004).

As ISC geralmente estão entre as três principais topografias de $\mathrm{IH}$. Em um estudo conduzido pelo CDC no período compreendido entre 1986 e 1996, a ISC foi a mais comum em pacientes cirúrgicos, perfazendo $38 \%$ de todas as infecções hospitalares (Mangram et al., 1999).

Em um estudo realizado no Canadá, em 2002, foi identificada a ISC (2,5\% dos casos) como a terceira infecção mais frequente dentre todas, precedida apenas pelas infecções do trato urinário e pneumonias (Gravel et al., 2007). 
No Brasil observa-se fenômeno semelhante, a ISC ocupa a terceira posição entre todas as infecções em serviços de saúde e compreende de 14 a $16 \%$ das infecções em pacientes hospitalizados, com taxa de incidência de 11\% (Brasil, 2009e).

O conhecimento de fatores de risco associados a todas as etapas do cuidado cirúrgico seria uma estratégia considerada ideal para a prevenção de ISC, e entende-se que é de conhecimento geral os cuidados a serem dispensados ao indivíduo, equipe e ambiente, nas fases cirúrgicas, no sentido de controlar os fatores de risco relacionados à ISC (Torres, 2011)

\subsection{Infecção de Sítio Cirúrgico em Ortopedia}

A ISC é definida como aquela que acomete tecido, órgão incisado e cavidade manipulada durante um procedimento cirúrgico, e pode ocorrer em decorrência de um ato operatório. Geralmente, as ISCs relacionadas aos procedimentos ortopédicos são consideradas graves; pois nessas cirurgias são utilizadas próteses, o que aumenta o risco de um quadro infeccioso e complicações que podem levar à perda do membro operado e até à morte (Khan et al., 2008).

A taxa de infecção em artroplastias totais e parciais, observada em um estudo de revisão de 305 pacientes submetidos a tal procedimento, realizado em hospital universitário geral de Belo Horizonte (MG-Brasil) foi de $8,5 \%$. As ISCs diagnosticadas ainda na internação foram todas do tipo incisional superficial, enquanto pós-alta foram identificadas apenas seis ISCs $(23,1 \%)$, sendo três superficiais e três profundas (Ercole, Chianca 2002). Outro estudo brasileiro, envolvendo quatro hospitais terciários também da cidade de Belo Horizonte (MG-Brasil), observou uma taxa de infecção em cirúrgicas ortopédicas de 1,4\%; sendo de 1,5\% nas artroplastias de joelho e 2,2\% naquelas de quadril (Ercole et al., 2011a). Uma terceira investigação realizada na mesma cidade, mas em apenas um hospital plúbico com dados de 2005 a 2007 e de internação hospitalar, identificou uma taxa de ISC em cirurgias ortopédicas de $1,8 \%$, sendo $33 \%$ de osteomielites e $43 \%$ de infecções profundas. Nesta análise foram obtidos os seguintes fatores de risco por análise univariada: tempo de cirurgia; potencial de contaminação 
da ferida; classificação através do American Society of Anesthesiology (ASA) do estado clínico do paciente; tipo de cirurgia; cirurgia de emergência e presença de implante (Ercole et al., 2011b).

As diferenças observadas nos três estudos, embora na mesma cidade, refletem características próprias dos hospitais envolvidos quanto a adesão às medidas de controle de ISC e às características dos pacientes, bem como tipo de cirurgias ortopédicas.

A presença da prótese é reconhecida pela sua capacidade para potencializar uma infecção, e desenvolver resistência do sistema imunológico aos agentes antimicrobianos. Considera-se, ainda, que o tipo de material utilizado para confecção da prótese, bem como, o seu formato, podem ser determinantes para a colonização bacteriana de suas superfícies (Dale et al., 2011).

Quando se estudam apenas artroplastias, os fatores de risco identificados podem ser diferentes. Estudo prospectivo caso-controle de oito anos com vigilância para ISC dos pacientes submetidos à artroplastia de quadril ou joelho, durante 12 meses, para estudar fatores de risco, observou que nas artroplastias de joelho a presença de secreção na ferida operatória esteve associada ao maior risco para ISC, enquanto a presença de dreno ao menor risco. Por outro lado, nas cirurgias de quadril, o índice de massa corporal, a perda de dreno foram fatores de risco. Quando a coorte foi analisada em conjunto, o uso de esteróide sistêmico, maior perda de drenos, presença de secreção na ferida operatória foram fatores preditores de infecção. O tempo médio para aparecimento da infecção foi de 54 dias (5 a 277 dias), principal agente etiológico S.aureus (40,0\%). Os autores confirmaram a hipótese de que o local da artroplastia pode apresentar fatores de risco diferentes para a ISC (Peel et al., 2011).

A revisão cirúrgica é um procedimento frequente nos casos de infecção em próteses. Estudo sobre infecções em implante total de quadril, que necessitaram de revisão cirúrgica, reviu os dados de 80.756 pacientes submetidos a artroplastia primária no período de 1995 a 2008, a partir do Danish Hip Artroplasty Registry, para identificar fatores de risco relacionados ao paciente e cirurgia. No período de estudo foram identificados $0,7 \%$ 
infecções pós-artroplastias, sendo que em 50,0\% dos casos foi preciso remover a prótese totalmente, $25 \%$ troca total da prótese e em $24 \%$ troca parcial da prótese. Observou-se maior risco relativo para infecção nos pacientes do sexo masculino e naqueles com diagnóstico de necrose de cabeça de fêmur avascular não-traumática previamente à cirurgia. $\mathrm{O}$ risco relativo também foi maior em pacientes com prótese híbrida e cimentada sem antibióticos, e nos procedimentos com duração superior a duas horas (Pedersen et al., 2010).

A técnica cirúrgica para o implante também mostra resultados distintos na análise de fatores de risco quando se separam os pacientes que necessitaram de revisão do implante. Estudo retrospectivo sobre infecção pós artropastia total e hemiartroplastia com dados obtidos de três bancos nacionais, Norwegian Artroplasty Register, Norwegian Fracture Register, Norwegian Surveillance System for Healthcare-Associated Infections no período de 2005 a 2009, encontrou as seguintes incidências de ISC: 3\% para as artroplastias (1,7\% infecções incisionais superficiais, 1,3\% profundas e $1,0 \%$ de ISC reoperadas) e $7,3 \%$ para as hemiartroplastias $(2,2 \%$ infecções incisionais superficiais, $5,1 \%$ profundas e $3,6 \%$ de ISC reoperadas). A incidência de revisão cirúrgica devido à infecção nas artroplastias e hemiartroplastias foi de $0,7 \%$ e $1,5 \%$, respectivamente. Quanto aos fatores de risco para ISC foram identificados idade $>80$ anos e ASA $\geq 3$; e para a revisão cirúrgica por infecção foram estatisticamente significativos a fixação da prótese sem cimento, cirurgia de emergência, escore de risco do National Nosocomial Infections Surveillance (NNIS) $\geq 2$ (ajustado por idade, sexo, tipo de cirurgia e método de fixação), idade $>70$ anos e sexo masculino (Dale et al., 2011).

As taxas de infecção tendem a ser maiores quando os serviços são capazes de recuperar as ISCs ocorridas pós-alta. Estudo sobre o impacto da vigilância pós-alta em pacientes submetidos a artroplastia de quadril e joelho e redução de fraturas expostas de fêmur, no período de 1999 a 2002, envolvendo nove hospitais participantes do Finnish Hospital Infection Program, encontrou uma taxa média de infecção de 3,3\% (variação de 0,8 a $6,4 \%$ ) e uma mediana de tempo de internação de oito dias. Em relação ao 
método de busca, $56,0 \%(28,0 \%$ a $90,0 \%)$ foram detectadas após a alta: $43,0 \%$ na readmissão, $34,0 \%$ pelo preenchimento do questionário de vigilância (quando o paciente busca o serviço de saúde com sinais e sintomas sugestivos de ISC), 11,0\% nas visitas de seguimento (dependendo do hospital, realizadas após dois meses e ano da cirurgia) e em 12,0\% não se identificou como foi recuperada a informação sobre ISC. Quanto à classificação da ISC, a proporção de identificação após a alta foi de $86,0 \%$ para as infecções de cavidades ou espaços, $80,0 \%$ para as incisionais profundas e $46,0 \%$ para as incisionais superficiais. Identificou-se o agente etiológico em $78,0 \%$ das ISC, mas, principlamente, nas ISC diagnosticadas durante a internação (93,0 \% vs $66,0 \%)$. Os principais agentes identificados na internação foram Staphylococcus coagulase negativo $(47,0 \%)$, Pseudomonas aeruginosa (13,0\%), Enterococcus (11,0\%) e Staphylococcus aureus $(8,0 \%) ;$ e após alta foram Staphylococcus coagulase negativo $(31,0 \%)$, Staphylococcus aureus $(31,0 \%)$ e Enterococcus $(13,0 \%)$ e Pseudomonas aeruginosa (3\%) (Huotari, Lyytikäinen, 2006).

Em um hospital terciário de ensino no Canadá foi realizada uma investigação do tipo caso-controle para determinar os fatores de risco para ISC de artroplastia primária de joelho no período de 1999 a 2001. Cabe ressaltar que neste hospital as salas operatórias não tinham fluxo laminar, havia protocolo de antibioticoprofilaxia e de anticoagulação profilática e todos os pacientes eram internados no dia da cirurgia. Os critérios de definição de ISC adotados eram do CDC e a vigilância pós-alta ocorreu até um ano após a cirurgia no consultório do médico ou na clínica ortopédica. A taxa média de infecção no período foi $1,1 \%$ e $68,2 \%$ das ISC foram de órgãos ou espaços. Os principais micro-organismos isolados foram S.aureus, S. coagulase negativo e P.aeruginosa. Pela análise de regressão logística identificaram-se como fatores de risco independentes para as ISC após artroplastia de joelho, a presença de drenos e o INR (international normalized ratio) pós cirúrgico aumentado (Minnema et al, 2004).

Embora a revisão cirúrgica nos casos de ISC em implantes seja comum, o risco de infecção profunda ou de órgãos e espaços neste tipo de procedimento é quatro vezes maior, segundo estudo realizado em pacientes 
submetidos a artroplastia de quadril (Leekha, 2010). Por isso, os trabalhos sobre ISC em artroplastias excluem as ISC pós-revisão cirúrgica.

Mesmo no estudo de revisão, tem sido difícil encontrar evidências de fatores de risco, comuns às ISC, em artroplastias. Revisão sistemática envolvendo estudos observacionais, no período de 2000 a 2008, com amostras acima de 100 pacientes submetidos à artroplastia de quadril, com ISC profundas e com relato de taxas de incidência e fatores de risco, identificou taxas de incidência de 0,2\% em ISC diagnosticadas durante a internação, a $1,1 \%$ em seguimentos até 5 anos após a cirurgia. No entanto, não havia uma padronização na definição de ISC, apenas dois estudos utilizaram os critérios do CDC. Os autores encontraram evidências de que a gravidade da doença de base do paciente e a duração da cirurgia seriam fatores de risco para infecção profunda em artroplastias primárias totais de quadril. Apesar de os achados, os autores comentam a respeito das limitações dos estudos analisados pela diversidade de desenhos metodológicos e pela falta de qualidade das coortes, o que impediu uma metanálise (Urquhart et al., 2010).

Realizou-se um estudo para identificar a incidência de contaminação perioperatória, em pacientes com artroplastia cimentada de joelho ou quadril. Foram acompanhados 80 pacientes, que seguiram um protocolo de prevenção de ISC, bem como a equipe cirúrgica e o ambiente cirúrgico. Obteve-se amostras para coleta por swab da pele, no local da incisão préoperatoriamente, a cada 30 minutos do sítio operatório, após fechamento da fáscia e da linha de sutura, antes do fechamento. Amostras contaminadas foram obtidas de 18 pacientes. O principal local de coleta de material contaminado foi na pele do paciente, após o preparo, e antes da colocação do campo adesivo plástico para a incisão, com isolamento de S.epidermidis na maioria das amostras. Apenas dois pacientes apresentaram sintomas pósoperatórios, um deles estava no grupo sem amostras contaminadas e o outro, que tinha amostra positiva para gram negativo na lâmina de pele, apresentou sintomas após $36 \mathrm{~h}$ com isolamento de gram negativo em hemocultura. As menores taxas de contaminação estiveram associadas, estatisticamente, ao menor número de pessoas paramentadas no sistema de fluxo laminar e ao menor número de pessoas na sala operatória (Byrne et al., 2007). 
Os programas de controle de infecção hospitalar têm adotado um pacote (bundle) de medidas, que quando aplicadas em conjunto, apresentam resultado melhor que individualmente. Estudo que utilizou bundle para redução de ISC superficiais em cirurgias de implantes para fraturas de fêmur em um hospital universitário em Basiléia (Suiça) conseguiu uma redução na taxa de ISC de 6,9\% para 2,0\% (Acklin et al., 2011).

Outro estudo aplicou pacote de medidas (bundle), em dois momentos de intervenção para avaliar a redução da contaminação intraoperatoria, em um seguimento de 207 cirurgias para recolocação de prótese de joelho ou quadril, em pacientes com osteoartrite ou artrite reumatóide, com vigilância epidemiológica das ISCs até 18 meses após a cirurgia, em um hospital universitário nos Países Baixos. A primeira intervenção solicitava que, todo material estéril fosse aberto e utilizado apenas na área de fluxo laminar. Após cinco meses, novo bundle foi introduzido com recomendações a cerca da paramentação cirúrgica da equipe, preparo do paciente fora da sala operatória (em uma sala de procedimentos) e controle de pessoal na sala operatória. Foi feito um grupo controle de pacientes, antes da primeira intervenção e dois grupos experimentais, um na primeira intervenção (grupo I) e outro na segunda intervenção (grupo II). Foram obtidas amostras aos pares de instrumentos usados, instrumentos não utilizados e de fragmentos de osso do local do implante no momento inicial da cirurgia (preparo do acetábulo no quadril ou do fêmur no joelho) e no momento final (preparo do fêmur no quadril ou da tíbia no joelho). O grau de contaminação foi de $32,9 \%$ no grupo controle, de $34,3 \%$ no grupo I e de 8,6\% no grupo II. Em todos os grupos a contaminação foi maior no primeiro momento da cirurgia. Durante o seguimento, no grupo controle $11,4 \%$ desenvolveram ISC superficial, no grupo I $(14,9 \%)$ e no grupo II $(1,4 \%)$ (Knobben et al., 2006).

Pelos relatos acima identificou-se que os pacotes de medida comportamental tem um efeito positivo na redução de ISC e que as medidas relacionadas ao processo de trabalho e comportamento humano, apresentam melhor resultado que as intervenções relacionadas ao ambiente. Ainda, independente do local de estudo, o S.aureus e o S.epidermidis são os principais agentes envolvidos nas artroplastias. 


\subsection{Micobacterioses}

As micobacterioses são doenças causadas por MNT, pertencentes ao gênero Mycobacterium, diferentes do Mycobacterium leprae e daquelas que compõem o complexo Mycobacterium tuberculosis (Alemida et al., 2003; Wagner e Young, 2004; Lopes et al., 2005).

Robert Koch, além de $M$. tuberculosis, descobriu e descreveu outras micobactérias ao final do século XIX, porém, apenas na metade do século XX foram reconhecidas as doenças causadas por esses micro-organismos, basicamente por meio do trabalho de classificação proposto por Ernest Runyon em 1954, baseado nas análises microbiológicas das micobactérias (Runyon, 1959). Runyon foi o primeiro a designar as miconactérias não tuberculosas de "micobactérias atípicas", caracterizadas por várias siglas, tais como "MOTT" (mycobacteria other than tuberculosis), ou seja, micobactérias outras que não sejam as tuberculosas; adotada em toda a literatura de língua inglesa; micobactérias ambientais, micobactérias oportunistas ou MNT, sendo esta denominação a mais utilizada e aceita, especialmente pelos clínicos, embora ainda seja controversa a melhor definição. (Brasil, 2007b).

As MNT, diferentes daquelas responsáveis pela tuberculose e pela lepra, são reconhecidas há mais de um século, apesar de descritas em isolamentos ocasionais de amostras clínicas (Barnes et al., 2004).

Até o surgimento da Síndrome da Imunodeficiência Adquirida (AIDS), não se dava elevada importância às infecções por MNT. Relatos de doenças pulmonares causadas por esse grupo eram esporádicos. Apenas a partir dos anos cinquenta, começaram a surgir relatos de séries de doenças pulmonares causadas por MNT (Ahren et al., 1995; ATS, 1997).

Atualmente, as micobacterioses têm ocorrido em pacientes de diferentes faixas etárias, hígidos e submetidos a procedimentos cirúrgicos, ou seja, as infecções passaram a ser adquiridas dentro da instituição hospitalar. (Hasegawa et al., 1992; Porat, Austin, 2008; Yinkey et al., 2010)

Estudo de 1959 mostrou que as MNT tinham relação com idade, raça e sexo; ocorriam raramente em jovens e eram encontradas predominantemente em idosos. Dos casos conhecidos, 51,8\% foram isoladas em indivíduos com mais de 54 anos; $88,0 \%$ tinham mais de 34 anos; aproximadamente $75,0 \%$ eram do sexo masculino, com predomínio da etnia branca (Prather et al., 1961). 
$\mathrm{Na}$ década de 80 , se reconhecia o aumento na frequência de micobacterioses e particularidades que as diferenciavam das causadoras de tuberculose, como pouca tendência a disseminação hematogênica, (visto que as lesões extrapulmonares secundárias eram raras), doença individual sem extensão epidêmica, maior ocorrência em homens em virtude de exposição profissional, sensibilidade inespecífica a tuberculina em portadores de micobacterioses e diferente resposta terapêutica aos tuberculostáticos (Andrade, 1986).

A infecção por micobactérias se manifesta por lesões nodulares, na pele, próximas ao portal cirúrgico, ou pelo simples aparecimento de secreção serosa, na deiscência ou na cicatriz cirúrgica. A presença de febre é facultativa, sendo a queixa mais comum o aparecimento de secreção, no local da incisão. A lesão poderá estar restrita à epiderme e à derme ou estar presente em todo o trajeto cirúrgico, inclusive atingindo a parede abdominal, articulações ou em outras cavidades. A infecção evolui com aspecto inflamatório crônico e granulomatoso, formando lentamente abscessos, com manifestação até um ano após o ato cirúrgico. As espécies mais comumente associadas a infecções na pele e tecido subcutâneo são Mycobacterium marinum, Mycobacterium ulcerans, Mycobacterium fortuitum, Mycobacterium chelonae e Mycobacterium abscessus, embora as três últimas sejam responsáveis por formação de abcessos nos locais de punção, ferimentos ou fraturas expostas (ATS, 1997; Brasil, 2007a).

As infecções de pele e tecido subcutâneo, por MNT, geralmente, se apresentam como abscessos piogênicos, com reação inflamatória aguda e supuração, ou evoluem lentamente, com inflamação crônica, formação de nódulos, ulceração, formação de loja e fistulização. O curso da doença é variável, sendo mais frequente a evolução crônica progressiva, com raros casos de cura espontânea. Não existem sinais patognomônicos. A suspeita, normalmente, é levantada devido à falta de resposta aos antibióticos mais utilizados no tratamento de patógenos habituais de pele (Brasil, 2007a).

As infecções causadas por MNT podem se manifestar nos pulmões onde assumem semelhança com a tuberculose, em nódulos linfáticos 
associados á área infectada, em lesões localizadas (granulomas) ou doença disseminada (Falkinham, 1996).

Situações de imunossupressão e co-morbidades como diabetes mellitus, neoplasia, doença pulmonar obstrutiva crônica, fibrose cística cirrose hepática são fatores de risco para estas infecções (Wagner, Young, 2004; Lopes et al., 2005).

O período de incubação das MNT deve ser considerado de duas semanas a doze meses, após a contaminação pelo micro-organismo (Brasil, 2007a e b).

O diagnóstico clínico deverá ser estabelecido a partir do momento em que o paciente for submetido a procedimentos laparoscópicos, artroscópicos, implantes de próteses ou órteses, lipoaspiração, nos últimos 12 meses; ou implantes de marcapasso, cirurgia oftalmológica ou cardíaca (componente epidemiológico); da observação clínica do aspecto das lesões, no orifício de entrada de cânulas e/ou trajeto "tunelizado" (quando se tratar de lipoaspiração); no tipo de abscesso, se frio ou quente (via de regra micobactérias produzem abscessos frios); da ausência de antecedentes ou de comorbidades, características de disseminação para outros sítios; do uso de propedêutica como ultra-sonografia e ressonância magnética de parede abdominal auxiliam na determinação das lesões com coleções líquidocaseosas (secreção), que deverão ser debridadas e ressecadas (Brasil, 2007a).

O diagnóstico laboratorial das micobacterioses é feito por baciloscopia, análise microbiológica e anátomo-patológico (Brasil 2009b):

- Baciloscopia consiste na pesquisa de bacilo álcool-ácido resistente (BAAR) em secreção onde MCR são identificadas como BAAR fortemente positivas.

- Análise Microbiológica é de fundamental importância para a identificação de uma micobactéria e de sua espécie, podendo identificá-la como de crescimento rápido, o que a diferencia da M. tuberculosis.

- Anátomo-patológico: em caso de peça cirúrgica pós-ressecção, observam-se as alterações histopatológicas típicas de infecções por micobactérias. 
Todas as amostras clínicas colhidas durante a ressecção cirúrgica devem ser preservadas, parte em solução salina para realização da cultura, parte em formaldeído para o exame anatomopatológico. Recomenda-se não fazer swabs, pela pouca competitividade das MCR; ou punções repetidas, para evitar outras contaminações e infecções cruzadas. Uma vez detectada a lesão, esta deve ser debridada, adequadamente, e com margem (Brasil, 2007a e 2009b).

Os exames de diagnóstico por imagem, como a ultrassonografia e/ou a ressonância magnética são indicados para diagnóstico, identificação e localização de coleções líquido-caseosas (secreção) a serem ressecadas (Brasil, 2007b).

Os pacientes com bacteriologia negativa (baciloscopia direta e análise microbiológica) terão seus diagnósticos estabelecidos por meio de critério clínico ou epidemiológico, somado à histopatologia com achado de granuloma, com ou sem necrose caseosa, em tecido retirado por biópsia ou ressecção (Brasil, 2007c).

A definição clínica compatível com micobacteriose ortopédica, de acordo com a Secretaria de Vigilância Sanitária/Ministério da Saúde (SVS/MS) e Agência Nacional de Vigilância Epidemiológica - Nota Técnica n01/2009, decorre das seguintes observações - paciente que apresentar dois ou mais dos sinais listados a seguir, em topografia correspondente ao acesso cirúrgico: hiperemia por mais de 1 semana; hipertermia por mais de 1 semana; edema por mais de 1 semana; nódulos com ou sem fistulização; ulcerações; fistulização; drenagem persistente de secreção serosa, purulenta, ou piosanguinolenta; difícil cicatrização (não responsiva a tratamentos convencionais); lesão em topografia correspondente ao trajeto de cânulas ou trocarte, com ou sem disseminação para áreas adjacentes; recidiva das lesões (Brasil, 2009b).

Para melhor investigação dos casos, definiu-se o que seria caso de micobacteriose nas modalidades: suspeito, provável, possível e confirmado (Brasil, 2009d)

- caso: paciente submetido a qualquer procedimento vídeo-assistido, a exemplo de laparoscopia, artroscopia, broncoscopia, endoscopia do sistema genitourinário, ou do sistema digestório para inserção de prótese biliar; 
qualquer procedimento no qual seja utilizada cânula de aspiração (lipoaspiração), instrumento de fibra ótica, implante de prótese, órtese oftalmológica, ceratotomia, cirurgia plástica, ortopédica, cardíaca, lipoaspiração, mesoterapia, preenchimento cutâneo com ácido hialurônico ou metacrilato, ou injeção por via intra-muscular, que apresente sinais de flogose persistente, por mais de 1 semana Suspeito: paciente submetido a procedimentos invasivos que apresenta dois ou mais sinais referidos como clínica compatível;

- possível: paciente que preenche os critérios de caso suspeito, mas sem investigação laboratorial, e que respondeu ao tratamento específico para micobactérias;

- provável: paciente que preenche os critérios de caso suspeito e que apresenta granulomas em tecido obtido de ferida cirúrgica ou tecidos adjacentes, ou baciloscopia positiva, mas cultura negativa para micobactéria;

- confirmado: paciente que preenche os critérios de caso suspeito e apresenta amostra, da ferida cirúrgica ou tecidos adjacentes, positiva para micobactéria.

Há cerca de 13 espécies de MNT, de virulência variável, reconhecidamente capazes de provocar doenças no homem, mas, certamente, a susceptibilidade humana a essas micobactérias varia muito entre as diferentes populações e etnias. Entretanto, com o impacto crescente da AIDS e com a conscientização de que essas micobactérias podiam ser causa de doenças, o enfoque mudou, o que permitiu, ao final da década de 80 , a introdução de drogas efetivas, primariamente a claritromicina (CRT) e a azitromicina (AZT), melhorando o desfecho dos doentes (Hisbello, 2000).

A ampla distribuição das MNT, associada à baixa virulência da maioria das espécies que compõem o grupo, contribui para a negligência destas espécies como agentes de infecções (Devi et al., 2003).

As MNT potencialmente patogênicas podem causar uma variedade de doenças em humanos e animais, que diferem em gravidade e importância em saúde pública. Geralmente, as doenças disseminadas em pacientes portadores de AIDS estão associadas a espécies de crescimento lento (ATS, 1997). Por outro lado, as infecções pós-traumáticas são causadas por espécies de crescimento rápido (Freitas et al., 2003; Winthrop et al., 2003). 
As Mycobacterium spp. também são classificadas conforme a capacidade de causar doença no homem, podendo ter um alto ou baixo potencial patogênico (Davidson, 1989) (Quadro 1).

Quadro 1. Classificação dos principais Mycobacterium spp. de acordo com o potencial patogênico.

\begin{tabular}{|c|c|}
\hline $\begin{array}{c}\text { MNT com elevado } \\
\text { potencial patogênico }\end{array}$ & $\begin{array}{c}\text { MNT com baixo } \\
\text { potencial patogênico }\end{array}$ \\
\hline M. abscessus & M. agri \\
\hline M. asiaticum & M. aurum \\
\hline M. avium & M. branderi \\
\hline M. avium subsp. paratuberculosis & M. chitae \\
\hline M. celatum & M. duvalli \\
\hline M. chelonae & M. fallax \\
\hline M. fortuitum & M. flavescens \\
\hline M. genavense & M. gastri \\
\hline M. haemophilum & M. gordonae \\
\hline M. immunogenum & M. hassiacum \\
\hline M. intracellulare & M. mageritense \\
\hline M. kansasii & M. neoaurum \\
\hline M. lentiflavum & M. nonchromogenicum \\
\hline M. malmoense & M. phlei \\
\hline M. marinum & M. porcinum \\
\hline M. mucogenicum & M. pulveris \\
\hline M. peregrinum & M. smegmatis \\
\hline M. scrofulaceum & M. terrae \\
\hline M. shimoidei & M. triviale \\
\hline M. simiae & M. vaccae \\
\hline M. szulgai & \\
\hline M. ulcerans & \\
\hline M. xenopi & \\
\hline M. massiliense & \\
\hline
\end{tabular}


Para fins clínicos, o setor de micobactérias do Instituto Adolfo Lutz utiliza nos laudos para liberação dos resultados de identificação de Mycobaterium spp. uma classificação para sugerir o grau de patogenicidade das cepas isoladas. O significado clínico é baseado na classificação de patogenicidade da espécie, na origem e no número de espécimes clínicos dos quais foram isoladas a mesma espécie de MNT. Dessa forma, cada resultado recebe uma classificação quanto ao possível significado clínico do isolamento (Brasil, 2005; Brasil, 2007a).

- Isolamento sugestivo da doença (Definitivas): quando a espécie potencialmente patogênica identificada se origina de uma amostra clínica coletada de sítio estéril como, líquor, sangue, medula óssea, linfonodos ou quando se têm, no mínimo, três isolamentos da mesma espécie, de sítios não estéreis como as doenças em tecidos moles e pele, histologia em biópsia de tecido compatível com granulomatose, associada ao isolamento de MNT.

- Isolamento potencialmente sugestivo da doença (Fortes): quando a espécie potencialmente patogênica identificada é isolada de uma ou mais amostras clínicas não estéreis (secreções pulmonares ou de tecidos moles), sem outro patógeno isolado. Quanto maior o número de amostras e o tempo de observação, maior a probabilidade diagnóstica. Progressão da doença durante quimioterapia anti-tuberculose, com baciloscopia e análise microbiológica com resultados positivos para MNT isoladas de fezes, em pacientes com AIDS.

- Isolamento raramente sugestivo da doença (Intermediárias): quando se identifica a espécie com baixo potencial patogênico a partir de uma ou mais amostras clínicas não estéreis como escarro ou MNT persistentemente isolada de escarro, em paciente com condições patológicas pulmonares subjacentes. Baciloscopia persistentemente positiva em paciente com AIDS, com análise microbiológica com resultado negativo.

A identificação de MNT é importante para estabelecer a terapêutica adequada, visto que possuem diferentes padrões de resistência às drogas. $A$ literatura refere que essas micobactérias são ambientais, mas patogênicas (CDC, 1998; Ryu et al., 2005).. 
A primeira descrição clínica e laboratorial do Mycobacterium fortuitum foi relatada por Costa, em 1936 (Costa-Cruz, 1938). Este foi também o primeiro caso de $\mathrm{IH}$, comprovadamente causado por MCR, pois o paciente teve um abscesso, decorrente de uma injeção intramuscular de vitamina. Em 1960, vários grupos de abscessos causados por MCR, após injeção, foram relatados no Congo, na Holanda, e nos EUA (Owen et al., 1963; Inman et al., 1969; Vandepitte, et al., 1969; Borghaus, 1973).

Em 1975, um conjunto de infecções do esterno, em cirurgias cardíacas, causado por M. abscessus ocorreu em um hospital, na Carolina do Norte (EUA) (Robicsek et al., 1978; Hoffman et al., 1981). Embora a fonte do surto nunca tenha sido encontrada, este foi o primeiro surto de infecção de ferida cirúrgica por MCR rastreado e relatado.

As infecções nosocomiais, ou relacionadas aos cuidados com a saúde, causadas por espécies do grupo $M$. chelonae-abscessus, representam um problema emergente em vários países e no Brasil. As ISC representam cerca de $43,0 \%$ das infecções extra-pulmonares por $M$. abscessus (Wallace et al., 1993a).

Há relatos de casos isolados e surtos relacionados à mamoplastia de aumento, cirurgia plástica facial, cirurgia cardíaca, mesoterapia, cirurgias oftalmológicas e injeções esteróides ou de medicamentos alternativos (Chadha et al., 1998; Galil et al., 1999), bem como de osteomielite e infecções do sítio de inserção de cateteres de diálise peritoneal (Pruitt et al., 1993; Meredith, Sexton, 1996; Bar et al., 2005; Ellis et al., 2005).

Muitos casos de MCR relatados envolvem procedimentos cutâneos e subcutâneos.

Houve um relato de ocorrência de infecção por $M$. chelonae e $M$. abcessus, após injeção de penicilina $\mathrm{G}$ no músculo glúteo em um hospital chinês envolvendo. 86 pacientes de janeiro/1997 a julho/1998. Foi concluído que a fonte de infecção era a tampa dos frascos, pela forma inadequada de manipulação da injeção de penicilina (Zhibang et al. 2002)

Em Toronto, Canadá, foi feito um estudo com 32 pacientes que realizaram acupuntura e desenvolveram infecção por micobactérias. De 23 
pacientes com amostras biológicas analisadas, em $26,1 \%$ foi confirmada a presença de M. abcessus (Tang et al., 2006).

Estudo sobre um surto de MCR após mesoterapia, na Venezuela, descreveu a epidemiologia, as características clínicas, o tratamento e a evolução dos pacientes com infecção causada por este tipo de microorganismo. Foram avaliados 49 casos de infecção deste tipo, entre março de 2002 a dezembro de 2003, a partir de amostras de 15 produtos, utilizados na mesoterapia, buscando a presença destas micobactérias. Os resultados demonstraram que $M$. abcessus e $M$. fortuitum foram as espécies mais comuns, mas também foram isoladas outras, tais como M.chelonae e M.simiae (Rivero- Olivera et al., 2006).

As infecções associadas ao M. fortuitum incluem doença pulmonar, endocardite, otite média, mastoidite e ceratite. Outros tipos de infecções, causadas por MCR, foram identificados em procedimentos cirúrgicos estéticos como liposucção e lipoescultura (Wagner, Young, 2004). A bactéria $M$. chelonae foi isolada num caso de ceratite, após cirurgia para correção de miopia (Seabra et al., 2001; Blanco et al., 2002). Também, descreveu-se um caso de ceratite, no qual $M$. abscessus foi isolada de uma amostra de córnea, mesmo após seis meses de tratamento com antimicrobianos (Gusmão et al., 2005). Não existem relatos de transmissão pessoa a pessoa, sendo as fontes ambientais as mais importantes (Katoch, 2004).

No Brasil, nos anos de 2004 e 2005, ocorreram surtos de infecção por MNT, relacionados a procedimentos cirúrgicos (implantes mamários), e estéticos, principalmente em Campinas - SP, investigados pelo Centro de Vigilância Epidemiológica da Secretaria de Estado da Saúde, em conjunto com as vigilâncias regionais e municipais, Instituto Adolfo Lutz e Centro de Vigilância Sanitária (Brasil, 2007b).

A ANVISA monitora a ocorrência de infecções pós-cirúrgicas por MNT, em diferentes regiões do país, de forma permanente. De 2003 até abril de 2008, foram notificados e confirmados 2.102 casos de infecção por MCR, distribuídos pelos estados do Rio de Janeiro (1.014), Pará (315), Espírito Santo (244), Goiás (230), Paraná (110), Rio Grande do Sul (79), São Paulo (43), Mato Grosso (21), Distrito Federal (16), Minas Gerais (10), Piauí (09), Mato Grosso 
do Sul (08), Bahia (2) e Paraíba (1) (Brasil, 2008). Até fevereiro de 2009, o número de infecções ocorrido em hospitais públicos e privado, clínicas de cirurgia plástica, oftalmológicas, de acupuntura, de estética e em unidade de vacinação reportados à ANVISA alcançava 2.128 casos (Brasil, 2009d).

Surtos de micobacterioses acometendo, aproximadamente, 1.000 pessoas, principalmente no estado do Rio de Janeiro, isolaram como agentes etiológicos: $M$. abscessus, $M$. chelonae e $M$. fortuitum, em pacientes submetidos à cirurgia vídeo-endoscópica, plástica, entre outras (Brasil, 2007c).

A ocorrência de micobacterioses, em Serviços de Saúde tem sido considerada, pela instância federal, como uma emergência epidemiológica e sua investigação vem sendo conduzida de modo articulado, pela ANVISA e Ministério da Saúde, com participação das Vigilâncias Epidemiológicas e Sanitárias, dos estados e dos municípios. A ANVISA efetua a monitoração da ocorrência de infecções pós-cirúrgicas por Mycobatreium spp., em diferentes regiões do país, de forma permanente (Brasil, 2008, 2009a).

A tabela 1 apresenta a distribuição de espécies identificadas nos casos confirmados, prováveis e suspeitos de infecção por Mycobacterium spp, segundo o ano de procedimento, no Estado de São Paulo de 2002 a 2010 (Brasil, 2010).

Tabela 1. Distribuição de espécies identificadas nos casos confirmados, prováveis e suspeitos de Infecção por Mycobacterium spp no Estado de São Paulo de 2002 a 2010.

\begin{tabular}{|c|c|c|c|c|c|c|c|c|c|}
\hline $\begin{array}{c}\text { Resultado } \\
\text { Cultura }\end{array}$ & 2002 & 2003 & 2004 & 2005 & 2006 & 2008 & 2009 & 2010 & Total \\
\hline M. fortuitum & 2 & 7 & 3 & - & - & 15 & 10 & 4 & 41 \\
\hline M. abscessus & - & - & 1 & 6 & 1 & 16 & - & - & 24 \\
\hline M. massiliense & - & - & - & - & - & 11 & 1 & - & 12 \\
\hline M. chelonae & - & - & - & - & - & 1 & - & 1 & 2 \\
\hline M. peregrinum & - & - & - & - & - & - & - & 1 & 1 \\
\hline M. porcinum & - & 1 & - & - & - & - & - & - & 1 \\
\hline M. senegalense & - & - & - & - & - & 1 & - & - & 1 \\
\hline Total & 2 & 8 & 4 & 6 & 1 & 44 & 11 & 6 & 82 \\
\hline
\end{tabular}

Fonte: SES, 2011 
A ANVISA recomendou, a partir do Informe Técnico $n^{\circ} 2$, para prevenir surtos bacterianos de ISC, ocasionados no Brasil; que, em se tratando de casos novos, é necessária a elaboração, implementação e controle de normas sobre os critérios de produtos hospitalares e métodos de limpeza, desinfecção e esterilização de artigos e superfícies, advindos das Comissões de Controle de Infecção Hospitalar (CClHs) e das Comissões de Farmácia e Terapêutica (CFTs), de cada hospital brasileiro (Brasil, 2007b).

\subsection{Características gerais de Mycobacterium spp.}

O gênero Mycobacterium é constituído por bacilos ligeiramente curvos, aeróbios, imóveis, não esporulados e não encapsulados, de 1 a $10 \mu \mathrm{m}$ de comprimento e 0,2 a $0,6 \mu \mathrm{m}$ de largura, imóveis e incapazes de formar esporos, conídeos e cápsulas. Seu crescimento se dá, em geral, sob forma de micélios ou filamentosa, dando origem a elementos bacilares ou cocóides. Estas bactérias possuem elevado teor de lipídios, sobretudo na parede celular, o que altera a sua permeabilidade à água, soluções corantes utilizadas em laboratório e agentes desinfetantes. A composição de sua parede não permite a coloração pelo método de Gram, e Ihe confere uma álcool-ácido resistência evidenciada pela técnica de coloração adaptada do método de Ziehl-Neelsen (Koneman e Stephen, 2001).

Algumas espécies de MCR foram descobertas recentemente, cabe ressaltar que este gênero contém elevado número de espécies. $O$ risco de infecção se justifica, pois são frequentemente encontradas no ambiente, no solo e na água (Fontana, 2008; Trabulsi, 2002).

Em algumas situações, a identificação das espécies de micobatérias não é possível devido às limitações metodológicas. Nesses casos, o resultado é fornecido de acordo com a classificação criada por Runyon (1959).

De acordo com as características fenotípicas, ou seja, segundo a taxa de crescimento e pigmentação, as MNT podem ser classificadas em quatro grupos com base em duas características: 1) produção de pigmentos carotenóides e 2) tempo de multiplicação, conforme resumido na Tabela 2 (Runyon, 1959; Collins et al., 1997). 
Tabela 2. Classificação das MNT de acordo com o tempo de crescimento e produção de pigmento

\begin{tabular}{clc}
\hline Grupos & \multicolumn{1}{c}{ Pigmentação } & Tempo de crescimento \\
\hline I & Fotocromógenas & Lento \\
II & Escotocromógenas & Lento \\
III & Não cromógenas & Lento \\
IV & Rápidos crescedores & Rápido
\end{tabular}

Fonte: Runyon (1959); Collins et al. (1997)

Os quatro grupos, em que foram enquadradas as MNT, são:

- Fotocromogênicas - aquelas capazes de produzirem pigmento amarelo forte apenas na presença de luz, e são micobactérias de crescimento lento, tais como o Mycobacterium kansaii, causador, por exemplo, de lesões pulmonares discretas no homem;

- Escotocromogênicas - porque produzem pigmento de cor semelhante à anterior, quer na presença ou ausência de luz, como Mycobacterium marinum; são produtoras de adenite cervical em crianças;

- Não cromógenas ou não fotocromógenas - não produzem pigmento de cor forte, são de crescimento lento, tais como a Mycobacterium avium; são agentes frequentes de doença pulmonar cavitária;

- Expressão rápidos crescedores - crescimento rápido, formam colônias visíveis em menos de uma semana, tais como o Mycobacterium fortuitum. Vale salientar, que as MNT, anteriormente classificadas, genericamente, como $M$. fourtuitum, foram recentemente subdivididas em M.fortuitum M.peregrinum, M.chelonae e M.abcessus (Runyon, 1959; Trabulsi, 2002; Fontana, 2008).

A árvore filogenética das micobactérias pode ser dividida em dois grandes grupos: micobactérias de crescimento rápido e micobactérias de crescimento lento. Micobactérias de crescimento rápido formam colônias visíveis a olho nu em até sete dias, quando incubadas em meio sólido. Aquelas de crescimento lento o fazem após sete a 30 dias de incubação. A temperatura ótima de multiplicação é variável, de acordo com a espécie, e 
oscila numa faixa de $25^{\circ} \mathrm{C}$ a $45^{\circ} \mathrm{C}$. A maioria das espécies é capaz de crescer em meios simples contendo aminoácidos, glicerol e sais minerais, mas algumas requerem suplementos (Wayne, Kubica, 1986; Brasil 2009b).

Em relação ao desenvolvimento, as espécies de Mycobacterium spp. apresentam características particulares de velocidade de crescimento, de acordo com a Tabela 3.

Tabela 3. Diferenciação de algumas espécies de Mycobacterium spp. em função da velocidade de crescimento

\begin{tabular}{lrcc}
\hline \multirow{2}{*}{ Mycobacterium spp. } & \multicolumn{3}{c}{ Velocidade de crescimento } \\
\cline { 2 - 4 } M. avium & Lento & Moderado & Rápido \\
M. bovis & + & - & - \\
M. fortuitum & + & - & - \\
M. intracellulare & - & - & + \\
M. kansasii & + & - & - \\
M. marinum & + & - & - \\
M. smegmatis & - & + & - \\
M. scrofulaceum & - & - & + \\
M. tuberculosis & + & - & - \\
M. ulcerans & + & - & - \\
\hline
\end{tabular}

Legenda: "+" = sim; "“" = não.

Fonte: Trabulsi LR, Alterthum F. Microbiologia. 5ª.ed. São Paulo: Atheneu; 2008.

As MCR, foco deste estudo, estão distribuídas na natureza, sendo possível seu isolamento na água dos rios, terra, poeira da casa, em máquinas de gelo, vegetação. No ser humano, podem ser isoladas da saliva e pele, por exemplo. Os componentes deste grupo são resistentes a muitos antibióticos (Katoch, 2004; Carvalho Jr et al., 2008; Retta, Sagripanti, 2008).

\subsection{Isolamento e Identificação de MNT I MCR}

As Mycobacterium spp. podem ser identificadas com base em testes fenotípicos (tempo de multiplicação, produção ou não de pigmentos, provas 
bioquímicas, sensibilidade a inibidores químicos) e testes genotípicos como PCR - Reação em Cadeia Polimerase e PFGE - Eletroforese em Gel de Campo Pulsado entre outros. (Tortoli, 2003).

A definição taxonômica do gênero Mycobacterium se baseia em marcadores quimiotaxonômicos sob três critérios, álcool-ácido resistência, sequência G-C (guanina-citosina) do seu DNA, presente em 61,0 a 71,0\% das cepas, e a síntese de ácidos micólicos. Estes ácidos graxos constituem o suporte molecular da álcool-ácido resistência e a análise de sua composição é um elemento essencial para a caracterização das espécies de micobactérias. Outros lipídios complexos, como ácidos graxos de cadeias curtas, fenolglicolipídios, peptidoglicolipídeos, também são bons marcadores para a identificação de numerosas espécies. Classicamente, a inclusão no gênero Mycobacterium repousa sobre propriedades morfológicas e tintoriais (Brasil, 2009a).

Os avanços na identificação das MNT determinam agrupamentos por similaridades, por exemplo, o grupo M.smegmatis, inclui o M.smegmatis propriamente dito e duas novas espécies descritas em 1999: M. goodii e $M$. wolinskyi (Brown et al., 1999). Bioquimicamente, o grupo M.smegmatis pode ser distinguido do grupo M.fortuitum e do grupo M.chelonae - M.abscessus, porque estes apresentam atividade arilsulfatase após três dias de exposição em oposição aos membros do grupo M.smegmatis (Brown-Elliot, Wallace, 2002). O grupo M.smegmatis é suscetível ao etambutol, mas não a claritromicina, esta característica poderia ajudar a distingui-la de outras do grupo MCR (Pulcini et al., 2006). M.wolinskyi não produz nenhum pigmento (Brown et al., 1999; Brown-Elliot, Wallace, 2002), que é o caso de aproximadamente $95,0 \%$ dos isolados de M.smegmatis propriamente dito e $78,0 \%$ dos isolados de M.goodii. A única espécie não pigmentada de MCR é M.wolinskyi que é susceptível ao etambutol. As três espécies do grupo M.smegmatis também podem ser separadas com base na susceptibilidade a tobramicina. M.smegmatis é susceptível a tobramicina (MIC $\leq 1 \mathrm{ug} / \mathrm{ml}$ ), enquanto M.goodii tem susceptibilidade intermédia (2 a $8 \mathrm{mg} / \mathrm{ml}$ ) e M.wolinskyi é resistente (> ug 8 / ml) (Brown-Elliot, Wallace, 2002). 
A classificação das espécies atualmente é: as pertencentes ao complexo M. fortuitum que incluem: M.fortuitum, M.peregrinum, variantes de M.fortuitum (M.houstonense, M.bonickei, M.septicum, M.mageritense, M.mucogenicum e M.senegalense); as micobatérias de complexo M.chelonae-abscessus, composto pelas espécies M.chelonae, M.abscessus, M.bolleti, M.immunogenun, M.massiliensi, e aquelas que compõem o complexo M.smegmatis, cujos componentes são M.smegmatis, M.goodii e M.wolinskyi. Há também, outras espécies não classificadas em complexos como: M.aurum, M.elephantis, M.flavescens, M.gadium, M.gilvum, M.neoaurum, M.parafortuitum, M.phocaium, M.vaccae, entre outras. (Hinrichsen, 2007; Macedo et al., 2009; Pitombo et al., 2009).

Com o objetivo de avaliar a diversidade das espécies de MNT, identificadas no estado de São Paulo, no período de 1991 a 1997, analisaram-se 1.892 cepas, isoladas de sítios estéreis e não-estéreis, de 1.248 pacientes, sendo identificadas as seguintes espécies: $M$. avium, $M$. kansasii, M. chelonae, M. fortuitum, M. szulgai, M. xenopi, M. marinum, $M$. gordonae, M. terrae e M. nonchromogenicum (Ueki et al., 2005).

Os autores (Ueki et al., 2005) concluíram que, na década de 1990, as taxas de isolamento de MNT aumentaram em comparação com o passado. Das dez espécies identificadas, sete foram mais frequentes entre os pacientes HIV-positivos. As espécies altamente patogênicas frequentemente isoladas foram: $M$. avium, $M$. intracellulare, $M$. kansasii, $M$. chelonae, $M$. abscessus, $M$. fortuitum e $M$. peregrinum, sendo raramente isoladas as espécies: $M$. marinum, M. xenopi, M. scrofulaceum, M. malmoense, M. szulgai, $M$. simiae, $M$. asiaticum, $M$. lentiflavum e $M$. genavense. Dentre as espécies com baixo potencial patogênico, a mais frequentemente isolada foi $M$. gordonae, sendo raramente isoladas as espécies $M$. triviale, $M$. nonchromogenicum e $M$. neoaurum. Das cepas relatadas, são de MCR: $M$. chelonae, $M$. abscessus, $M$. fortuitum e M.peregrinum.

\subsection{Considerações sobre as infecções hospitalares por MCR}

Dados da Rede Nacional de Investigação de Surtos e Eventos Adversos em Serviços de Saúde (Reniss) divulgou em 2009 a confirmação 
de 1.997 casos de infecção por MCR no Brasil, com maior expressão nos estados de Rondônia, Pernambuco e Espírito Santo (Brasil, 2009d).

As MCR foram reconhecidas como contaminantes de medicamentos injetáveis, próteses entre outros insumos a saúde. Acresce-se que são incluídas as espécies com pigmentação amarela e sem pigmentação, relacionadas à ocorrência de doenças em humanos, que são M.fortuitum e M.chelonae, às vezes citados como complexo M.fortuitum-chelonae associadas, a infecções de pele, tecido subcutâneo e olhos. (Hinrichsen, 2007; Macedo et al., 2009; Pitombo et al., 2009).

Os surtos de micobacterioses, no Brasil, tem sido relacionados ao reprocessamento de materiais utilizados em procedimentos invasivos, principalmente aqueles submetidos à desinfecção de alto nível (Pitombo, et al., 2009).

As infecções por MCR estão fortemente relacionadas às falhas nos processos de limpeza, desinfecção e esterilização de produtos médicos. $\mathrm{Na}$ maioria dos serviços de saúde investigados, o instrumental cirúrgico foi submetido, somente, ao processo de desinfecção e não ao processo de esterilização como é definido pela Resolução (RE) da ANVISA - n 2606/06. Também foi detectada a precariedade no funcionamento das Centrais de Material e Esterilização destes serviços, já que não possuem registros e validação dos processos de limpeza, desinfecção e esterilização dos instrumentais cirúrgicos (Brasil, 2008).

Diversos estudos apontam que as micobactérias são amplamente reconhecidas como sendo as formas bacterianas mais resistentes aos agentes desinfetantes e/ou esterilizantes (Katoch, 2004; Carvalho Jr et al., 2008; Retta, Sagripanti, 2008). Essa resistência é decorrente de uma estrutura específica e da baixa permeabilidade da parede celular, que é composta por um alto conteúdo de ácidos micólicos e lipídicos, os quais atuam como barreira aos agentes químicos (Hernández et al., 2005, 2008).

Johnson et al. (1982) analisaram 12.505 artroscopias, reutilizando materiais após 15 minutos de imersão em solução de glutaraldeído a 2,0\%. Encontraram infecções pós-operatória em 0,04\% dos casos; em 80,0\% 
destes, após a artroscopia se realizou procedimento por artrotomia. Esse percentual foi menor do que o esperado para qualquer cirurgia limpa.

Em um estudo realizado no Hospital Universitário da USP-SP, foram avaliadas as dificuldades na limpeza dos artigos de uso único. Entre outros dados, foi verificado que mais da metade dos artigos pesquisados não foram desmontáveis e transparentes, o que pode comprometer o processo de limpeza. Em 38,5\% destes houve dificuldades na limpeza manual. Os autores sugeriram avaliação criteriosa para a tomada de decisão quanto ao reuso, além de outros meios para a lavagem destes materiais, tais como o uso de lavadoras ultras-sônicas. (Graziano et al., 2006).

De acordo com as investigações realizadas durante a epidemia por Mycobacterium spp. no Estado do Rio de Janeiro, envolvendo 63 hospitais com casos notificados, diversos aspectos inadequados na prática préoperatória foram observados em relatórios de supervisores e equipes médicas envolvidas em diferentes hospitais (Duarte et al., 2009). Dentre estes pontos, podem ser citados: ausência de registros efetivos de soluções de glutaraldeido comerciais utilizadas na desinfecção de alto nível quanto à marca, tempo de imersão dos instrumentos, validade, confirmação da concentração e $\mathrm{pH}$, presença ou não de matéria orgânica; não-utilização de recipientes adequados para armazenamento das soluções em uso e processo de desinfecção; ausência de uniformidade quanto ao profissional responsável pela limpeza e desinfecção e carência de treinamento específico; ausência de procedimentos operacionais padrão e/ou protocolos com detalhes das condutas a serem aplicadas na limpeza e desinfecção; reutilização de material descartável; ausência de controle microbiológico do funcionamento das autoclaves ou investigação microbiológica do instrumental por amostragem e inadequado sistema de vigilância de infecções pós-cirúrgicas (Pitombo et al., 2009).

A tolerância ao glutaraldeído não foi o único fator desencadeante dos surtos, pois há diversos casos de infecções causadas por espécies não tolerantes ao glutaraldeído. Tal fato indica que a remoção inadequada de resíduos orgânicos, antes da exposição dos instrumentais cirúrgicos ao biocida, é uma condição necessária para que as bactérias possam aderir 
aos instrumentos cirúrgicos e sobreviver à ação do glutaraldeído (Brasil, 2009 a e b).

Dentre os procedimentos estéticos observou-se maior variedade de patógenos micobacterianos associados aos quadros de infecção póscirúrgicos como $M$. abscessus, M. chelonae, M. fortuitum e M. massiliense (clone BRA100), o que pode indicar menor rigor na aplicação dos métodos de limpeza e desinfecção para o instrumental utilizado para essas finalidades, favorecendo, dessa forma, a sobrevivência de MCR nãoresistentes a desinfetantes (Duarte et al., 2009).

Apesar da efetividade sobre várias bactérias (esporuladas ou não), algumas são capazes de desenvolver resistência ao glutaraldeído (Retta, Sagripanti, 2008). Atentos a esse risco, Walsh et al. (1999) sugeriram que mudanças no $\mathrm{pH}$ ou na concentração poderiam ser suficientes para eliminar tal resistência. Outra opção, de acordo com os autores, seria o uso de outro aldeído (orto-ftalaldeído), sabidamente efetivo nessa eventualidade, inclusive contra bactérias esporuladas.

Os pré-requisitos a serem observados quando há re-esterilização de cânulas ou lâminas de videoartroscopia são a capacidade de esterilização ou de degermação de alto nível de qualquer solução desinfetante, como a obtida por glutaraldeído, água oxigenada, hipoclorito de sódio, ácido acético, depende da sua capacidade de penetrar, adequadamente, na superfície a ser tratada e da prévia retirada, por limpeza mecânica, de remanescentes teciduais, que possam manter o patógeno dentro do objeto. Todas as cânulas providas de sistema de válvulas ou extremamente finas, que não permitam adequada limpeza de sua luz, não são passíveis de esterilização ou desinfecção de alto nível, pela utilização do glutaraldeído. A lâmina de shaver de 3,2 mm não se enquadra em nenhuma dessas limitações, concluindo que foi eficaz na desinfecção dessas lâminas, mesmo quando deliberadamente contaminadas por MNT. Como todo estudo in vitro, os achados deste trabalho não podem ser diretamente aplicados à situação in vivo, onde diversos são os fatores que podem interferir na resposta agressor-hospedeiro. (Carvalho Jr et al., 2008). 
Dentre os aspectos recentes envolvendo as MCR relacionadas aos surtos no Brasil, estão sendo concluídos os estudos de avaliação da suscetiblidade do clone BRA100 de M. massiliense a desinfetantes diversos, como ortoftaldeído (OPA) e o ácido peracético, de forma a propor novas alternativas para desinfecção de instrumentais médicos ou odontológicos termossensíveis para contribuir à adequação de medidas proibitivas para o uso de soluções desinfetantes. Adicionalmente, é importante ressaltar a nova proposta de reclassificação taxonômica das espécies $M$. massiliense e M. bolletii como subespécies de $M$. abscessus, devido à alta similaridade fenotípica e genética entre esses micro-organismos (Leão et al., 2009).

Com base nestes achados e de forma a prevenir a ocorrência de novos surtos por MCR, foi publicado recentemente a suspensão cautelar do uso de glutaraldeído a $2 \%$ como desinfetante ou esterilizante líquido para artigos críticos, pela Secretaria de Estado de Saúde do Rio de Janeiro (Resolução SESDEC $n^{\circ} 431$, de 29 de agosto de 2008), e a proibição de esterilização química líquida pela ANVISA (Resolução da Diretoria Colegiada - RDC n8, de 27 de fevereiro de 2009), sem a existência de alternativas imediatas respaldadas pelo conhecimento científico (Pitombo et al., 2009, Brasil 2009a).

O uso de barreiras mecânicas (luvas, máscaras, gorros, entre outros) e a esterilização dos instrumentos foram se tornando práticas padrões. Outro avanço foi a introdução da antibioticoprofilaxia para a redução das taxas de ISC. A antissepsia, assepsia e profilaxia com antimicrobianos permitiram a realização de procedimentos cada vez mais complexos, em larga escala e com segurança (Mangran et al., 1999).

A eficácia no processamento de material utilizado em procedimentos invasivos ér um aspecto importante na ocorrência de MNT hospitalares. No entanto, apesar dos avanços tecnológicos na área de esterilização e desinfecção parece que pode haver outros fatores envolvidos com 0 aumento da frequência de infecções causadas por esses agentes (Mangran et al., 1999). 


\section{OBJETIVOS}

Analisar a ocorrência de infecções de sítio cirúrgico, por micobactérias de crescimento rápido, em pacientes submetidos a procedimentos ortopédicos, por meio de revisão integrativa.

\subsection{Específicos}

- Caracterizar as infecções de sítio cirúrgico por micobactérias de crescimento rápido

- Verificar a presença de fatores que possam explicar as infecções de sitio cirúrgico, por micobactérias de crescimento rápido 


\section{MATERIAL E MÉTODOS}

\subsection{Tipo de Estudo}

Foi realizada uma revisão integrativa, da literatura nacional e internacional, sobre as publicações referentes às micobacterioses de aquisição hospitalar por MCR em pacientes cirúrgicos.

A revisão integrativa da literatura é um dos métodos de pesquisa utilizados na Prática Baseada em Evidências (PBE), que permite a incorporação das evidências na prática clínica. Esse método tem a finalidade de reunir e sintetizar resultados de pesquisas sobre um delimitado tema ou questão, de maneira sistemática e ordenada, contribuindo para o aprofundamento do conhecimento do tema investigado. Desde 1980, a revisão integrativa é relatada na literatura como método de pesquisa (Roman, Friedlander, 1998).

A PBE focaliza sistemas de classificação de evidências, geralmente caracterizados de forma hierárquica, dependendo do delineamento de pesquisa, ou seja, da abordagem metodológica adotada para o desenvolvimento do estudo (Galvão, 2006).

Segundo Cooper (1989), a revisão integrativa é a mais ampla modalidade de pesquisa de revisão, por permitir a inclusão simultânea de estudos experimentais e não experimentais, questões teóricas ou empíricas. Em decorrência disso permite maior entendimento acerca de um fenômeno ou problema de saúde. Além disso, os objetivos desse tipo de revisão permitem subsidiar a elaboração de conceitos, a revisão de teorias e evidências. Realizada com rigor metodológico, contribui para o desenvolvimento da teoria e tem aplicabilidade direta nas práticas de saúde e na elaboração de políticas (Whittemore, Knafl, 2005).

A revisão integrativa inclui a análise de pesquisas relevantes que dão suporte para a tomada de decisão e a melhoria da prática clínica (Benefield, 2003), possibilitando a síntese do estado do conhecimento de um determinado assunto, além de apontar lacunas do conhecimento que precisam ser preenchidas com a realização de novos estudos (Polit, Beck, 2006). 
Este método de pesquisa permite a síntese de múltiplos estudos publicados e possibilita conclusões gerais a respeito de uma particular área de estudo. É um método valioso para a enfermagem, pois, muitas vezes, os profissionais não têm tempo para realizar a leitura de todo o conhecimento científico disponível, devido ao volume existente, além da dificuldade para realizar a análise crítica destes estudos (Polit, Beck, 2006).

Para o desenvolvimento desta revisão, serão observadas as seguintes etapas: questão do estudo; fontes de busca; estratégia de busca; critérios de inclusão e exclusão; material de análise; coleta de dados; síntese e avaliação dos artigos; interpretação e discussão dos resultados; conclusão e apresentação da revisão integrativa (Mendes et al., 2008).

\subsection{Questão do Estudo}

A questão formulada para a pesquisa foi: Há fatores em comum que explicam a ocorrência de infecções de sítio cirúrgico, por MCR, em procedimentos cirúrgicos?

\subsection{Fontes de Busca do Estudo}

Para a seleção dos artigos foram utilizados os seguintes portais: ISI WEB OF KNOWLEDGE, Biblioteca Virtual em Saúde (BVS) e PUBMED. Foi incluída a base de dados: EMBASE, pois esta não se encontra nos portais selecionados para a busca. Isso foi feito com a intenção de ampliar o âmbito da pesquisa, minimizando possíveis vieses nessa etapa do processo de elaboração da revisão integrativa.

\subsection{Estratégia de Busca do Estudo}

Para a busca selecionaram-se descritores do DECS (Descritores em Ciências da Saúde) e Medical Subject Headings Section (MESH). A busca foi realizada pelo acesso on-line, utilizando os critérios de inclusão e exclusão estabelecidos. Realizou-se no dia 26 de janeiro de 2011, por portais e uma base de dados. 
Para uma busca exaustiva foram utilizadas palavras do senso comum, mas como não houve alteração no número de publicações encontradas, optou-se por manter apenas os termos essenciais.

Em virtude das características específicas para o acesso das bases de dados selecionadas, as estratégias utilizadas para localizar os artigos foram adaptadas para cada uma, ou seja, utilização ou não de aspas, tendo como eixo norteador a questão do estudo e os critérios de inclusão da revisão integrativa, previamente estabelecidos.

O ISI WEB OF KNOWLEDGE é composto pelas bases de dados: WEB OF SCIENCE ${ }^{R}$, CURRENT CONTESTS CONNECT ${ }^{R}$, DERWENT INNOVATIONS INDEX ${ }^{S M}$, ZOOLOGICAL RECORD ${ }^{R}$, JOURNAL CITATION REPORT ${ }^{\mathrm{R}}$.

Os descritores utilizados foram: (mycobacterium OR mycobacteria NOT tuberculosis OR atypical mycobacteria OR mycobacteria atypical OR mycobacterium infections, atypical) AND (cross infection OR nosocomial infection OR hospital infection) AND (surgery OR surgical procedures OR endoscopy OR surgery plastic OR plastic surgery OR surgical procedures, operative OR organ transplant).

A BVS é composta pelas bases de dados: LILACS, IBECS, MEDLINE, COCHRANE e SCIELO. Os descritores foram: (mycobacterium OR "mycobacteria NOT tuberculosis" OR "atypical mycobacteria" OR "mycobacteria atypical" OR "mycobacterium infections, atypical") AND ("cross infection" OR "nosocomial infection" OR "hospital infection") AND (surgery OR "surgical procedures" OR endoscopy OR "surgery plastic" OR "plastic surgery" OR "surgical procedures, operative" OR "organ transplant").

O PUBMED é composto pelas bases de dados: MEDLINE, LIFE SCIENCE JOURNALS AND ONLINE BOOKS.

Os descritores foram: (mycobacterium OR mycobacteria NOT tuberculosis OR atypical mycobacteria OR mycobacteria atypical OR mycobacterium infections, atypical) AND (cross infection OR nosocomial infection OR hospital infection) AND (surgery OR surgical procedures OR endoscopy OR surgery plastic OR plastic surgery OR surgical procedures, operative OR organ transplant). 
Os descritores para o EMBASE foram assim apresentados: (mycobacterium OR mycobacteria NOT tuberculosis OR 'atypical mycobacteria' OR 'mycobacteria atypical OR 'mycobacterium infections, atypical') AND ('cross infection' OR 'nosocomial infection' OR 'hospital infection') AND (surgery OR 'surgical procedures' OR endoscopy OR 'surgery plastic' OR 'plastic surgery' OR 'surgical procedures, operative` OR 'organ transplant').

\subsection{Critérios de Inclusão e Exclusão}

Os critérios de inclusão dos artigos, publicados na literatura científica nacional e internacional, para o início desta revisão integrativa, que permitissem a obtenção de dados sobre a epidemiologia das MCR de origem hospitalar em pacientes submetidos a procedimentos cirúrgicos.

Foram excluídos os estudos sobre infecções por micobacterioses, em procedimentos não cirúrgicos como acupuntura e mesoterapia; administração de medicamentos por via parenteral; estudos sobre contaminação de produtos para a saúde e processamento de materiais, que não descreveram os pacientes e intervenções cirúrgicas envolvidas na ocorrência do evento. Foram excluídos os ensaios teóricos e livros eletrônicos do PUBMED. Também foram excluídos artigos com pacientes menores de 15 anos.

\subsection{Procedimento de busca do material de análise}

Por motivos descritos a seguir, o procedimento envolveu dois momentos e a necessidade de escolher um procedimento cirúrgico para análise.

Primeiramente, foi realizada a busca I $(\mathrm{BI})$. Os estudos publicados na literatura científica nacional e internacional (periódicos pré-selecionados) foram analisados pelo título e resumo, para confirmar a presença dos critérios de inclusão. Num segundo momento, para análise dos dados, os textos selecionados foram lidos na íntegra. Foram utilizados artigos disponíveis nas bases de dados selecionadas, que permitiram a obtenção de informações sobre a questão proposta. Os trabalhos não disponíveis full text 
foram solicitados por meio do Serviço de Acesso a Documentos (SCAD), após analisados foi construída uma figura da seleção dos artigos.

$\mathrm{Na}$ leitura dos artigos percebeu-se que nas referências constavam artigos de interesse que não haviam sido capturados pela busca realizada com os descritores escolhidos. Decidiu-se então repetir a busca adicionando a relação das MCR encontradas nos artigos lidos.

Desta maneira, em setembro de 2011 repetiu-se a busca utilizandose os dois métodos de busca em separado, pois o número elevado de descritores digitados em uma única vez dificultava o processo.

Os descritores utilizados para a busca no método 2 (BII) foram: surgery AND (mycobacterium goodii OR mycobacterium peregrinum OR mycobacterium smegmatis OR mycobacterium fortuitum OR Mycobacterium chelonae OR Mycobacterium abscessus OR Mycobacterium thermoresistibile OR Mycobacterium bolletii OR Mycobacterium massiliense OR rapidly growing mycobacteria).

Pelo método inicial de busca (BI) foram localizados 757 artigos e pelo método 2 (BII) 542, totalizando 1.299.

Pelo número elevado de artigos pré-selecionados, decidiu-se por uma especialidade cirúrgica, pois seria inviável analisar todos estes artigos. Optou-se pela especialidade de ortopedia, dessa maneira, foram selecionados no total 21 artigos. A Figura 1 sintetiza o processo de busca. 
BUSCA I

(BI)
BUSCA II

(BII)

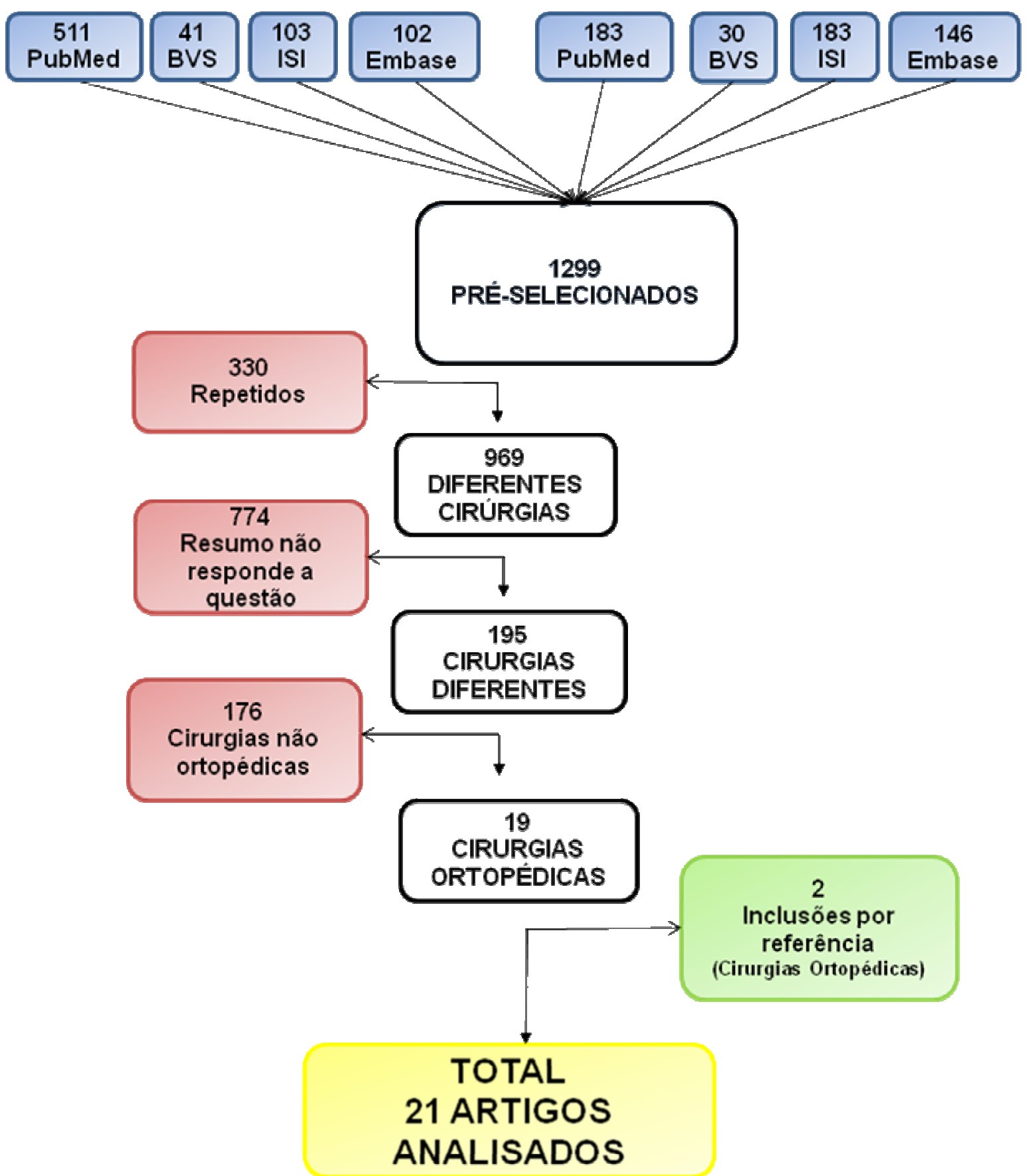

Figura 1. Distribuição do número de artigos encontrados nas diferentes etapas da Revisão Integrativa: Pré-selecionados, Descartados e Incluídos.

Legenda: Cor azul - pré-selecionados; vermelho - descartados; e verde - incluídos através das referências dos artigos analisados; e amarelo - total analisados. 
Durante o desenvolvimento da Revisão Integrativa, dentre os periódicos previamente selecionados, foram excluídos os estudos que estavam repetidos, os com resumo ou texto na íntegra, que não respondiam a questão e finalmente os que não tratavam de cirurgia ortopédica, como computada na Figura 1.

Do total de publicações pré-selecionadas ( $n=1.299)$, após efetuados os descartes, apenas 21 artigos foram incluídos posterior avaliação quanto a questão e aos critérios de inclusão deste estudo.

No Figura 2 verificamos a distribuição do número de publicações científicas encontradas nas diferentes fontes eletrônicas, num total de 1.299 periódicos escritos em diferentes idiomas. A maior quantidade foi detectada no portal PubMed $(n=694)$.

\section{Busca}

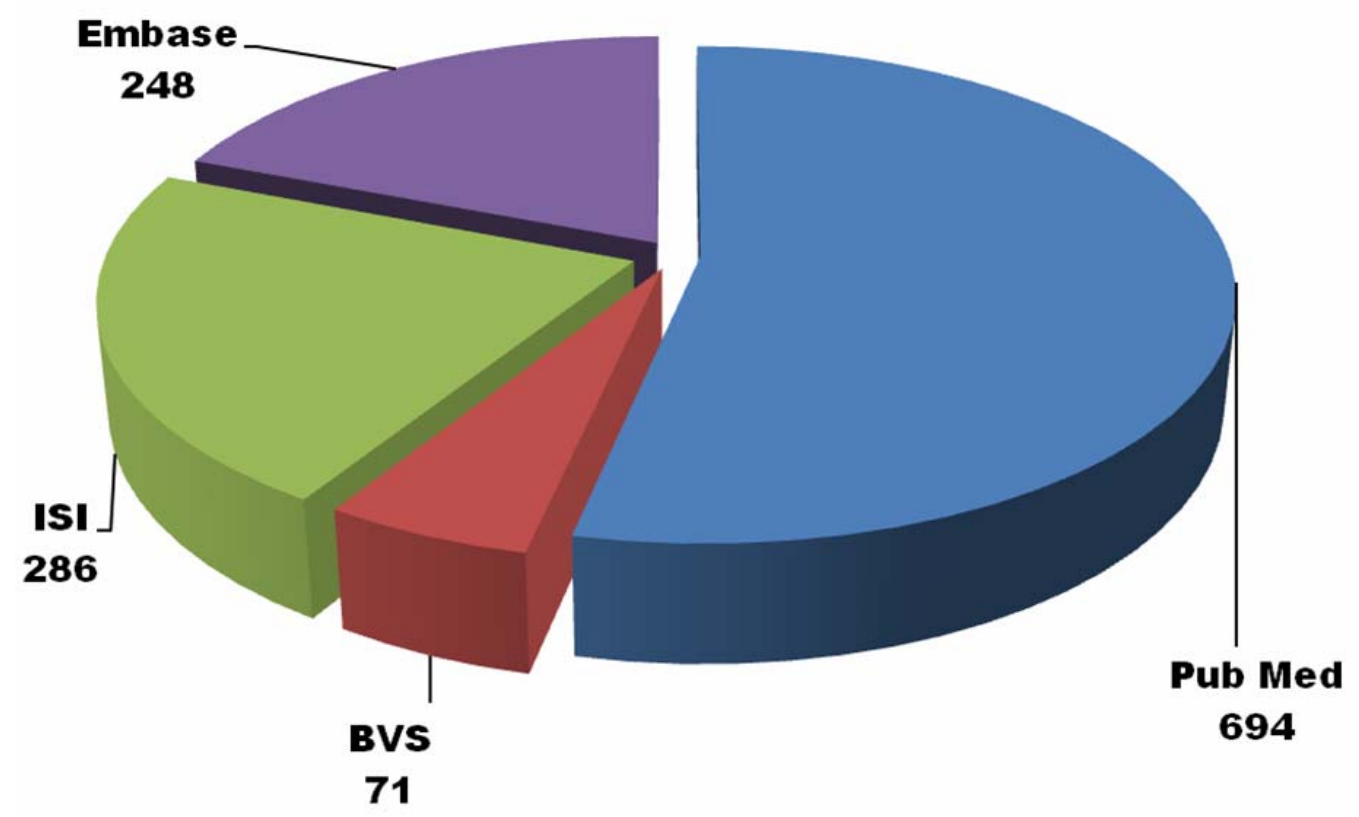

Figura 2 - Distribuição do número de periódicos pré-selecionados de acordo com a fonte eletrônica de busca. 


\subsection{Coleta de Dados}

A coleta de dados dos artigos incluídos na revisão integrativa foi efetuada por meio de um instrumento adaptado de Ursi e Galvão (2006), para o objeto da presente investigação (Apêndice $A$ ), contendo os seguintes itens: identificação do artigo original e características metodológicas do estudo; com os respectivos sub-itens: tipo de estudo, objetivo ou questão de investigação, população do estudo, local do estudo, período do estudo, agente, classificação do agente, característica das infecções, fonte presumível da infecção, taxas de infecção, surto, número de casos, tipo de procedimento, desfecho, análise (quando pertinente), implicações, particularidades e conclusão.

\subsection{Síntese e Avaliação dos Artigos}

Para apresentação da síntese dos artigos, foi utilizado um quadro sinóptico (Apêndice B), adaptado de Souza et al. (2010), contendo os seguintes enfoques considerados pertinentes: título do artigo, autor, periódico, ano, país, idioma, número de casos, tipo de procedimento, agente isolado, fontes de infecção, objetivo e conclusão.

\subsection{Interpretação e Discussão dos Resultados}

A apresentação dos resultados foi feita de forma descritiva, possibilitando ao leitor a avaliação da aplicabilidade da revisão integrativa elaborada. Para os dados quantitativos presentes nos estudos, quando possível, foram feitas medidas de tendência central e de variabilidade.

\subsection{Conclusão e Apresentação da Revisão Integrativa}

A apresentação da revisão integrativa foi realizada através de quadros e tabelas, para possibilitar maior clareza em relação aos achados. 


\section{RESULTADOS}

Dentre os 21 artigos avaliados, a maioria dos estudos (19 / 90,5\%) foi publicada no idioma inglês e dois (10,5\%) em Francês - E1 e E3, variando quanto ao continente e país de origem de edição: quatro da Europa (3 França e 1 Bélgica), três da Ásia (1 China, 1 Japão e 1 Taiwan), dois da Oceania (2 Austrália) e 12 da América do norte (EUA).

Em relação ao tipo de estudo, o qual se refere a diferentes tipos de procedimentos cirúrgicos ortopédicos, prevaleceram os Relatos de Caso (20 / 95,2\%), assim houve um único Estudo Retrospectivo (E-14), realizado nos EUA, em 2007, que analisou oito casos de micobacterioses de crescimento rápido.

O Apêndice $B$ compreende o conjunto dos 21 quadros sinópticos correspondentes à síntese das informações publicadas em cada estudo (Quadros 1 ao 21 - E1 ao E21).

A Figura 3 apresenta a produção científica sobre micobacteriose em pacientes submetidos a procedimentos cirúrgicos ortopédicos, de acordo com a data de publicação.

Quanto à quantidade de artigos incluídos na revisão integrativa (21), foi observado um pequeno número de publicações, sobre casos de micobacterioses, em cirurgias ortopédicas, nas décadas de 70 (6/17,7\%), de 80 (3 / 8,8\%) e de 90 (2 / 5,9\%); na década seguinte houve um aumento significativo (22 / 64,7\%) como demonstrado na Figura 3. 


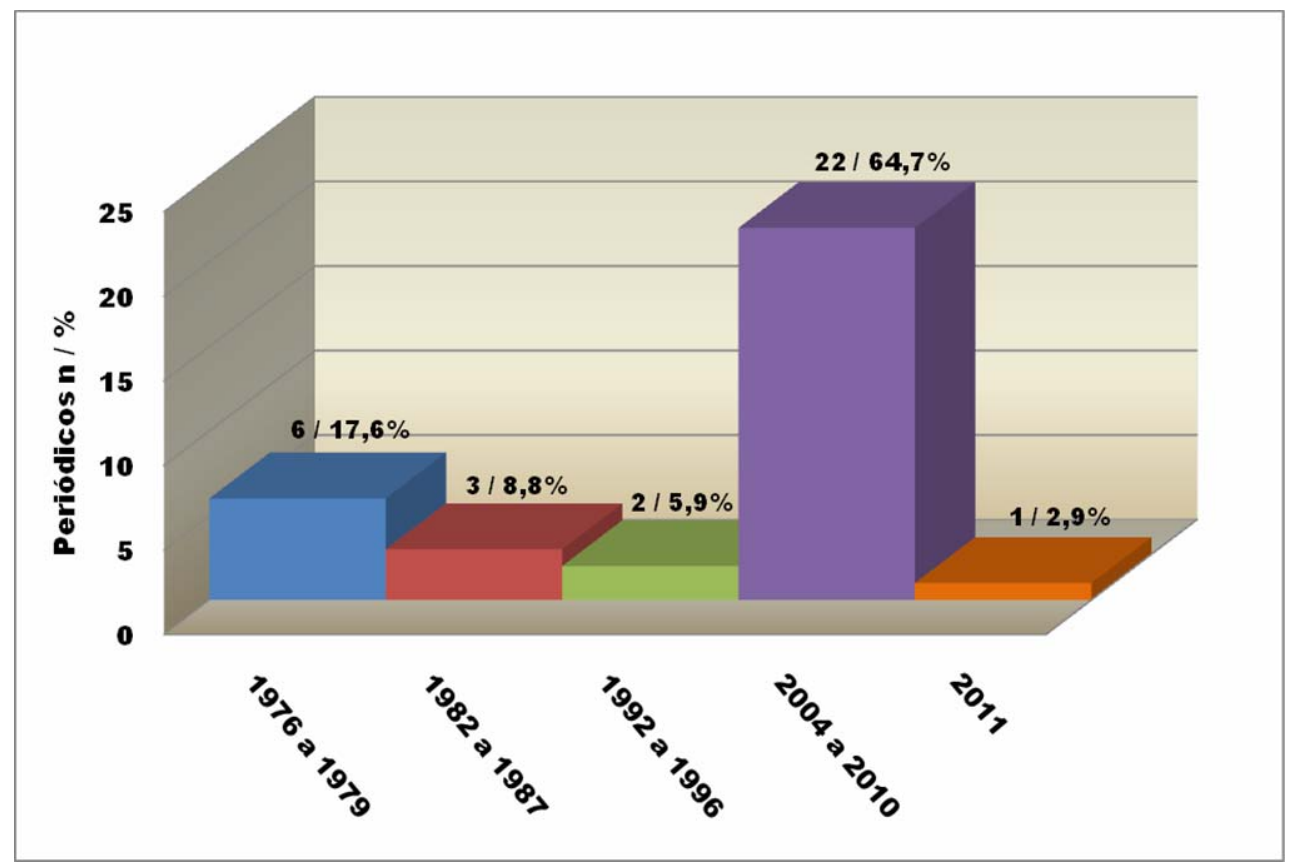

Figura 3. Produção científica sobre micobacteriose ( $\mathrm{n}$ total $=34$ ).

A Tabela 4 apresenta uma síntese panorâmica dos estudos incluídos nesta revisão, de acordo com os autores, periódicos, ano de publicação, país, tipo de estudo, número de pacientes, sexo, idade, procedimento cirúrgico, tipo de prótese ou parafuso, início dos sintomas e tempo de segmento médio / desfecho.

Avaliando-se o perfil dos pacientes, com micobacteriose ortopédica, quanto ao sexo e à idade, verificamos, que dentre os 26 pacientes dos Relatos de Caso, nove (34,6\%) eram masculinos (ð) e 17 (65,4\%) femininos (q), com média de idade variando de 15 a 83 anos; enquanto que, no Estudo Retrospectivo (E14), com oito indivíduos - 4 / 50\% § e 4 / 50\% क a idade variou de 60 a 87 anos, com média igual a 72,6 anos, estes considerados idosos. 
Tabela 4. Síntese panorâmica dos estudos incluídos na Revisão Integrativa. São Paulo, 2012.

\begin{tabular}{|c|c|c|c|c|c|c|c|c|c|c|c|}
\hline Estudo & Autores & $\begin{array}{l}\text { Revista I } \\
\text { Periódico }\end{array}$ & $\begin{array}{c}\text { Ano } \\
\text { Publicação }\end{array}$ & País & $\begin{array}{l}\text { Tipo de } \\
\text { estudo }\end{array}$ & $\begin{array}{c}\mathrm{N}^{0} \text { de } \\
\text { Paciente }\end{array}$ & $\begin{array}{l}\text { Paciente - } \\
\text { Sexo I } \\
\text { Idade } \\
\end{array}$ & Procedimento Cirúrgico & $\begin{array}{c}\text { Tipo de prótese ou } \\
\text { parafuso }\end{array}$ & $\begin{array}{c}\text { Início dos } \\
\text { Sintomas (Após } \\
\text { Última Cirurgia) } \\
\end{array}$ & $\begin{array}{c}\text { Tempo de Segmento } \\
\text { I Desfecho }\end{array}$ \\
\hline E1 & $\begin{array}{l}\text { Bergogne-Berezin, } \\
\text { E.; Nouhouayi, A.; } \\
\text { Pierre, J. }\end{array}$ & $\begin{array}{l}\text { Revue } \\
\text { Française des } \\
\text { Maladies } \\
\text { Respiratories }\end{array}$ & 1976 & França & Relato de Caso & 1 & $\mathrm{C} 1-\mathrm{M} / 62$ & $\begin{array}{l}\text { C1 - Artroplastia total de quadril } \\
\text { direito }\end{array}$ & $\begin{array}{c}\text { C1 - Prótese de quadril } \\
\text { esquerdo }\end{array}$ & 28 dias & 9 anos / NC \\
\hline E2 & $\begin{array}{l}\text { Booth, J.E.; } \\
\text { Jacobson, J.A.; } \\
\text { Kurrus, T.A.; } \\
\text { Edwards, T.W. }\end{array}$ & $\begin{array}{l}\text { The Journal of } \\
\text { Bone and } \\
\text { Joint Surgery }\end{array}$ & 1979 & EUA & $\begin{array}{l}\text { Relato de } \\
\text { Casos }\end{array}$ & 2 & $\begin{array}{l}C 1-F / 62 \\
C 2-F / 50\end{array}$ & $\begin{array}{c}\text { C1 - Artroplastia - joelho direito } \\
\text { C2 - Artroplastia - Liberação } \\
\text { cirúrgica do túnel do carpo } \\
\text { (pulso direito) }\end{array}$ & $\begin{array}{l}\text { C1 - Prótese de joelho } \\
\text { C2 - Prótese Silastic, } \\
\text { no trapézio do punho } \\
\text { direito }\end{array}$ & $\begin{array}{l}\mathrm{C} 1-1 \text { ano e } 10 \\
\text { meses } \\
\text { C2 }-10 \text { dias }\end{array}$ & $\begin{array}{l}\text { C1 }-3 \text { anos / Cura } \\
\text { C2 - } 2 \text { meses / Cura }\end{array}$ \\
\hline E3 & $\begin{array}{l}\text { Badelon, O.; } \\
\text { David, H.; Meyer, } \\
\text { L.; Radault, A.; } \\
\text { Zucman, J. }\end{array}$ & $\begin{array}{l}\text { Revue de } \\
\text { Chirurgie } \\
\text { Orthopédique }\end{array}$ & 1979 & França & $\begin{array}{l}\text { Relato de } \\
\text { Casos }\end{array}$ & 3 & $\begin{array}{l}\mathrm{C} 1-\mathrm{F} / 73 \\
\mathrm{C} 2-\mathrm{F} / 77 \\
\mathrm{C} 3-\mathrm{M} / 70\end{array}$ & $\begin{array}{c}\text { C1- Artroplastia - Prótese total } \\
\text { de quadril bilateral } \\
\text { C2- Artroplastia - Prótese total } \\
\text { de quadril bilateral } \\
\text { C3- Artroplastia - Prótese total } \\
\text { de quadril direita }\end{array}$ & $\begin{array}{c}\text { C1 - Prótese McKee } \\
\text { Postel, no quadril direito } \\
\text { C2 - Prótese McKee } \\
\text { Postel, total de quadril } \\
\text { esquerdo } \\
\text { C3 - Prótese MacKee } \\
\text { Postel, total no quadril } \\
\text { direito }\end{array}$ & $\begin{array}{l}\text { C1 - } 2 \text { meses } \\
\text { C2 - } 3 \text { meses } \\
\text { C3 - } 2 \text { dias }\end{array}$ & $\begin{array}{c}\text { C1 - } 2 \text { anos e } 7 \\
\text { meses / Cura } \\
\text { C2 - } 4 \text { meses / NR } \\
\text { C3 - } 3 \text { anos e } 6 \\
\text { meses / NR }\end{array}$ \\
\hline E4 & $\begin{array}{l}\text { Horadam, V.W.; } \\
\text { Smilack, J.D.; } \\
\text { Smith, E.C. }\end{array}$ & $\begin{array}{l}\text { South Medical } \\
\text { Journal }\end{array}$ & 1982 & EUA & Relato de Caso & 1 & $\mathrm{C} 1-\mathrm{F} / 78$ & $\begin{array}{l}\text { C1 - Artroplastia - Substituição } \\
\text { total de prótese de quadril } \\
\text { bilateral }\end{array}$ & $\begin{array}{l}\text { C1 - Prótese Aufranc - } \\
\text { Turner em quadril } \\
\text { bilateral total } \\
\text { C1 - Prótese foi } \\
\text { substituida por uma } \\
\text { longa haste Aufranc- } \\
\text { Turner no fêmur }\end{array}$ & C1 - 21 dias & C1 - 10 meses / Óbito \\
\hline E5 & $\begin{array}{c}\text { Moerman, J.; } \\
\text { Vandepitte, J.; } \\
\text { Corbeel, L.; } \\
\text { Coppens, N.; } \\
\text { Mannaerts, R.; } \\
\text { Vanhandenhove, } \\
\text { I.; Van den Broeck, } \\
\text { H. }\end{array}$ & $\begin{array}{l}\text { Acta Clinica } \\
\text { Belgica }\end{array}$ & 1985 & Bélgica & Relato de Caso & 1 & $\mathrm{C} 1-\mathrm{M} / 77$ & $\begin{array}{l}\text { C1 - Artroplastia - Inserção de } \\
\text { prótese total no quadril bilateral }\end{array}$ & $\begin{array}{c}\text { C1 - Prótese total de } \\
\text { quadril (2) }\end{array}$ & C1 - 1 mês & C1 - 9 meses / Cura \\
\hline E6 & $\begin{array}{l}\text { Herold, R.C.; } \\
\text { Lotke, P.A.; } \\
\text { MacGregor, R.R. }\end{array}$ & $\begin{array}{l}\text { Clinical } \\
\text { Orthopaedics } \\
\text { and Related } \\
\text { Research }\end{array}$ & 1987 & EUA & Relato de Caso & 1 & $\mathrm{C} 1-\mathrm{F} / 30$ & $\begin{array}{l}\text { C1 - Artroplastia total de joelho } \\
\text { direito }\end{array}$ & $\begin{array}{l}\text { C1 - Prótese de joelho } \\
\text { direito }\end{array}$ & C1 - 1 dia & $\begin{array}{c}\text { C1 - } 2 \text { anos e } 10 \\
\text { meses / Cura }\end{array}$ \\
\hline
\end{tabular}

Legenda: C - Paciente / Caso; F - feminino; M - masculino; NR - Não Relatado. 
Tabela 4 (cont.). Síntese panorâmica dos estudos incluídos na Revisão Integrativa. São Paulo, 2012.

\begin{tabular}{|c|c|c|c|c|c|c|c|c|c|c|c|}
\hline Estudo & Autores & $\begin{array}{l}\text { Revista I } \\
\text { Periódico }\end{array}$ & $\begin{array}{c}\text { Ano } \\
\text { Publicação }\end{array}$ & País & $\begin{array}{l}\text { Tipo de } \\
\text { estudo }\end{array}$ & $\begin{array}{c}\mathrm{N}^{0} \text { de } \\
\text { Paciente }\end{array}$ & $\begin{array}{l}\text { Paciente - } \\
\text { Sexo I } \\
\text { Idade }\end{array}$ & Procedimento Cirúrgico & $\begin{array}{c}\text { Tipo de prótese ou } \\
\text { parafuso }\end{array}$ & $\begin{array}{c}\text { Início dos } \\
\text { Sintomas (Após } \\
\text { Última Cirurgia) }\end{array}$ & $\begin{array}{c}\text { Tempo de Segmento } \\
\text { I Desfecho }\end{array}$ \\
\hline E7 & $\begin{array}{c}\text { Hasegawa, T.; } \\
\text { Watanabe, R.; } \\
\text { Hayashi, K.; } \\
\text { Inufusa, A.; } \\
\text { Nakagawa, H. }\end{array}$ & $\begin{array}{l}\text { Archives } \\
\text { Orthopaedic } \\
\text { and Trauma } \\
\text { Surgery }\end{array}$ & 1992 & Japão & Relato de Caso & 1 & $\mathrm{C} 1-\mathrm{M} / 17$ & $\begin{array}{c}\text { C1 - Fixação intramedular por } \\
\text { haste kuntsher da tíbia e fíbula } \\
\text { direita }\end{array}$ & $\begin{array}{l}\text { C1 - Parafuso } \\
\text { Küntscher para } \\
\text { correção de fratura de } \\
\text { tíbia e fíbula direita }\end{array}$ & C1 - 1 mês & C1 - 5 meses / Cura \\
\hline E8 & $\begin{array}{l}\text { Pring, M.; Eckhoff, } \\
\text { D.G. }\end{array}$ & $\begin{array}{l}\text { The Journal of } \\
\text { Arthroplasty }\end{array}$ & 1996 & EUA & Relato de Caso & 1 & C1 - F / 66 & $\begin{array}{l}\text { C1 - Artroplastia total de joelho } \\
\text { direito }\end{array}$ & $\begin{array}{l}\text { C1 - Prótese total de } \\
\text { joelho direito }\end{array}$ & C1 - 1 mês e 2 dias & C1 - 7 meses / NR \\
\hline E9 & $\begin{array}{l}\text { Ferguson, D.D.; } \\
\text { Gershman, K.; } \\
\text { Jensen, B.; } \\
\text { Arduino, M.J.; } \\
\text { Yakrus, M.A.; } \\
\text { Cooksey, R.C.; } \\
\text { Srinivasan, A. }\end{array}$ & $\begin{array}{l}\text { Emerging } \\
\text { Infectious } \\
\text { Diseases }\end{array}$ & 2004 & EUA & $\begin{array}{l}\text { Relato de } \\
\text { Casos }\end{array}$ & 2 & $\begin{array}{l}\text { C1 - M / } 64 \\
\text { C3 - F / } 75\end{array}$ & $\begin{array}{l}\text { C1 - Artroplastia total de quadril } \\
\text { esquerdo } \\
\text { C3 - Artroplastia - Substituição } \\
\text { total de joelho esquerdo }\end{array}$ & $\begin{array}{l}\text { C1 - Prótese total de } \\
\text { quadril esquerdo } \\
\text { C3 - Prótese total de } \\
\text { joelho esquerdo }\end{array}$ & $\begin{array}{l}\text { C1 - } 1 \text { ano } \\
\text { C3 - } 14 \text { dias }\end{array}$ & $\begin{array}{c}\text { C1 - } 1 \text { ano e } 4 \text { meses } \\
\text { / NR } \\
\text { C3 - } 1 \text { mês / NR }\end{array}$ \\
\hline E10 & $\begin{array}{l}\text { Wong, T.C.; Chan, } \\
\text { W.F.; Tsang, W.L.; } \\
\text { Yeung, S.H.; Ip, } \\
\text { F.K. }\end{array}$ & $\begin{array}{l}\text { The Journal of } \\
\text { Arthroplasty }\end{array}$ & 2005 & China & Relato de Caso & 1 & $\mathrm{C} 1-\mathrm{F} / 67$ & $\begin{array}{l}\text { C1 - Artroplastia total de quadril } \\
\text { esquerdo }\end{array}$ & $\begin{array}{l}\text { C1 - Prótese total de } \\
\text { quadril esquerdo }\end{array}$ & C1 -3 anos & $\begin{array}{l}\text { C1 - } 9 \text { anos e } 10 \\
\text { meses / Cura }\end{array}$ \\
\hline E11 & Saccente, M. & $\begin{array}{l}\text { Scandinavian } \\
\text { Journal of } \\
\text { Infectious } \\
\text { Diseases }\end{array}$ & 2005 & EUA & Relato de Caso & 1 & $\mathrm{C} 1-\mathrm{F} / 44$ & $\begin{array}{c}\text { C1 - Artroplastia total bilateral } \\
\text { de joelho }\end{array}$ & $\begin{array}{l}\text { C1 - Prótese total de } \\
\text { joelho bilateral }\end{array}$ & C1 - 8 meses & $\begin{array}{c}\text { C1 - } 1 \text { ano e } 7 \text { meses } \\
\text { / Cura }\end{array}$ \\
\hline E12 & $\begin{array}{c}\text { Pulcini, C.; } \\
\text { Vandenbussche, } \\
\text { E.; Podglajen, I.; } \\
\text { Sougakoff, W.; } \\
\text { Truffot-Pernot, C.; } \\
\text { Buu-Hoï, A.; } \\
\text { Varon, E.; } \\
\text { Mainardi, J.L. }\end{array}$ & $\begin{array}{l}\text { Journal of } \\
\text { Clinical } \\
\text { Microbiology }\end{array}$ & 2006 & França & Relato de Caso & 1 & $\mathrm{C} 1-\mathrm{F} / 83$ & $\begin{array}{c}\text { C1 - Artroplastia total de quadril } \\
\text { esquerdo }\end{array}$ & $\begin{array}{l}\text { C1 - Prótese total de } \\
\text { quadril esquerdo }\end{array}$ & C1 -10 dias & $\begin{array}{c}\text { C1 - } 1 \text { ano e } 10 \\
\text { meses / Cura }\end{array}$ \\
\hline E13 & $\begin{array}{l}\text { Cornelius, L.; } \\
\text { Reddix, R.; } \\
\text { Burchett, C.; Bond, } \\
\text { G.; Fader, R. }\end{array}$ & $\begin{array}{l}\text { Journal of } \\
\text { Surgical } \\
\text { Orthopaedic } \\
\text { Advances }\end{array}$ & 2007 & EUA & $\begin{array}{l}\text { Relato de } \\
\text { Casos }\end{array}$ & 3 & $\begin{array}{l}\mathrm{C} 1-\mathrm{F} / 70 \\
\mathrm{C} 2-\mathrm{F} / 60 \\
\mathrm{C} 3-\mathrm{F} / 50\end{array}$ & $\begin{array}{c}\text { C1 - Artroplastia total de joelho } \\
\text { direito } \\
\text { C2 - Artroplastia total de joelho } \\
\text { direito } \\
\text { C3 - Artroplastia total de quadril } \\
\text { direito }\end{array}$ & $\begin{array}{l}\text { C1 - Prótese de joelho } \\
\text { direito } \\
\text { C2 - Prótese de joelho } \\
\text { direito } \\
\text { C3 - Prótese de quadril } \\
\text { direito }\end{array}$ & $\begin{array}{c}\text { C1 - } 14 \text { dias } \\
\text { C2 - } 1 \text { mês e } 5 \text { dias } \\
\text { C3 }-3 \text { meses }\end{array}$ & $\begin{array}{c}\text { C1 - } 15 \text { meses / Cura } \\
\text { C2 - } 6 \text { meses / Cura } \\
\text { C3 - } 4 \text { meses e } 3 \\
\text { semanas / NR }\end{array}$ \\
\hline
\end{tabular}

Legenda: C - Paciente / Caso; F - feminino; M - masculino; NR - Não Relatado. 
Tabela 4 (cont.). Síntese panorâmica dos estudos incluídos na Revisão Integrativa. São Paulo, 2012.

\begin{tabular}{|c|c|c|c|c|c|c|c|c|c|c|c|}
\hline Estudo & Autores & $\begin{array}{l}\text { Revista I } \\
\text { Periódico }\end{array}$ & $\begin{array}{c}\text { Ano } \\
\text { Publicação }\end{array}$ & País & $\begin{array}{l}\text { Tipo de } \\
\text { estudo }\end{array}$ & $\begin{array}{c}\mathbf{N}^{0} \text { de } \\
\text { Paciente }\end{array}$ & $\begin{array}{l}\text { Paciente - } \\
\text { Sexo I } \\
\text { Idade } \\
\end{array}$ & Procedimento Cirúrgico & $\begin{array}{l}\text { Tipo de prótese ou } \\
\text { parafuso }\end{array}$ & $\begin{array}{c}\text { Início dos } \\
\text { Sintomas (Após } \\
\text { Última Cirurgia) } \\
\end{array}$ & $\begin{array}{l}\text { Tempo de Segmento } \\
\text { I Desfecho }\end{array}$ \\
\hline E14 & $\begin{array}{l}\text { Eid, A.J.; Berbari, } \\
\text { E.F.; Sai, I.G.; } \\
\text { Wengenack, N.L.; } \\
\text { Osmon, D.R.; } \\
\text { Razonable, R.R. }\end{array}$ & $\begin{array}{l}\text { Clinical } \\
\text { Infectious } \\
\text { Diseases }\end{array}$ & 2007 & EUA & $\begin{array}{c}\text { Estudos } \\
\text { Retrospectivo }\end{array}$ & 8 & $\begin{array}{l}C 1-F / 74 \\
C 2-M / 78 \\
C 3-M / 60 \\
C 4-M / 76 \\
C 5-F / 66 \\
C 6-M / 69 \\
C 7-F / 71 \\
C 8-F / 87\end{array}$ & $\begin{array}{c}\mathrm{C} 1, \mathrm{C} 2, \mathrm{C} 3, \mathrm{C} 4, \mathrm{C} 5, \mathrm{C} 6 \text { e } \mathrm{C} 7 \mathrm{a}- \\
\text { Artroplastia total de joelho } \\
\text { bilateral ( } 7 \text { casos) } \\
\mathrm{C} 8 \text { - Artroplastia total de quadril } \\
\text { bilateral (1 caso) } \\
\text { C7b - Artroplastia de cotovelo } \\
\text { bilateral ( } 1 \text { caso) }\end{array}$ & $\begin{array}{c}-7 \text { próteses bilateral de } \\
\text { joelho } \\
-2 \text { de quadril } \\
-2 \text { de cotovelo }\end{array}$ & $\begin{array}{c}\mathrm{C} 1-6 \text { anos e } 5 \\
\text { meses } \\
\text { C2 }-7 \text { anos e } 6 \\
\text { meses } \\
\text { C3 }-7 \text { dias } \\
\text { C4 }-7 \text { anos e } 6 \\
\text { meses } \\
\text { C5 - } 3 \text { meses } \\
\text { C6 }-2 \text { anos e } 6 \\
\text { meses } \\
\text { C7a }-13 \text { anos e } 6 \\
\text { meses } \\
\text { C7b - } 15 \text { anos } \\
\text { C8 }-2 \text { meses }\end{array}$ & $\begin{array}{c}\text { C1 - } 120 \text { semanas / } \\
\text { Cura } \\
\text { C2 - } 58 \text { semanas / } \\
\text { Cura } \\
\text { C3 - } 107 \text { semanas / } \\
\text { Cura } \\
\text { C4 - } 24 \text { semanas / } \\
\text { NR } \\
\text { C5 - } 189 \text { semanas / } \\
\text { NR } \\
\text { C6 - } 23 \text { semanas / } \\
\text { NR } \\
\text { C7a - } 3 \text { semanas / } \\
\text { NR } \\
\text { C7b - } 3 \text { semanas / } \\
\text { NR } \\
\text { C8 - } 326 \text { semanas / } \\
\text { Cura }\end{array}$ \\
\hline E15 & $\begin{array}{l}\text { Porat, M.D.; } \\
\text { Austin, M.S. }\end{array}$ & $\begin{array}{l}\text { The Journal of } \\
\text { Arthroplasty }\end{array}$ & 2008 & EUA & Relato de Caso & 1 & $\mathrm{C} 1-\mathrm{M} / 68$ & $\begin{array}{c}\text { C1 - Artroplastia - Cirurgia de } \\
\text { joelho bilateral }\end{array}$ & $\begin{array}{c}\mathrm{C} 1 \text { - Prótese de joelho } \\
\text { bilateral }\end{array}$ & 16 anos & $\begin{array}{c}16 \text { anos e } 10 \text { meses / } \\
\text { NR }\end{array}$ \\
\hline E16 & $\begin{array}{l}\text { Cheung, I.; Wilson, } \\
\text { A. }\end{array}$ & The Knee & 2008 & Austrália & Relato de Caso & 1 & $\mathrm{C} 1-\mathrm{M} / 68$ & C1 - Artroplastia total de joelho & C1 - Prótese de joelho & 3 meses & 10 meses / Cura \\
\hline E17 & $\begin{array}{l}\text { Jacoby, S.M.; } \\
\text { Sivalingam, J.J.; } \\
\text { Raikin, S.M. }\end{array}$ & $\begin{array}{l}\text { Foot \& Ankle } \\
\text { International }\end{array}$ & 2008 & EUA & Relato de caso & 1 & $\mathrm{C} 1-\mathrm{M} / 55$ & $\begin{array}{l}\text { C1 - Correção cirúrgica: } \\
\text { debridamento do tendão de } \\
\text { Aquiles (tornozelo), flexor longo } \\
\text { do hálux, com transferência do } \\
\text { tendão do calcâneo e } \\
\text { ostectomia. }\end{array}$ & $\begin{array}{l}\text { C1 - Parafuso } \\
\text { bioabsorvivel }\end{array}$ & 23 dias & $\begin{array}{c}2 \text { anos e } 2 \text { meses } / \\
\text { Cura }\end{array}$ \\
\hline E18 & $\begin{array}{l}\text { Oh, H.L.; Chen, } \\
\text { D.B.; Seeto, B.G.; } \\
\text { Macdessi, S.J. }\end{array}$ & The Knee & 2009 & Australia & Relato de caso & 1 & C1 - F/ 15 & $\begin{array}{l}\text { C1 - Reconstrução do ligamento } \\
\text { cruzado anterior do joelho } \\
\text { esquerdo }\end{array}$ & $\begin{array}{l}\text { C1 - Parafuso } \\
\text { bioabsorvivel }\end{array}$ & 3 meses & $\begin{array}{c}1 \text { ano e } 7 \text { meses / } \\
\text { Cura }\end{array}$ \\
\hline E19 & $\begin{array}{l}\text { Hetsroni, I.; } \\
\text { Rosenberg, H.; } \\
\text { Grimm, P.; Marx, } \\
\text { R.G. }\end{array}$ & $\begin{array}{l}\text { Journal of } \\
\text { Bone and } \\
\text { Joint Surgery }\end{array}$ & 2010 & EUA & Relato de caso & 1 & $\mathrm{C} 1-\mathrm{M} / 40$ & $\begin{array}{c}\text { C1 - Reparo do tendão patelar } \\
\text { esquerdo }\end{array}$ & $\begin{array}{l}\text { Ausência de Prótese / } \\
\text { parafuso }\end{array}$ & 1 mês & $\begin{array}{c}1 \text { ano e } 4 \text { meses / } \\
\text { Cura }\end{array}$ \\
\hline E20 & $\begin{array}{l}\text { Yinkey, L.M.; } \\
\text { Halsey, E.S.; } \\
\text { Lloyd, B.A. }\end{array}$ & $\begin{array}{l}\text { Infectious } \\
\text { Diseases in } \\
\text { Clinical } \\
\text { Practice }\end{array}$ & 2010 & EUA & Relato de caso & 1 & C1 - F / 40 & $\begin{array}{c}\text { C1 - Artroplastia total de quadril } \\
\text { esquerdo }\end{array}$ & $\begin{array}{l}\text { C1 - Prótese total de } \\
\text { quadril esquerdo }\end{array}$ & 2 anos & 4 anos e 1 mês/ Cura \\
\hline E21 & $\begin{array}{l}\text { Wang, S.X.; Yang, } \\
\text { C.J.; Chen, Y.C.; } \\
\text { Lay, C.J.; Tsai, } \\
\text { C.C. }\end{array}$ & $\begin{array}{l}\text { Internal } \\
\text { Medicine }\end{array}$ & 2011 & Taiwan & Relato de caso & 1 & C1 - F / 72 & $\begin{array}{l}\text { C1 - Artroplastia total de joelho } \\
\text { direito }\end{array}$ & $\begin{array}{l}\text { C1 - Prótese total de } \\
\text { joelho direito }\end{array}$ & 5 meses & $\begin{array}{l}2 \text { anos e } 8 \text { meses/ } \\
\text { Cura }\end{array}$ \\
\hline
\end{tabular}

Legenda: C - Paciente / Caso; F - feminino; M - masculino; NR - Não Relatado 
De acordo com a OMS, os 26 pacientes citados anteriormente, foram subdivididos, quanto à faixa etária em três grupos: adolescentes (13 a 17 anos), com média de 16 anos, sendo 10 / 17 anos e 1 ㅇ / 15 anos, totalizando ( $n=2$ ) ; adultos (15 a 59 anos), com idade média de 30,6 anos e 47,5 anos, sendo $2 \widehat{0}$ e 5 \% , respectivamente, totalizando $(n=7)$ e idosos $(\geq 60$ anos), com média de idade de 68,2 anos e 71,2 anos, sendo $60^{\lambda}$ e 11 , respectivamente, totalizando $(n=17)$.

Em relação aos procedimentos cirúrgicos a que foram submetidos os 34 pacientes avaliados, verificamos que, dentre os 26 derivados dos Relatos de Caso, 25 (96,2\%) passaram por cirurgias com colocação de prótese ou parafuso e um $(3,8 \%)$ sem estes componentes protéticos; subdivididos quanto ao sítio cirúrgico, em artroplastia de joelho - uma ou bilateral (11 pacientes / 42,3\%), com 13 colocação de prótese $(50,0 \%)$ ou de quadril uma ou bilateral / total (11 pacientes / 42,3\%) / 13 próteses $(50,0 \%)$; liberação cirúrgica do túnel do carpo (pulso direito) - n=1 (E2-C2); fixação intramedular de tíbia e fíbula (perna direita) - $n=1 / 3,85 \%$ (E7-C1); debridamento do tendão de Aquiles (tornozelo) - $n=1 / 3,85 \%$ (E17-C1) e reconstrução do ligamento cruzado anterior (joelho esquerdo), único que colocou parafuso $-n=1 / 3,85 \%$ (E18-C1); além do paciente $(n=1 / 3,85 \%)$ do estudo E19-C1, que sofreu reparo do tendão patelar (joelho esquerdo).

Quanto aos oito pacientes (18 próteses) do Estudo Retrospectivo (E14 - C1 ao C8), todos foram submetidos à artroplastias bilaterais (total): de joelho ( 7 pacientes $-87,5 \%$ e 14 próteses $-77,8 \%$ ), de quadril ( 1 paciente - 12,5\% e 2 próteses $11,1 \%$ ) ou de cotovelo (1 paciente - $12,5 \%$ e 2 próteses - 11,1\%); ressaltando-se que o caso $C 7$ ( $\$$ - 71 anos) sofreu cirurgia de cotovelo e joelho em épocas diferentes, respectivamente 1977 e 1979. Em suma, foram oito pacientes, com prótese bilateral (16), e o C7 que fez duas cirurgias, ou seja, mais duas próteses, assim totalizando 18 próteses.

De acordo com os procedimentos cirúrgicos realizados nos 34 pacientes com micobacteriose ortopédica, 33 / 97,06\% foram com colocação de próteses / parafuso (E18-C1 - + / 15 anos) artroplastias uni ou bilaterais entre outros, enquanto que apenas em um $(2,94 \%)$ caso $(E 19-C 1-\delta / 40$ 
anos) a cirurgia ortopédica foi sem o implante destes componentes (Tabela 4). Quanto ao sítio da cirurgia ortopédica, num total de $n=36$ computou-se: 19 / 52,78\% pacientes (7 o e 12 +) de joelho; 1 / 2,78\% de tíbia e fíbula (perna direita); 13 / 36,11\% (4 o e 9 \%) de quadril e 1 / / 2,78\% de tornozelo I pé; totalizando para membros inferiores $(n=34)$. Além de, 1 + $(2,78 \%)$ de cotovelo, realizada no paciente (E14-C7 - 74 anos) posteriormente operada do joelho (1977 e 1999) e 1 क (2,78\%) de pulso; totalizando para membros superiores $(n=2)$, como demonstrado na figura 4 . Com predominância de cirurgias ortopédicas em membros inferiores, pacientes do sexo feminino, nas próteses de joelho e quadril, ou seja, joelho: 12 (35,3\%) mulheres em 34 pacientes ou $12(63,1 \%)$ mulheres em 19 próteses; e quadril: 9 (26,5\%) mulheres em 34 pacientes ou $9(69,2 \%)$ mulheres em 13 próteses.

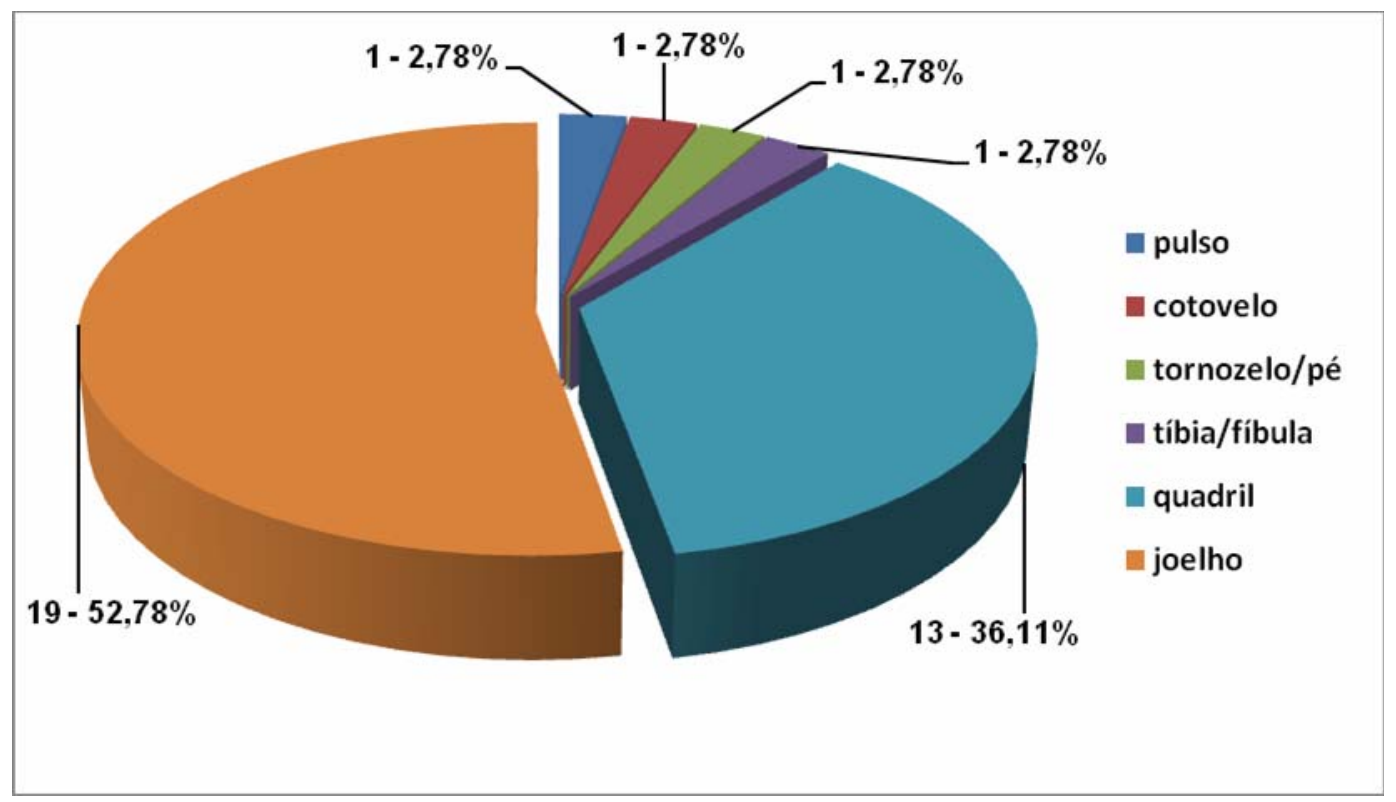

Figura 4: Distribuição dos pacientes, quanto aos procedimentos cirúrgicos ortopédicos realizados

De acordo com a data em que ocorreu o início dos sintomas decorrentes da micobacteriose, o tempo de segmento médio dos pacientes e o desfecho (cura ou óbito), constatou-se que, para o início dos sintomas, após a cirurgia, o tempo variou de 1 a 2 dias (24 ou 48 horas) a 5.840 dias (16 anos); o acompanhamento médico ocorreu durante um período oscilante 
de 21 dias (E14-C7) a 6.140 dias (16 anos e 10 meses); quanto aos desfechos, quando relatados, foi a cura para $18(52,9 \%)$ pacientes e óbito para $1(2,9 \%)$ do sexo feminino (E4).

O tempo entre a cirurgia e o início dos sintomas foi mencionado para os $34(100 \%)$ pacientes, mas a análise foi feita para 33 pacientes, pois se considerou apenas o primeiro episódio de infecção por MCR. Neste grupo a média foi de 653,6 dias (93 semanas), desvio padrão \pm 1.343 dias (192 semanas), mediana de 80 dias (11,4 semanas) e moda de 90 dias (3 meses). O intervalo interquartil foi de 352 dias (50 semanas). A Figura 5 mostra a distribuição dos tempos de início do sintomas após a cirurgia e o box plot com os outliers.
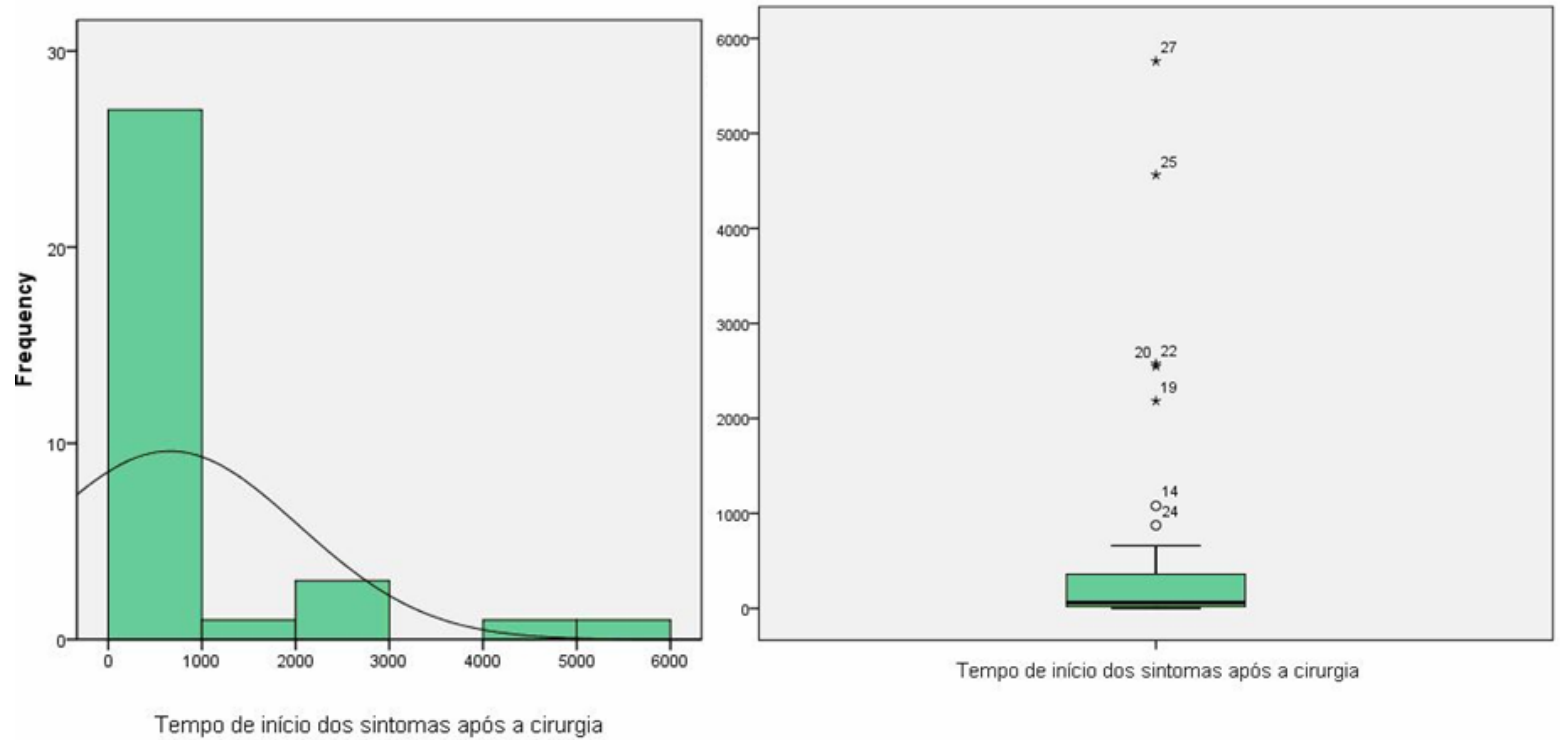

Figura 5 - Distribuição do tempo para início dos sintomas e box plot com os outliers.

Caso os outliers (acima de 1 ano) fossem retirados da análise, se obteria uma média de 101 dias ou 14 semanas (DP \pm 160,2 dias ou 23 semanas), mediana de 32 dias (8 semanas) e moda de 90 . Nesta análise foram excluídos sete pacientes e o intervalo interquartil foi de 72 dias. A Figura 6 mostra a distribuição dos tempos de início do sintomas, após a cirurgia e o box plot sem os outliers 

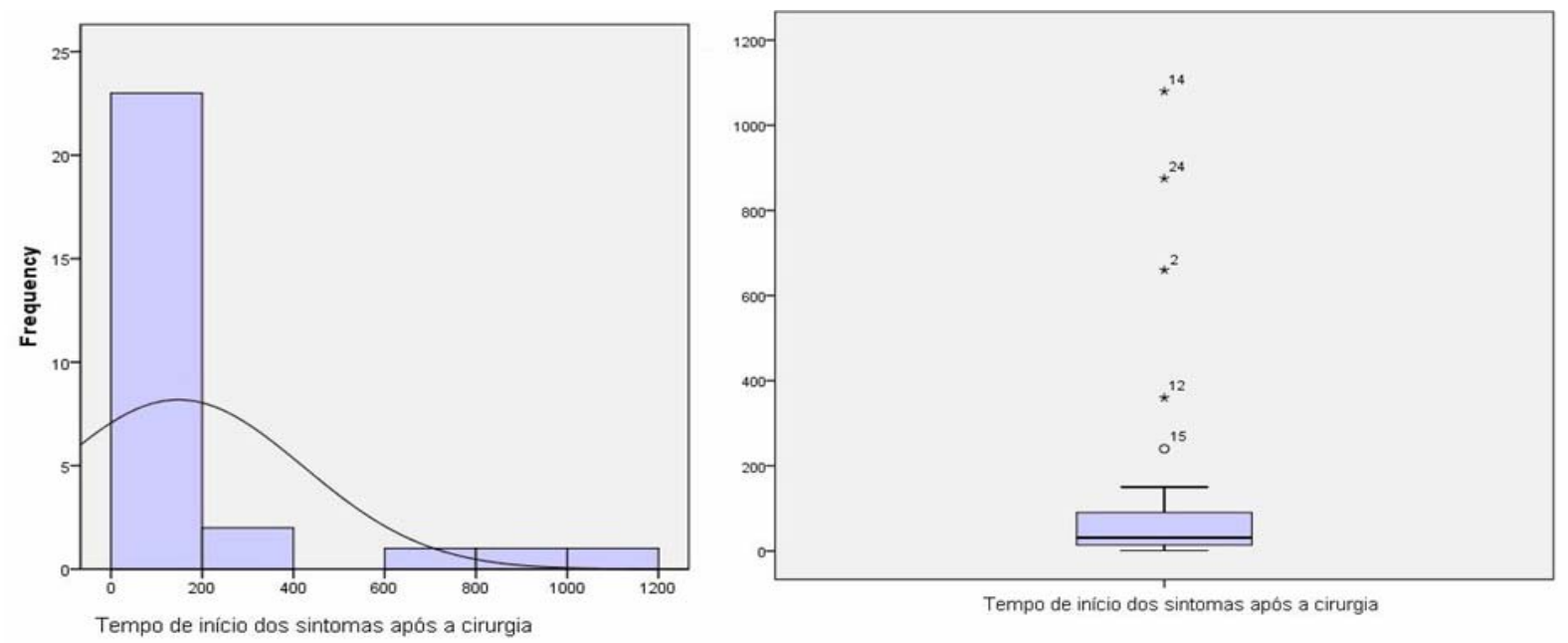

Figura 6. Box plot para o tempo de início dos sintomas, após a cirurgia sem os outliers (acima de um ano).

Excluindo-se os pacientes com mais de um ano de tempo de início dos sintomas, após a cirurgia, observa-se pelos histogramas das figuras 5 e 6 que é possível analisar-se melhor a distribuição dos tempos relatados pelos autores.

O Quadro 2, apresenta a distribuição numérica dos sinais e sintomas, dos pacientes com ISC.

Quanto aos variados sinais e sintomas relatados pelos pacientes, os mais prevalentes foram: dor (21/61,8\%), secreção (17 / 50,0\%), edema (14 / 41,2\%), febre (14 / 41,2\%), eritema (9 / 26,5\%), fístula (7 / 20,6\%), calor (5 / $14,7 \%)$, tremor (2 / 5,9\%), abscesso (2 / 5,9\%) e hematoma (1/3,0\%). 
Quadro 2 Distribuição dos sinais e sintomas dos pacientes de ortopedia com ISC.

\begin{tabular}{|c|c|c|c|c|c|}
\hline \multirow{2}{*}{\multicolumn{2}{|c|}{ Sinais - Sintomas }} & \multirow{2}{*}{\multicolumn{2}{|c|}{ Estudo / Caso }} & \multicolumn{2}{|c|}{ Pacientes } \\
\hline & & & & $n$ & $\%$ \\
\hline \multirow{10}{*}{ 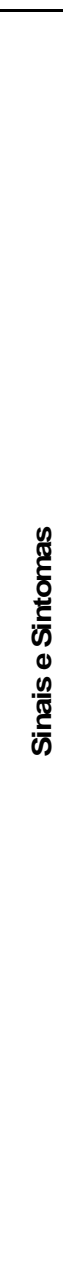 } & Calor & $\begin{array}{l}E 2-C 1 \text { e } C 2 \\
E 3-C 2\end{array}$ & \begin{tabular}{|l|} 
E7-C1 \\
E13-C1
\end{tabular} & 5 & 14,7 \\
\hline & Eritrema & $\begin{array}{l}E 2-C 1 \text { e } C 2 \\
E 3-C 2 \\
E 6-C 1 \\
E 7-C 1 \\
E 8-C 1\end{array}$ & \begin{tabular}{|l|}
$E 13-C 1$ \\
$E 14-C 2$ \\
$E 19-C 1$
\end{tabular} & 9 & 26,5 \\
\hline & Edema & $\begin{array}{l}E 2-C 1 \text { e } C 2 \\
E 6-C 1 \\
E 7-C 1 \\
E 8-C 1 \\
E 11-C 1\end{array}$ & $\begin{array}{l}\text { E14-C2, C3, C4, C5, C6 e C7 } \\
\text { E20-C1 } \\
\text { E21-C1 }\end{array}$ & 14 & 41,2 \\
\hline & Dor & $\begin{array}{l}E 2-C 1 \text { e C2 } \\
E 6-C 1 \\
E 7-C 1 \\
E 8-C 1 \\
E 9-C 1 \text { e C3 } \\
E 11-C 1 \\
E 12-C 1\end{array}$ & $\begin{array}{l}\text { E13-C1 } \\
\text { E14-C1, C2, C3, C4, C6, C7 e C8 } \\
\text { E15-C1 } \\
\text { E17-C1 } \\
\text { E20-C1 } \\
\text { E21-C1 }\end{array}$ & 21 & 61,8 \\
\hline & Febre & $\begin{array}{l}E 2-C 1 \\
E 3-C 1, \text { C2 e C3 } \\
E 6-C 1 \\
E 7-C 1 \\
E 13-C 1 \text { e C3 }\end{array}$ & \begin{tabular}{|l|} 
E14-C1, C3 e C8 \\
E19-C1 \\
E2O-C1 \\
E21-C1
\end{tabular} & 14 & 41,2 \\
\hline & Tremor & E2-C1 & E19-C1 & 2 & 5,9 \\
\hline & Hematoma & E6-C1 & & 1 & 3,0 \\
\hline & Abscesso & E3-C1 & E14-C1 & 2 & 5,9 \\
\hline & Fístula & \begin{tabular}{|l} 
E1-C1 \\
E3-C1, C2 e C3 \\
E6-C1
\end{tabular} & \begin{tabular}{|l|}
$\mathrm{E} 7-\mathrm{C} 1$ \\
$\mathrm{E} 11-\mathrm{C} 1$
\end{tabular} & 7 & 20,6 \\
\hline & Secreção & $\begin{array}{l}E 1-C 1 \\
E 2-C 1 \text { e C2 } \\
E 3-C 2 \text { e C3 } \\
E 4-C 1 \\
E 6-C 1 \\
E 7-C 1 \\
E 8-C 1\end{array}$ & \begin{tabular}{|l|}
$E 9-C 1$ e C3 \\
E12-C1 \\
E13-C2 e C3 \\
E14-C1 \\
E17-C1 \\
E19-C1
\end{tabular} & 17 & 50,0 \\
\hline
\end{tabular}

Em relação às intervenções realizadas nos pacientes submetidos à cirurgia(s) ortopédica(s), após o diagnóstico de ISC, a mais frequente foi a antibioticoterapia - 34 / 100\%, remoção de prótese total - 17 / 50,0\%, drenagem - 14 / 41,2\%, debridamento cirúrgico - 14 / 41,2\%, irrigação - 8 / $23,5 \%$, revisão cirúrgica $-6 / 17,6 \%$, readmissão $-5 / 14,7 \%$, troca da prótese total (prótese nova) - 3/8,8\%, remoção de componentes da prótese - 3 / 8,8\% e reimplante da prótese (mesma) - 1/2,9\%. (Quadro 3) 
Quadro 3. Distribuição das intervenções médicas após o diagnóstico de ISC.

\begin{tabular}{|c|c|c|c|c|c|}
\hline \multirow{2}{*}{\multicolumn{2}{|c|}{ Intervenções Cirúrgicas }} & \multirow{2}{*}{\multicolumn{2}{|c|}{ Estudo / Caso }} & \multicolumn{2}{|c|}{ Pacientes } \\
\hline & & & & $\mathbf{n}$ & $\%$ \\
\hline \multirow{10}{*}{ 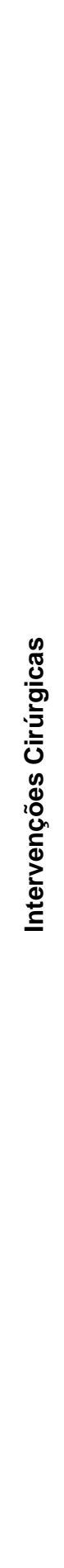 } & Drenagem & $\begin{array}{l}\text { E2-C1 e C2 } \\
\text { E3-C1, C2 e C3 } \\
\text { E4-C1 } \\
\text { E5-C1 } \\
\text { E6-C1 }\end{array}$ & \begin{tabular}{|l}
$E 7-C 1$ \\
E9-C1 e C3 \\
E11-C1 \\
E13-C3 \\
E17-C1
\end{tabular} & 14 & 41,2 \\
\hline & Irrigação & $\begin{array}{l}E 2-C 1 \\
E 3-C 1 \\
E 4-C 1 \\
E 7-C 1\end{array}$ & \begin{tabular}{|l|}
$\mathrm{E} 13-\mathrm{C} 1$ e C2 \\
$\mathrm{E} 15-\mathrm{C} 1$ \\
$\mathrm{E} 17-\mathrm{C} 1$
\end{tabular} & 8 & 23,5 \\
\hline & Debridamento Cirúrgico & $\begin{array}{l}E 2-C 1 \\
E 4-C 1 \\
E 6-C 1 \\
E 8-C 1 \\
E 10-C 1 \\
E 11-C 1 \\
E 13-C 1 \text { e C2 }\end{array}$ & $\begin{array}{l}\text { E15-C1 } \\
\text { E16-C1 } \\
\text { E17-C1 } \\
\text { E18-C1 } \\
\text { E19-C1 } \\
\text { E20-C1 }\end{array}$ & 14 & 41,2 \\
\hline & Remoção da Prótese total & $\begin{array}{l}\text { E2-C2 } \\
\text { E3-C1 } \\
\text { E4-C1 } \\
\text { E6-C1 } \\
\text { E8-C1 } \\
\text { E9-C1 e C3 } \\
\text { E10-C1 } \\
\end{array}$ & \begin{tabular}{|l|} 
E11-C1 \\
E12-C1 \\
E13-C1 e C3 \\
E14-C3, C4 e C5 \\
E16-C1 \\
E20-C1
\end{tabular} & 17 & 50,0 \\
\hline & $\begin{array}{c}\text { Troca da Prótese total } \\
\text { (prótese nova) }\end{array}$ & \begin{tabular}{|l|}
$E 2-C 1$ \\
$E 6-C 1$ \\
\end{tabular} & E21-C1 & 3 & 8,8 \\
\hline & $\begin{array}{l}\text { Remoção de Componentes } \\
\text { da Prótese }\end{array}$ & $\begin{array}{l}\mathrm{E} 10-\mathrm{C} 1 \\
\mathrm{E} 17-\mathrm{C} 1\end{array}$ & E18-C1 & 3 & 8,8 \\
\hline & $\begin{array}{c}\text { Reimplante da prótese } \\
\text { (mesma) }\end{array}$ & $\begin{array}{l}\mathrm{E} 8-\mathrm{C} 1 \\
\mathrm{E} 14-\mathrm{C} 3 \text { e C6 }\end{array}$ & $\begin{array}{l}\text { E15-C1 } \\
\text { E16-C1 e E21-C1 }\end{array}$ & 2 & 5,9 \\
\hline & Readmissão & \begin{tabular}{|l}
$E 2-C 1$ \\
$E 3-C 2$ \\
E4-C1
\end{tabular} & $\begin{array}{l}E 5-C 1 \\
E 6-C 1\end{array}$ & 5 & 14,7 \\
\hline & Revisão Cirúrgica & \begin{tabular}{|l|}
$\mathrm{E} 8-\mathrm{C} 1$ \\
$\mathrm{E} 9-\mathrm{C} 1$ \\
$\mathrm{E} 10-\mathrm{C} 1$ \\
\end{tabular} & \begin{tabular}{|l}
$\mathrm{E} 11-\mathrm{C} 1$ \\
$\mathrm{E} 13-\mathrm{C} 1$ e C2
\end{tabular} & 6 & 17,6 \\
\hline & Antibioticoterapia & $\begin{array}{l}\text { E1-C1 } \\
\text { E2-C1 e C2 } \\
\text { E3-C1, C2 e C3 } \\
\text { E4-C1 } \\
\text { E5-C1 } \\
\text { E6-C1 } \\
\text { E7-C1 } \\
\text { E8-C1 } \\
\text { E9-C1 e C3 } \\
\text { E10-C1 } \\
\text { E11-C1 }\end{array}$ & $\begin{array}{l}\mathrm{E} 12-\mathrm{C} 1 \\
\mathrm{E} 13-\mathrm{C} 1, \mathrm{C} 2 \text { e } \mathrm{C} 3 \\
\mathrm{E} 14-\mathrm{C} 1, \mathrm{C} 2, \mathrm{C} 3, \mathrm{C} 4, \mathrm{C} 5, \mathrm{C} 6, \mathrm{C} 7 \text { e } \mathrm{C} 8 \\
\mathrm{E} 15-\mathrm{C} 1 \\
\mathrm{E} 16-\mathrm{C} 1 \\
\mathrm{E} 17-\mathrm{C} 1 \\
\mathrm{E} 18-\mathrm{C} 1 \\
\mathrm{E} 19-\mathrm{C} 1 \\
\mathrm{E} 20-\mathrm{C} 1 \\
\mathrm{E} 21-\mathrm{C} 1\end{array}$ & 34 & 100,0 \\
\hline
\end{tabular}

A Tabela 5 apresenta uma síntese das características observadas para isolamento e/ou identificação fenotípica (semeadura em meios de 
cultura; coloração de Gram e/ou Ziehl-Neelsen; testes bioquímicos; antibiograma), e/ou genotípica (PCR; PFGE) das micobactérias detectadas nos diferentes materiais biológicos enviados para análises microbiológicas, relatada por pequeno número de estudos avaliados.

Em relação ao Gram e Ziehl Neelsen verificou-se resultado positivo ou negativo para MNT. Os meios de cultura utilizados foram agar simples, sangue, ogawa ou soja tripticase; além de Lowenstein-Jensen, Coletsos, 7H10 e Mac Conkey. Já nos testes bioquímicos, antibiograma, PCR e PFGE verificou-se a realização destes testes.

Em um pequeno número dos estudos de micobacteriose ortopédica foi relatada a realização de esfregaços para coloração de Gram $(28,0 \%)$ e/ou Ziehl - Neelsen (42,8\%), seguida ou não de semeadura em meios de cultura (sólidos e/ou líquidos) adequados para o isolamento das bactérias presentes, visando principalmente a detecção de MCR (7 / 33,3\%); quanto à identificação perfunctória das micobactérias encontradas, com testes bioquímicos e/ou determinação do perfil de sensibilidade aos antibióticos prescritos (antibiograma - difusão em meio sólido ou microdiluição), também foi pouco realizada, respectivamente em 4 / 19,0\% e 14 / 66,7\% estudos. Quanto à identificação final do micro-organismo isolado, foram citados as técnicas de PCR e PFGE, realizadas em 5 / 23,8\% e 3 / 14,3\% dos estudos avaliados.

Analisando os dados da Tabela 5, podemos observar que, dentre os 21 estudos avaliados (34 casos) para a identificação do(s) agente(s) etiológico(s) da(s) ISCs não foi seguida a metodologia de rotina (identificação fenotípica, complementada com genotípica em laboratórios de referência, quando necessário), pois, por exemplo, nos casos em que foram detectados M.fortuitum $(n=22)$ a semeadura e isolamento em meios de cultura seletivos ou não, foi realizada somente em quatro casos; antibiograma para determinar o perfil de sensibilidade aos antibióticos - 12 casos; PCR - 5 casos e PFGE - três casos, o que pode influenciar na confiabilidade do resultado, principalmente quanto à espécie do agente etiológico, além de que impossibilita relacionar esses dados com os de outros estudos. 
Quanto às demais espécies, os exames microbiológicos relatados para isolamento e identificação, também ocorreram em baixo número de casos estudados como, por exemplo: M.chelonae - E1-C1 (antibiograma), E8-C1 (nenhum), E1-C1/C2/C6 (testes bioquímicos, antibiograma e PCR); M.abscessus - E14-C3/C7 (testes bioquímicos, antibiograma e PCR); E20C1 (antibiograma) e E21-C1 (antibiograma e PCR). M.smegmatis - E14-C3 (testes bioquímicos e PCR). M.wolinskyi - E12-C1 (testes bioquímicos, antibiograma e PCR). M.goodii - E9-C1/C3 (antibiograma, PCR e PFGE) e M.farcinogenes - E10-C1 (nenhum).

Analisando os dados da Tabela 6 quanto à espécie de MCR isoladas dos sítios de infecção dos diferentes procedimentos cirúrgicos ortopédicos constatamos que M.fortuitum foi isolada de todos; M.chelonae - joelho e quadril; M.abscessus - joelho, quadril e cotovelo; M.goodii - joelho (E9-C3); enquanto que as demais foram detectadas num só tipo de ISCs; M.smegmatis - joelho (E14-C3); M.farcinogenes - quadril (E10-C1) e M.wolinskyi - quadril (E12-C1). 
Tabela 5. Características observadas para detecção dos agentes microbianos das micobaterioses ortopédicas. São Paulo, 2012.

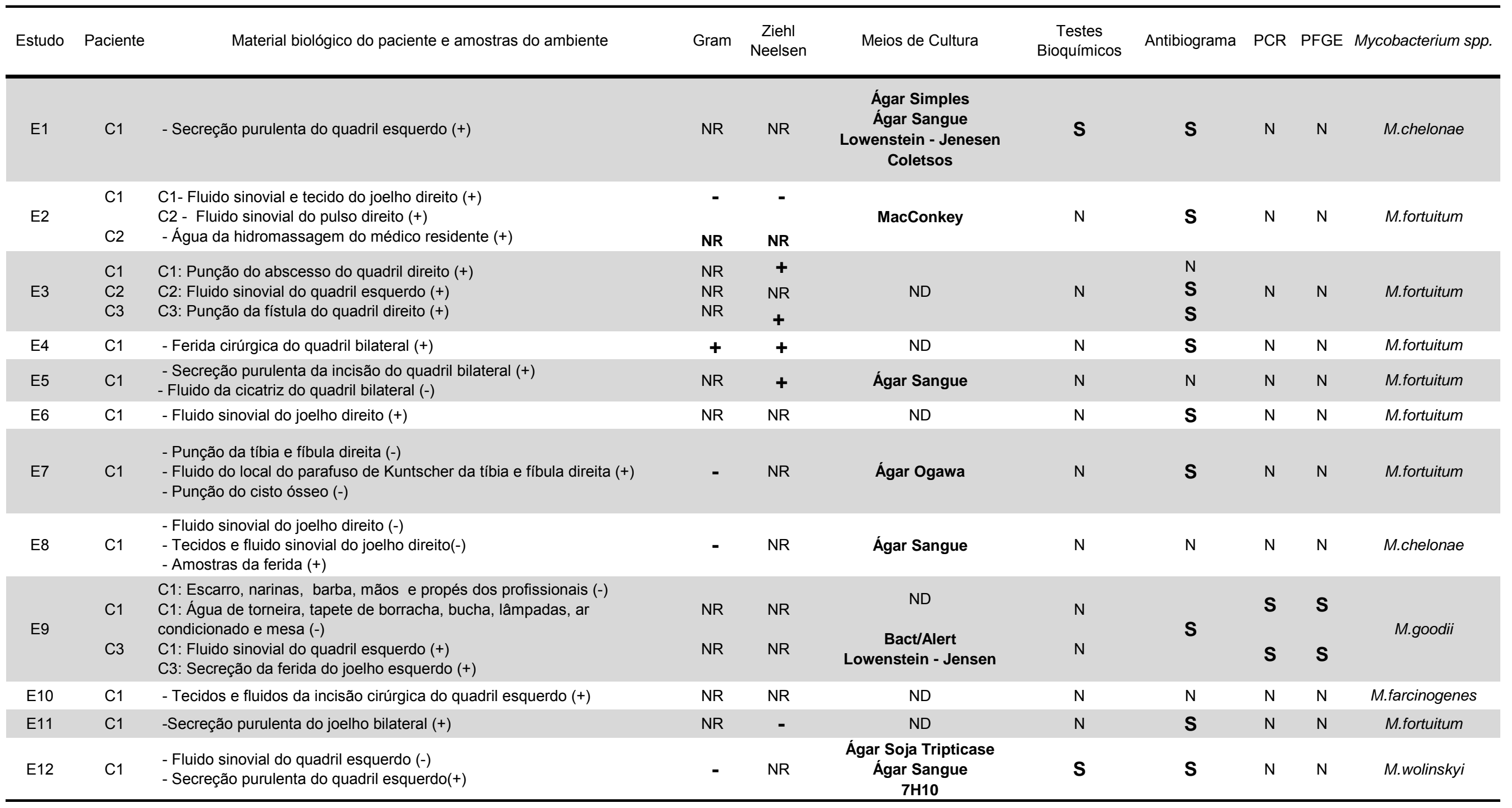

Legenda: S - C - Paciente / Caso; NR - Não Relatado; "+" - Resultado positivo para MNT; "-" - Resultado negativo para MNT; S - teste realizado; N - teste não realizado; PCR Reação em Cadeia Polimerase; PFGE - Eletroforese em Gel de Campo Pulsado. 
Tabela 5 (cont.). Características observadas para detecção dos agentes microbianos das micobaterioses ortopédicas. São Paulo, 2012.

\begin{tabular}{|c|c|c|c|c|c|c|c|c|c|c|}
\hline Estudo & Paciente & Material biológico do paciente e amostras do ambiente & Gram & $\begin{array}{l}\text { Ziehl } \\
\text { Neelsen }\end{array}$ & Meios de Cultura & $\begin{array}{l}\text { Testes } \\
\text { Bioquímicos }\end{array}$ & Antibiograma & PCR & PFGE & Mycobacterium spp. \\
\hline E13 & $\begin{array}{l}\mathrm{C} 1 \\
\mathrm{C} 2 \\
\mathrm{C} 3\end{array}$ & $\begin{array}{l}\text { C1: Fluido sinovial do joelho direito }(+) \\
\text { C1: Secreção purulenta do joelho direito }(-) \\
\text { C2: Amostras intraoperatórias }(+) \\
\text { C2: Fluido sinovial do joelho direito }(+) \\
\text { C3: Secreção purulenta do quadril direito }(+) \\
\text { C3: Amostras intraoperatórias }(+)\end{array}$ & $\begin{array}{l}\text { NR } \\
N R \\
N R\end{array}$ & $\begin{array}{l}\text { NR } \\
\text { NR } \\
\text { NR }\end{array}$ & ND & $\mathbf{S}$ & $\mathrm{N}$ & $\mathrm{N}$ & $\mathbf{S}$ & M.fortuitum \\
\hline E14 & $\begin{array}{l}\mathrm{C} 1 \\
\mathrm{C} 2 \\
\mathrm{C} 3 \\
\mathrm{C} 4 \\
\mathrm{C} 5 \\
\mathrm{C} 6 \\
\mathrm{C} 7 \\
\mathrm{C} 8\end{array}$ & $\begin{array}{l}\text { - Fluido sinovial das artroplastias (+) } \\
\text { - Tecidos profundos das artroplastias (+) }\end{array}$ & NR & NR & NR & $\mathbf{S}$ & $\mathbf{S}$ & $\mathbf{S}$ & $\mathrm{N}$ & $\begin{array}{l}\text { M.chelonae } \\
\text { M.chelonae } \\
\text { M.smegmatis } \\
\text { M.fortuitum } \\
\text { M.fortuitum } \\
\text { M.chelonae } \\
\text { M.abscessus } \\
\text { M.fortuitum }\end{array}$ \\
\hline E15 & C1 & $\begin{array}{l}\text { - Fluido sinovial do joelho esquerdo }(+) \\
\text { - Fluido sinovial do joelho direito }(+)\end{array}$ & NR & NR & NR & $\mathrm{N}$ & $\mathrm{N}$ & $\mathbf{S}$ & $\mathrm{N}$ & M.fortuitum \\
\hline E16 & $\mathrm{C} 1$ & $\begin{array}{l}\text { - Secreção purulenta da articulação do joelho (+) } \\
\text { - Amostras intraoperatória }(+)\end{array}$ & NR & NR & NR & $\mathrm{N}$ & $\mathrm{N}$ & $\mathrm{N}$ & $\mathrm{N}$ & M.fortuitum \\
\hline E17 & C1 & - Secreção purulenta da região profunda do tendão de Aquiles (+) & NR & + & NR & $\mathrm{N}$ & $\mathrm{N}$ & $\mathrm{N}$ & $\mathrm{N}$ & M.fortuitum \\
\hline E18 & $\mathrm{C} 1$ & $\begin{array}{l}\text { - Secreção do ligamento do joelho esquerdo (-) } \\
\text { - Amostra intraoperatória do joelho esquerdo (+) }\end{array}$ & NR & NR & NR & $\mathrm{N}$ & $\mathrm{N}$ & $\mathrm{N}$ & $\mathrm{N}$ & M.fortuitum \\
\hline E19 & C1 & - Secreção purulenta e tecidos do reparo do tendão patelar esquerdo (+) & NR & NR & NR & $\mathrm{N}$ & $\mathbf{S}$ & $\mathrm{N}$ & N & M.fortuitum \\
\hline E20 & C1 & - Fluido sinovial do quadril esquerdo (+) & NR & - & NR & $\mathrm{N}$ & $\mathbf{S}$ & $\mathrm{N}$ & $N$ & M.abscessus \\
\hline E21 & $\mathrm{C} 1$ & - Fluido sinovial do joelho direito $(+)$ & - & - & NR & $\mathrm{N}$ & $\mathbf{S}$ & $\mathbf{S}$ & $\mathrm{N}$ & $\begin{array}{l}\text { M.abscessus } \\
\text { M.fortuitum }\end{array}$ \\
\hline
\end{tabular}

Legenda: S - C - Paciente / Caso; NR - Não Relatado; "+" - Resultado positivo para MNT; "-" - Resultado negativo para MNT; S - teste realizado; N - teste não realizado, PCR Reação em Cadeia Polimerase; PFGE - Eletroforese em Gel de Campo Pulsado. 
Avaliando-se a distribuição das espécies de Mycobacterium quanto ao número de casos / pacientes com ISC, constatamos que M.fortuitum foi a mais prevalente $(22 / 64,7 \%)$, seguida de M.chelonae $(5 / 14,7 \%)$; além de M.abscessus (3 / 8,8\%); M.goodii (2 / 5,9\%), M.smegmatis, M.farcinogenes e M.wolinsky, isoladas respectivamente de $1 / 2,9 \%$ caso(Figura 7). Apenas em um caso (E21-C1) - 1 / 2,9\% foram isoladas duas espécies (M.fortuitum e M.abscessus) de um só tipo de material biológico (fluído sinovial do joelho direito); enquanto que nos dois diferentes tipos de material biológico analisados do mesmo paciente (E13-C2 e C3; E15-C1 e E16-C1) foi detectada a mesma espécie de M.fortuitum.

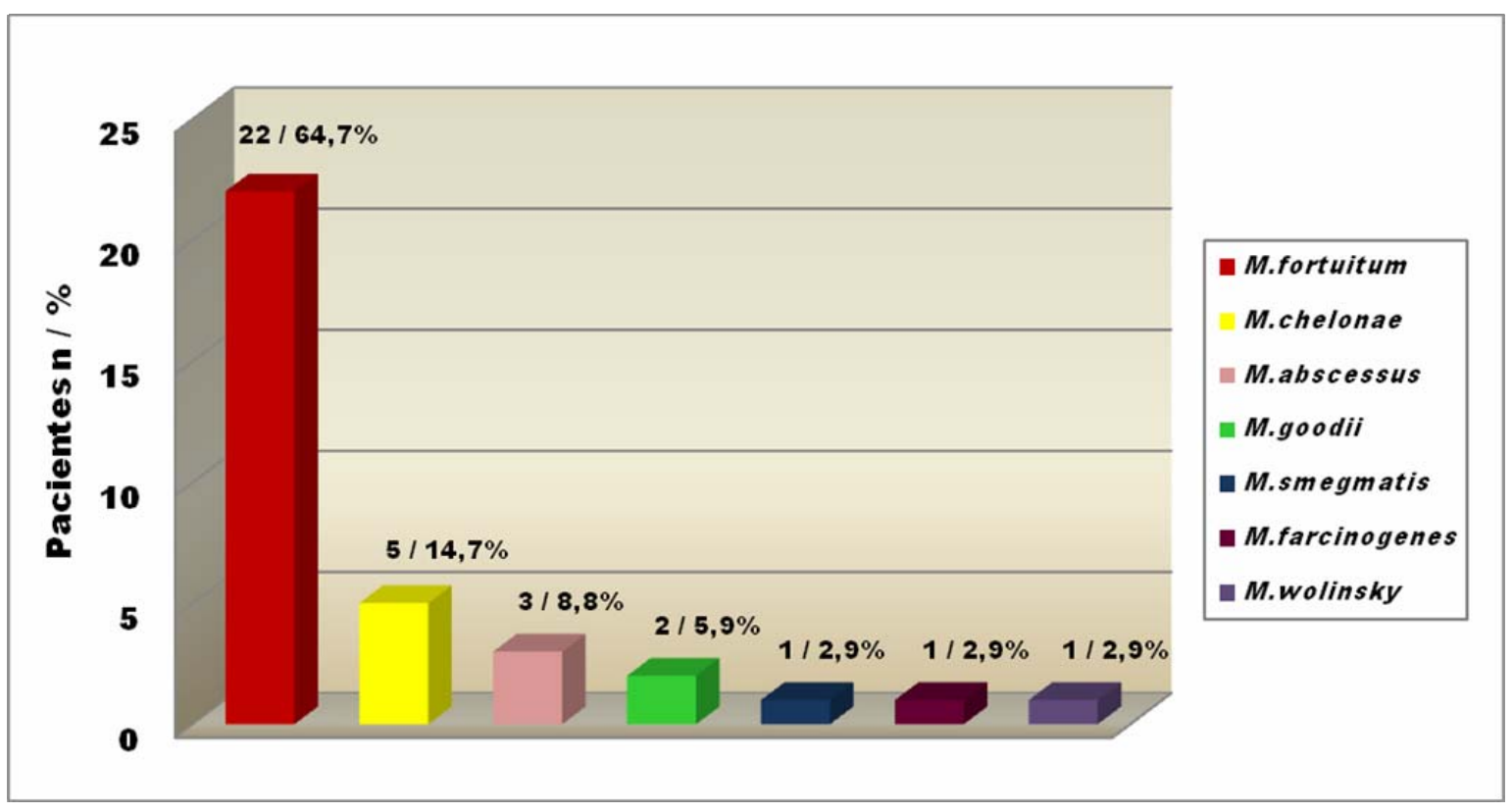

Figura 7. Distribuição das espécies de Mycobacterium, de acordo com o número de pacientes com micobacteriose ortopédica.

Quanto aos tipos de procedimento cirúrgicos ortopédicos (com ou sem prótese / parafuso), verificamos que a espécie M.fortuitum foi detectada tanto em artroplastias de quadril quanto de joelho, com exceção de uma prótese de quadril (E14-C8); M.chelonae - nas próteses de joelho (E8-C1 e $\mathrm{E} 14-\mathrm{C} 1 / \mathrm{C} 2 / \mathrm{C} 6)$ e quadril (E1-C1); M.abscessus - joelho (E21-C1), quadril (E21-C1) e cotovelo (E14-C7); M.goodii - joelho (E9-C A qualidade do processamento de material utilizado em procedimentos invasivos 3 ) e quadril 
(E9-C1); M.smegmatis - joelho (E14-C3); M.farcinogenes - quadril (E10-C1) e M.wolinsky - quadril (E12-C1), como demonstrado na Tabela 6. Cabe ressaltar que, a soma dos sítios cirúrgicos (joelho) na Tabela 6, totaliza 11 e não 12; pois, em um mesmo sítio cirúrgico, foram encontradas duas espécies diferentes de micro-organismos, esta informação confirma-se na Tabela 2, no estudo 21 . 
Tabela 6. Distribuição das espécies de Mycobacterium de acordo com os sítios dos procedimentos e com o número de casos e próteses.

\begin{tabular}{|c|c|c|c|c|c|c|c|c|}
\hline & $\begin{array}{c}\text { Sítios Cirúrgicos } \\
\text { (NC/NP) }\end{array}$ & $\begin{array}{l}\text { M.fortuitum } \\
\text { (NC/NP) }\end{array}$ & $\begin{array}{l}\text { M.chelonae } \\
\text { (NC/NP) }\end{array}$ & $\begin{array}{l}\text { M.abscessus } \\
\text { (NC/NP) }\end{array}$ & $\begin{array}{r}\text { M.goodii } \\
\text { (NC/NP) }\end{array}$ & $\begin{array}{l}\text { M.farcinogenes } \\
\text { (NC/NP) }\end{array}$ & $\begin{array}{l}\text { M.wolinsky } \\
\text { (NC/NP) }\end{array}$ & $\begin{array}{l}\text { M.smegmatis } \\
\text { (NC/NP) }\end{array}$ \\
\hline \multirow{7}{*}{ Relatos de Casos } & Joelho $11 / 13$ & $9 / 11$ & $1 / 1$ & $1 / 1$ & $1 / 1$ & - & - & - \\
\hline & $\begin{array}{l}\text { Quadril 11/13 } \\
\text { Fixação }\end{array}$ & $6 / 8$ & $1 / 1$ & $1 / 1$ & $1 / 1$ & $1 / 1$ & $1 / 1$ & - \\
\hline & $\begin{array}{c}\text { Intramedular da tíbia } \\
\text { e fíbula } 1 / 1 \\
\text { Liberação cirúrgica }\end{array}$ & $1 / 1$ & - & - & - & - & - & - \\
\hline & $\begin{array}{c}\text { do túnel do carpo } \\
1 / 1\end{array}$ & $1 / 1$ & - & - & - & - & - & - \\
\hline & $\begin{array}{c}\text { Debridamento do } \\
\text { tendão de Aquiles } \\
1 / 1\end{array}$ & $1 / 1$ & - & - & - & - & - & - \\
\hline & $\begin{array}{l}\text { Reconstrução do } \\
\text { ligamento cruzado } \\
\text { anterior } 1 / 1\end{array}$ & $1 / 1$ & - & - & - & - & - & - \\
\hline & $\begin{array}{c}\text { Reparo do tendão } \\
\text { patelar* } 1 / 1\end{array}$ & $1 / 1$ & - & - & - & - & - & - \\
\hline \multirow{3}{*}{ Estudo Retrospectivo } & Joelho $7 / 7$ & $2 / 2$ & $3 / 3$ & $1 / 1$ & - & - & - & $1 / 1$ \\
\hline & Quadril 1/1 & $1 / 1$ & - & - & - & - & - & - \\
\hline & Cotovelo $1 / 1$ & - & - & $1 / 1$ & - & - & - & - \\
\hline
\end{tabular}

Legenda: $\left(^{*}\right)$ - Sem colocação de prótese / parafuso; NC - número de casos; NP - número de prótese. 
Quanto ao perfil de sensibilidade/resistência das frequências das diferentes espécies de Mycobacterium isoladas de ISC ortopédicos, subdividimos os resultados obtidos nos diferentes estudos, frente aos testes realizados, com antimicrobianos (antibióticos e/ou quimioterápicos) preconizados pelo Clinical and Laboratory Standards Institute (CLSI, 2011) e os outros citados (não preconizados).

Analisando-se o comportamento das espécies (R / S) frente ao antimicrobianos preconizados pelo CLSI (2011) verificamos que as espécies M.fortuitum, M.chelonae e M.abscessus, prevalentes nos casos de micobacterioses ortopédicas, foram resistentes $(R)$ a maior número de antibióticos, sendo multirresistentes na maioria, ou seja, $\mathrm{R}$ a três ou mais agentes, como demonstrado na Tabela 7.

Dos 21 estudos analisados, somente 11 identificaram resistência ou sensibilidade, devido a isto não foram colocados na tabela abaixo os demais casos.

Tabela 7. Comportamento das cepas de Mycobacterium spp. frente aos antimicrobianos preconizados pelo CLSI (2011).

\begin{tabular}{|c|c|c|c|c|c|c|c|c|c|c|c|c|}
\hline Estudo & Agentes & Paciente & AMK & CFX & CIP & CLR & DOX & IMP & LNZ & MOX & $\mathrm{TOB}$ & SXT \\
\hline E1 & M.chelonae & C1 & NT & NT & NT & NT & NT & NT & NT & NT & $\mathrm{S}$ & NT \\
\hline \multirow[b]{2}{*}{ E2 } & \multirow{2}{*}{ M.fortuitum } & C1 & $\mathbf{S}$ & NT & NT & NT & NT & NT & NT & NT & NT & NT \\
\hline & & $\mathrm{C} 2$ & $S$ & NT & NT & NT & NT & NT & NT & NT & NT & NT \\
\hline E4 & M.fortuitum & C1 & S & $\mathbf{R}$ & NT & NT & NT & NT & NT & NT & NT & $\mathbf{R}$ \\
\hline E6 & M.fortuitum & C1 & $\mathbf{R}$ & $\mathbf{R}$ & NT & NT & $\mathbf{R}$ & NT & NT & NT & $\mathbf{R}$ & NT \\
\hline \multirow{2}{*}{ E9 } & \multirow{2}{*}{ M.goodii } & C1 & NT & NT & $\mathrm{S}$ & NT & S & NT & NT & NT & NT & S \\
\hline & & C3 & NT & NT & $\mathrm{S}$ & NT & S & NT & NT & NT & NT & S \\
\hline E11 & M.fortuitum & C1 & $\mathbf{S}$ & $\mathbf{R}$ & $\mathbf{R}$ & $\mathbf{S}$ & S & $\mathbf{S}$ & NT & NT & NT & $\mathbf{R}$ \\
\hline E12 & M.wolinskyi & C1 & $\mathbf{S}$ & $\mathbf{R}$ & $\mathbf{S}$ & $\mathbf{R}$ & NT & $\mathbf{S}$ & $\mathbf{S}$ & $\mathbf{S}$ & $\mathbf{R}$ & NT \\
\hline \multirow{8}{*}{ E14 } & M.chelonae & C1 & $\mathbf{R}$ & $\mathbf{R}$ & $\mathbf{R}$ & $\mathbf{S}$ & $\mathbf{R}$ & $\mathbf{R}$ & NT & NT & $\mathbf{R}$ & $\mathbf{R}$ \\
\hline & M.chelonae & C2 & $\mathbf{R}$ & $\mathbf{S}$ & $\mathbf{R}$ & NT & $\mathbf{R}$ & $\mathbf{R}$ & NT & NT & $\mathbf{R}$ & $\mathbf{R}$ \\
\hline & M.smegmatis & C3 & $\mathrm{S}$ & $\mathbf{R}$ & $S$ & $S$ & $\mathrm{~S}$ & $\mathrm{~S}$ & $S$ & NT & $\mathrm{S}$ & $\mathrm{S}$ \\
\hline & M.fortuitum & C4 & S & $\mathbf{R}$ & $\mathrm{S}$ & S & $\mathbf{R}$ & $\mathrm{S}$ & $\mathrm{S}$ & NT & $\mathbf{R}$ & $\mathrm{S}$ \\
\hline & M.fortuitum & C5 & S & $\mathbf{R}$ & $S$ & $\mathbf{R}$ & $\mathbf{R}$ & $\mathbf{S}$ & $S$ & NT & $\mathbf{R}$ & $\mathbf{S}$ \\
\hline & M.chelonae & C6 & $\mathbf{S}$ & $\mathbf{R}$ & $\mathbf{R}$ & S & $\mathbf{R}$ & $\mathbf{R}$ & $\mathbf{S}$ & NT & $\mathbf{S}$ & $\mathbf{R}$ \\
\hline & M.abscessus & $\mathrm{C7}$ & S & $\mathbf{R}$ & $\mathbf{R}$ & S & $\mathbf{R}$ & $\mathbf{R}$ & $\mathbf{R}$ & NT & $\mathbf{R}$ & $\mathbf{R}$ \\
\hline & M.fortuitum & C8 & S & $\mathbf{R}$ & $\mathbf{S}$ & NT & NT & NT & NT & NT & NT & $\mathbf{R}$ \\
\hline E19 & M.fortuitum & C1 & NT & NT & NT & S & NT & $\mathbf{S}$ & NT & NT & $\mathbf{S}$ & $S$ \\
\hline E20 & M.abscessus & C1 & $\mathbf{S}$ & $\mathbf{R}$ & NT & $\mathbf{S}$ & NT & $\mathbf{R}$ & $\mathbf{R}$ & NT & $\mathbf{R}$ & NT \\
\hline E21 & M.abscessus & C1 & S & S & S & $\mathbf{S}$ & $\mathbf{S}$ & NT & NT & NT & NT & NT \\
\hline $5<1$ & M.fortuitum & 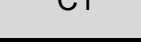 & S & $\mathrm{S}$ & $\mathbf{S}$ & $\mathrm{S}$ & S & $\mathrm{S}$ & NT & NT & NT & NT \\
\hline
\end{tabular}

Legenda: AMK - Amicacina; CFX - Cefoxitina; CIP - Ciprofloxacina; CLR - Claritromicina; DOX Doxiciclina; IMP - Imipinem; LNZ - Linezolida; MOX - Moxifloxacina; TOB - Tobramicina; SXT Trimetoprim-Sulfametoxazol; S - sensibilidade; R - resistência; NT - não testado. 
Embora as espécies possam apresentar sensibilidades diferentes entre si, sinteizando-se os achados da tabela 7 obteve-se que $87,5 \%$ eram sensíveis a amicacina, $83,3 \%$ a ciprofloxacina, $83,3 \%$ a claritromicina, $71,4 \%$ a linezolida, $58,3 \%$ ao imipenem, $46,2 \%$ a doxaciclina, $46,0 \%$ ao trimetropimsulfametoxazol, $33,3 \% \mathrm{v}$ a tobramicina e $21,4 \%$ a cefoxitina. A sensibilidade a moxifloxacina foi de $100 \%$, mas somente uma cepada foi testada.

Em relação aos demais tipos de agentes antimicrobianos testados $(n=29)$ nos diferentes estudos desta revisão (Tabela 8); constatamos que M.fortuitum foi a única espécie que apresentou cepas resistentes (2) a todos os antimcrobianos testados, mas cabe lembrar que esses antimicrobianos não são os recomendados pelo CSLI para teste de sensibilidade. Além disso, as demais espécies foram testadas, frente a um pequeno número de agentes ( 3 ou menos).

Dos 21 estudos analisados, somente nove apresentaram resultados de resistência ou sensibilidade, devido a isto não foram colocados na tabela 8 , os restantes.

Em relação às fontes investigadas, tem-se: provavelmente de origem iatrogênica - não confirmada (E1-C1 e E5-C1); hábito do médico residente de ortopedia presente nas cirurgias de utilizar a hidromassagem antes de operar - não confirmada (E2- C1 e C2); componentes líquidos ou pó do cimento metilmetacrilato ou a prótese metálica - não confirmada(E4-C1); injeções de cortisona por sinovite crônica durante 5 anos da cirurgia - não confirmada (E6-C1); sistema de ar condicionado ou a solução de imersão para enxágue da prótese - não confirmadas (E13-C1,C2 e C3); sabão na água, onde foi realizada a imersão do pé (recomendação do podólogo) - não confirmada (E17); parafuso bioabsorvível utilizado na cirurgia - não confirmada (E18); injeções intra-articulares de dexametasona - não confirmadas (E21); e não citadas (E3-C1,C2 e C3; E7, E8, E9-C1 e C3; E10C1;E11-C1; E12-C1; E14-C1aoC8; E15; E16; E19 e E20). 
Tabela 8 - Comportamento das cepas de Mycobacterium spp. frente aos antibióticos não preconizados pelo CLSI, 2011.

\begin{tabular}{|c|c|c|c|c|c|c|c|c|c|c|}
\hline \multirow[t]{2}{*}{ Antimicrobianos } & \multirow{2}{*}{$\begin{array}{c}\text { M.chelonae } \\
\text { E1 } \\
\text { C1 }\end{array}$} & \multirow{2}{*}{$\begin{array}{c}\text { M.fortuitum } \\
\text { E2 } \\
\text { C1 }\end{array}$} & \multicolumn{2}{|c|}{$\begin{array}{c}\text { M.fortuitum } \\
\text { E3 }\end{array}$} & \multirow{2}{*}{$\begin{array}{c}\text { M.fortuitum } \\
\text { E4 } \\
\text { C1 }\end{array}$} & \multirow{2}{*}{$\begin{array}{c}\text { M.fortuitum } \\
\text { E6 } \\
\text { C1 }\end{array}$} & \multirow{2}{*}{$\begin{array}{c}\text { M.fortuitum } \\
\text { E7 } \\
\text { C1 }\end{array}$} & \multirow{2}{*}{$\begin{array}{c}\text { M.wolinskyi } \\
\text { E12 } \\
\text { C1 }\end{array}$} & \multirow{2}{*}{$\begin{array}{c}\text { M.fortuitum } \\
\text { E19 } \\
\text { C1 }\end{array}$} & \multirow{2}{*}{$\begin{array}{c}\text { M.abscessus } \\
\text { E20 } \\
\text { C1 }\end{array}$} \\
\hline & & & C2 & C3 & & & & & & \\
\hline APP & NT & NT & $\mathbf{R}$ & NT & NT & NT & NT & NT & NT & NT \\
\hline AMP & NT & NT & NT & NT & $\mathbf{R}$ & NT & NT & NT & NT & NT \\
\hline AZM & NT & NT & NT & NT & NT & NT & NT & NT & NT & $\mathbf{S}$ \\
\hline $\mathrm{CB}$ & NT & NT & NT & NT & $\mathbf{R}$ & NT & NT & NT & NT & NT \\
\hline CAP & NT & NT & NT & NT & NT & $\mathbf{R}$ & NT & NT & NT & NT \\
\hline CFL & NT & NT & NT & $\mathbf{R}$ & $\mathbf{R}$ & NT & NT & NT & NT & NT \\
\hline MA & NT & NT & NT & NT & $\mathbf{R}$ & NT & NT & NT & NT & NT \\
\hline CLI & NT & NT & NT & NT & $\mathbf{R}$ & NT & NT & NT & NT & NT \\
\hline COM & NT & NT & $\mathbf{R}$ & $\mathbf{R}$ & NT & NT & NT & NT & NT & NT \\
\hline $\mathrm{COL}$ & NT & NT & NT & NT & $\mathbf{R}$ & NT & NT & NT & NT & NT \\
\hline ERY & NT & NT & NT & NT & $S$ & $\mathbf{R}$ & NT & NT & NT & NT \\
\hline STR & $\mathbf{S}$ & NT & NT & $\mathbf{R}$ & $\mathbf{R}$ & NT & $\mathbf{S}$ & NT & $\mathbf{S}$ & NT \\
\hline EMB & NT & NT & NT & NT & $\mathbf{R}$ & $\mathbf{S}$ & NT & NT & NT & NT \\
\hline $\mathrm{ET}$ & NT & NT & NT & $\mathbf{R}$ & $\mathbf{S}$ & NT & NT & NT & NT & NT \\
\hline GEN & $\mathbf{S}$ & $\mathbf{S}$ & NT & $\mathbf{R}$ & $\mathbf{R}$ & NT & NT & NT & $\mathbf{S}$ & NT \\
\hline INH & NT & NT & NT & $\mathbf{R}$ & $\mathbf{R}$ & NT & $\mathbf{S}$ & NT & NT & NT \\
\hline KAN & $\mathbf{S}$ & $\mathbf{S}$ & $\mathbf{S}$ & NT & $\mathbf{S}$ & $\mathbf{R}$ & NT & NT & $\mathbf{S}$ & $\mathbf{S}$ \\
\hline LEV & NT & NT & NT & NT & $\mathbf{R}$ & NT & NT & NT & NT & NT \\
\hline MIN & NT & NT & NT & NT & NT & $\mathbf{R}$ & NT & $\mathbf{S}$ & NT & NT \\
\hline NEO & NT & NT & NT & NT & NT & NT & NT & NT & $\mathbf{S}$ & NT \\
\hline OFX & NT & NT & NT & NT & NT & NT & NT & $\mathbf{S}$ & NT & NT \\
\hline PAS & NT & NT & NT & NT & $\mathbf{R}$ & NT & NT & NT & NT & NT \\
\hline PEN & NT & NT & $\mathbf{R}$ & $\mathbf{R}$ & NT & NT & NT & NT & NT & NT \\
\hline PEN - G & NT & NT & NT & NT & $\mathbf{R}$ & NT & NT & NT & NT & NT \\
\hline RIF & NT & NT & $\mathrm{NT}$ & NT & $\mathrm{R}$ & NT & $\mathrm{R}$ & NT & NT & NT \\
\hline TET & NT & $\mathbf{S}$ & NT & NT & $\mathbf{S}$ & NT & NT & NT & NT & NT \\
\hline TGC & NT & NT & NT & NT & NT & NT & NT & NT & $\mathbf{S}$ & $\mathbf{S}$ \\
\hline SX & NT & NT & NT & NT & NT & $\mathbf{R}$ & NT & NT & NT & NT \\
\hline VAN & NT & $\mathbf{S}$ & NT & NT & NT & NT & NT & NT & NT & NT \\
\hline
\end{tabular}

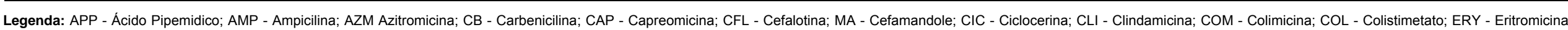
STR - Estreptomicina; EMB - Etambutol; ET - Etionamida; GEN - Gentamicina; INH Isoniazida;KAN - Kanamicina; LEV - Meticilina; MIN - Minociclina; NEO - Neomicina; OFX - Ofloxacina; PAS - Para-amino-saliciclico; PEN - Penicilina; PEN-G - Penicilina G; ROX - Roxitromicina; TET - Tetraciclina; TGC - Tigeciclina; SX - Sulfametoxazol; VAN - Vancomicina; S - sensibilidade; R - resistência; NT - não testado. 


\section{DISCUSSÃO}

Neste estudo foram avaliados os possíveis fatores intrínsecos e extrínsecos, que podem influenciar no surgimento de micobacteriose, após, procedimentos cirúrgicos ortopédicos. O alto risco de ISC é uma das principais preocupações, em qualquer procedimento cirúrgico ortopédico (Torres, 2001).

As ISC's estão entre as causas mais frequentes de complicações no período pós-operatório, ocupando lugar de destaque em relação a todas as IH / IRAS (Torres, 2001).

Durante o desenvolvimento desta Revisão Integrativa, verificou-se que dentre os periódicos previamente selecionados, somente $21(1,6 \%)$ foram incluídos para avaliação, por analisarem, especificamente, casos de micobacteriose em ISC ortopédica. O aumento na incidência de doenças causadas MCR a partir do ano 2000 pode ser influenciado por alguns fatores, dentre eles a introdução de novas tecnologias laboratoriais que permitem melhor recuperação e identificação mais precisa das espécies micobacterianas, confirmando o diagnóstico. (Cornelius et al., 2007, Wang et al., 2011).

A tendência a alta precoce do paciente no pós-operatório tem dificultado a vigilância epidemiológica das ISC, pois ela pode se manifestar após a alta. Este problema é maior quando não há um sistema de vigilância pós-alta das ISC efetivo. O estudo prospectivo realizado em nove hospitais na Finlândia detectou que das ISC's diagnosticadas após a alta, 43,0\% foram na readmissão, 34,0\% em questionários de seguimento pós-alta e 10,6\% em visitas de avaliação (Huotari, Lyytikäinen, 2006).

No presente estudo observou-se que o tempo para definir 0 diagnóstico de infecção por MCR pode ultrapassar um ano, e nestes casos até mesmo um sistema de vigilância epidemiológica pós-alta efetivo poderia falhar na recuperação destes dados.

Estudo de Kaalita et al. (2005) ressalta que infecção de articulação protética por MNT não causa complicações pós-operatórias imediatas. 
As infecções profundas em próteses podem ser subdivididas em precoces (até três meses após a cirurgia), tardias (dentro de 18 meses até dois anos) e demoradas. Tanto as precoces quanto as tardias pode ser causadas durante o procedimento por contato direto na ferida, contaminação do ar ambiente ou infecção cruzada na unidade (Knobben et al., 2010). Geralmente as infecções demoradas ocorrem por contaminação via hematogênica como durante a inserção de um cateter vesical, infecção de um cateter endovenoso, ou pele ou sepsis dentária. No entanto, as infecções por via hematogênica são responsáveis por apenas um pequeno número de infecções em cirurgias ortopédicas (Ainscow, Denham, 1984).

Dado o aumento no número de casos de ISC por micobactérias, responsáveis por alguns surtos no Brasil, e diante da necessidade de consolidação nacional do perfil epidemiológico e sanitário destes eventos, a ANVISA disponibilizou um fluxo padronizado de notificações de infecções micobacterianas em feridas cirúrgicas, para todas as instituições de saúde. A notificação objetiva identificar a magnitude do problema no país, conhecer o perfil epidemiológico dos surtos; prevenir e controlar infecções, por MNT, após procedimentos invasivos (Brasil, 2009b).

Avaliando a produção científica sobre micobacteriose (número de casos ou pacientes submetidos a procedimentos ortopédicos), quanto à data de publicação dos periódicos (1976 a 2011), verificou-se um aumento significativo da produção científica no período de 2000 a 2010, contabilizando mais da metade dos artigos encontrados, com uma moda em 2008, em relação às décadas antecedentes, o que pode ser atribuído ao maior número de laboratórios de referência, que permitem acompanhar / comprovar o diagnóstico microbiológico, quanto ao gênero / espécie de MNT isolada em diferentes materiais biológicos, coletados dos sítios de infecção, além de obrigatoriedade de notificação. Além disso, em função dos surtos ocorridos, com melhor caracterização do quadro clínico, os profissionais de saúde têm estado mais atentos na identificação dessas infecções.

Outroa autores comentam que nos últimos anos tem havido maior sensibilização e interesse no isolamento de todas as espécies do gênero Mycobacterium (Martín-Casabona et al., 2004; Griffith et al., 2007). 
Por coincidência ou não, em 2008 no Estado de São Paulo, num período de observação de 2002 a 2010, 50,0\% das notificações de infecções por MCR ocorreram no ano de 2008 (Brasil, 2010). Cabe lembrar que nenhum artigo foi encontrado sobre ISC em ortopedia de origem nacional para esta revisão integrativa.

As ISC's em procedimentos ortopédicos são complicações graves, que influenciam, diretamente, os resultados cirúrgicos esperados pelo médico e paciente, aumentam a morbi-mortalidade e os custos associados (Whitehouse et al., 2002, Bosco et al., 2010), daí a necessidade de diagnóstico precoce.

Em ortopedia, especificamente em artroplastias de joelho e quadril, o tempo para o aparecimento dos sinais e sintomas caracteriza a ISC como precoce ou tardia (Torres, 2011). Castella et al. (2010) encontraram 95,3\% das ISCs em próteses de joelho e quadril, diagnosticadas nos primeiros 90 dias. Segundo Moyad et al. (2008), recidivas da ISC podem ocorrer a qualquer momento, sendo que uma das conseqüências seria a retirada do implante (prótese / parafuso).

De forma geral a infecção hospitalar, de sitio cirúrgico, manifesta-se de 4 a 6 dias após o procedimento cirúrgico e, no máximo, até 30 dias ,se não ocorreu implante de material protético. Quando houve necessidade de colocar prótese / parafuso, a ISC pode ser diagnosticada até um ano após a cirurgia ortopédica (RABHAE et al., 2007).

No presente estudo, constatou-se que o início dos sintomas, após a cirurgia ortopédica, variou de um a dois dias até 16 anos, sendo que, dentre os diferentes sinais e sintomas, relatados pelos pacientes, os mais prevalentes foram dor, secreção, edema e febre.

Os resultados encontrados nesta revisão confirmam a literatura consultada, quanto aos sinais e sintomas de ISC apresentados pelos pacientes, após procedimentos cirúrgicos ortopédicos, independente do agente isolado, principalmente, em cirurgias de médio e grande porte (Barrteo, 2002; Cabral, 2010; Torres, 2011). 
Cabral (2010) relatou que pacientes submetidos à cirurgias artroscópicas e laparoscópicas apresentaram sinais e sintomas de infecção localizada, incluindo dor, eritema, febre, abscesso e lesões no sítio cirúrgico.

Teve-se dúvida sobre manter ou excluir do estudo sete artigos, em que o início dos sintomas ocorreu após um ano e alguns foram internados até 16 anos após o evento cirúrgico. As micobacterioses não se curam sem tratamento, mas a evolução até uma manifestação clínica que gere a hipótese de uma infecção por MNT pode ser muito demorada, sobretudo pela dificuldade na identificação das MNT em cultura por apresentarem um tempo de crescimento superior ao das demais bactérias, como observado na revisão realizada. Os pacientes com sinais inespecíficos, que podem ser confundidos com um processo inflamatório, são tratados com antinflamatórios orais ou de aplicação intrarticular que podem mascarar o quadro. Como os pacientes não relataram ou apresentaram história de infecção, que por via hematogênica pudesse ter infectado a prótese, optouse por manter esses casos no estudo como se fossem de origem hospitalar. No entanto, a mediana do tempo de aparecimento dos sintomas após a cirurgia foi de 80 dias considerando os 34 casos relatados e de 32 dias, quando os pacientes com tempo superior a um ano foram excluídos.

Em alguns casos, houve a suspeita de inoculação de MCR na cavidade articular por aplicações de corticóides injetáveis, que também podem mascarar o quadro por um período de tempo maior. Este fato, além de o fato do período de incubação das MNT poder se estender de duas semanas a doze meses (Brasil, 2007a e b) e a dificuldade em recuperação do agente etiológico na suspeita de infecção podem ter contribuído para os casos diagnosticados muito tempo depois da cirurgia.

Em relação às intervenções médicas, após o diagnóstico de ISC, as mais prevalentes foram antibioticoterapia para todos os pacientes, remoção de prótese, drenagem e debridamento cirúrgico para quase metade dos pacientes, e reimplante da prótese para $17,6 \%$ dos pacientes.

Husted et al. (2010) efetuando um estudo de readmissões e óbitos ocorridos em 90 dias, em 1.731 indivíduos submetidos à artroplastias primárias unilaterais de joelho e quadril, detectou 28 novas internações por 
ISC e 15 outras com suspeita de processos infecciosos que não foram confirmados. Desse total, nove evoluíram para reoperação, sendo que seis deles tiveram os implantes removidos e 11 sofreram debridamento e antibioticoterapia, aumentado em 178 dias a permanência hospitalar.

Geralmente, as curas de osteomielite por MCR tem sido conseguidas após a drenagem cirúrgica e remoção da prótese combinada com terapia antibiótica, por um mínimo de seis meses (Wallace 1998; Brown-Elliot, Wallace, 2002), com base em testes de sensibilidade in vitro, do agente etiológico isolado. Os autores também sugerem que as fluoroquinolonas novas, tais como a moxifloxacina, são promissoras para o tratamento deste tipo de infecção.

No presente estudo, a moxiflocina foi testada em apenas um paciente e com resultado de sesnibilidade positivo.

A estratificação dos pacientes, de acordo com a localização, a extensão do acometimento das lesões e a presença ou não de comorbidades, são de suma importância para se elaborar a estratégia terapêutica (Brown-Elliott, Wallace, 2002). Em algumas situações a hospitalização será necessária para prover esquema de antibioticoterapia, por via parenteral. Na presente revisão, todos os pacientes permaneceram internados para tratamento.

De acordo com Brown-Elliott e Wallace (2002) não se encontram disponíveis, na literatura indexada no PubMed, estudos controlados e randomizados, comparando os diferentes esquemas e os tempos de tratamento, nas diversas apresentações clínicas das infecções, causadas por MCR. Nos casos, em que foi obtido o diagnóstico etiológico, o esquema terapêutico foi baseado no teste de sensibilidade (antibiograma) e na espécie identificada.

A nota técnica da ANVISA recomenda o uso de amicacina, claritromicina e imipenem por seis meses para o tratamento de infecções por MCR (Brasil, 2009b).

Nos estudos em que se fez teste de sensibilidade aos antimicrobianos, quando testados, a sensibilidade à amicacina, claritromicina e clartiromicina foram superiores a $80,0 \%$, no entanto a sensibilidade ao imipenem foi próxima a $60,0 \%$. 
Diversas espécies de MNT já foram associadas a biofilmes em instrumentos cirúrgicos e sistemas de água em ambientes hospitalares, isto tem relevantes implicações diretas em epidemiologia, sobrevida do meio ambiente e resistência a biocidas e antimicrobianos (Lima, Leão, 2010).

A formação de biofilmes em superfícies é determinada em parte pela hidrofobicidade e composição de ácido micólico da parede celular dos organismos e pelas condições ambientais e presença de nutrientes no interior das tubulações de água em ambientes hospitalares. Alguns materiais são relevantes para a formação do biofilme, como metais (aço inoxidável, cobre) e plásticos (cloridrato de polivinil - PVC - e policarbonato PC) (Williams et al., 2009).

Nos materiais implantados cirurgicamente, a formação de biofilme é uma das causas mais importantes de fracasso da intervenção ortopédica e, de maneira geral, a ISC não é resolvida, sem a remoção dos implantes e longas cargas de antibióticos. Ainda assim, algumas variações fenotípicas de pequenas colônias bacterianas, de crescimento mais lento, poderiam permanecer e/ou não serem identificadas pelos exames laboratoriais, dificultando o real diagnóstico da infecção, e propiciando as recidivas (Neut et al., 2007).

Nas ISCs, que se manifestaram dentro das primeiras duas a quatro semanas e foram submetidas a revisão cirúrgica local para debridamento e irrigação, sem a retirada dos componentes, é possível evitar a formação do biofilme na superfície do material protético, com resultado favorável. (Moyad et al., 2008).

Casos de MCR relacionados a falhas no processo de reprocessamento de materiais utilizados em procedimentos endoscópicos por glutaraldeído também mobilizaram órgãos públicos de vigilância epidemiológica e sanitária. Resultados de investigações realizadas pelos integrantes da Rede Nacional de Investigação de Surtos em Serviços de Saúde (Reniss) confirmam a ocorrência de infecções por MCR, em pessoas submetidas a procedimentos invasivos em que o instrumental foi submetido à desinfecção por glutaraldeido (Brasil, 2012 ) 
Pesquisas mostram que soluções aquosas de glutaraldeído com concentração maior que $2 \%$, tamponadas em pH 7,5 a 8,5 com bicarbonato de sódio, causam efetivamente a morte de bactérias vegetativas em tempo menor que dois minutos, enquanto que para $M$. tuberculosis, fungos e vírus o tempo pode se estender até 10 minutos; e os esporos das espécies Bacillus e Clostridium necessitam de tres horas. Observou-se entre os microorganismos resistentes ao gluraldeído, micobacterias atípicas (Mycobacterium chelonae, Mycobacterium avium intracellulare, M. xenopi), Methylobacterium mesophilicum, Trichosporon, fungos ascósporos (Microascus cinereus, Cheatomium globosum) e Cryptosporidium (Rutala, Weber, 2008).

O Mycobacterium chelonae pode ser isolado de próteses suínas para válvulas de coração imersas em solução de glutaraldeído $0,2 \%$ e foi relacionado à infecções cirúrgicas cardíacas por MCR (Rutala, Weber, 2008).

Analisando as taxas de ISC, num hospital público de Belo Horizonte (MG) - Brasil, Torres (2011) constatou que, na clínica ortopédica, a incidência de ISC foi de 2,2\%, no período de 2008 a 2009. Dessas, 39,0\% foram classificadas como incisão profunda e $37,3 \%$ como osteomielites, infecções que demandam tratamento antimicrobiano, eventualmente associado a outras intervenções médicas cirúrgicas. Dos pacientes que se infectaram, $77,9 \%$ necessitaram de readmissão. Observou-se que, do total de pacientes que evoluíram para a osteomielite, $81,8 \%$, retornaram ao hospital.

As infecções incisionais profundas são aquelas identificadas até 30 dias do procedimento, ou até um ano, quando foram colocados implantes no local e a infecção envolve partes moles (fáscia e músculo). Quando a ISC envolve órgãos ou espaços manipulados durante o procedimento, excetuando-se as infecções de pele e partes moles, e ocorre até 30 dias após a sua realização ou até um ano quando na presença de implantes, passa a ser denominada infecção de órgãos e cavidades (Edwards et al., 2008). 
Os estudos desta revisão não classificaram as ISC conforme a classificação do CDC, mas também não tinham por objetivo primário estudar a epidemiologia da ISC, mas sim descrever o caso de uma infecção por MCR e as dificuldades no isolamento e tratamento dos pacientes. Pelas intervenções realizadas, pressupõe-se que quase $60,0 \%$ das infecções eram de cavidade ou espaço por terem envolvido revisão cirúrgica da prótese, troca do implante, remoção da prótese ou parte de seus componentes.

Quanto aos desfechos, quando relatados, verificou-se nesta revisão, a cura da micobacteriose ortopédica para cerca de $60 \%$ dos pacientes e um paciente evolui a óbito.

Antes de se efetuar a avaliação quanto às espécies do agente etiológico isolado das ISC's - bactérias do gênero Mycobacterium, do grupo MCR, pôde-se observar na Tabela 5, as características adotadas nos 21 estudos desta revisão, pouco relatadas, quanto ao material enviado para exame microbiológico dos sítios cirúrgicos infectados e/ou do ambiente, supostamente envolvidos na contaminação intraoperatória, além das provas efetuadas para isolamento e identificação microbiológicas da micobactéria.

Concorda-se com Macedo et al. (2009), quando enfatiza que é importante a identificação das espécies de MNT / MCR dos casos de ISC's ortopédicos, pois permite a realização de estudos epidemiológicos detalhados; orienta a análise laboratorial das amostras de material biológico do paciente e do ambiente; amplia o conhecimento sobre os perfis de sensibilidade das diferentes espécies aos antimicrobianos, além de que representa um importante subsídio para a prática clínica, frente às infecções associadas a tais micro-organismos.

É importante salientar que, no Brasil, o resultado deve ser prontamente reportado ao médico assistente e obrigatoriamente, notificado à ANVISA, sendo detectada a presença de BAAR (bacilo álcool-ácido resistentes) no método de Ziehl - Neelsen, nos materiais biológicos examinados, com resultados confirmados pela bacterioscopia das colônias suspeitas (Brasil, 2009b).

Nos estados, nos quais o LACEN (laboratório central) não estiver capacitado, ou não dispuser dos insumos necessários para realizar o teste 
de sensibilidade (antibiograma), por microdiluição, segundo os critérios do CLSI (2003), e a identificação da espécie por método molecular; a cultura crescida em meio sólido deverá ser enviada diretamente para um Centro de Referência. A Rede Nacional de Laboratórios de Saúde Pública, da Secretaria de Vigilância em Saúde, tem organização hierárquica, apresentando como Laboratório de Referência Nacional, para Micobactérias, o Centro de Referência Professor Hélio Fraga, na cidade do Rio de Janeiro (Brasil, 2009b).

Avaliando-se a distribuição das espécies de Mycobacterium isoladas, quanto ao número de casos / pacientes infectados, nesta revisão, verificou-se predominância de M.fortuitum, seguida de M.chelonae.

As técnicas de PCR e/ou PFGE têm sido reportadas como métodos de identificação de MNT/MCR, causadora de surtos, incluindo M.fortuitum, M.chelonae e M.abscessus (Wallace et al., 1993b)

Martín-Casabona et al. (2004) realizaram um estudo multicêntrico, envolvendo 41 laboratórios clínicos, de 14 países (o Brasil foi o único da América Latina), com a finalidade de verificar o aumento no número de uma determinada espécie de MNT e a existência de algum padrão de distribuição geográfica entre certas espécies, principalmente aquelas que causam infecção ou doenças. Observou-se que entre as MNT isoladas, houve um aumento progressivo ao longo dos anos e, as espécies mais frequentemente isoladas foram M.avium, M.gordonae, M.xenopi, M.kansasii, além de M.fortuitum $(87,6 \%)$, predominante também nesta revisão. Dentre essas espécies, apenas o M. fortuitum é uma MCR.

Ao longo dos últimos anos (2000/2010), a ANVISA acompanhou a ocorrência de infecções pós-cirúrgicas por MNT, nas diferentes regiões do país. Os resultados dessas investigações revelaram pacientes expostos nos estados do Mato Grosso, Rio de Janeiro e Goiás, com confirmação de infecção por M.abscessus, M.chelonae e M.fortuitum, em pessoas submetidas a procedimentos invasivos, particularmente naqueles efetuados por vídeo, cujos instrumentais médicos sofreram desinfecção de alto nível em solução de glutaraldeído (Brasil, 2007a). 
Segundo Sampaio et al. (2006a), o agente etiológico mais prevalente, na maioria das cidades brasileiras, é a espécie M.massiliense, exceto nas infecções secundárias de mamoplastias, onde a maior prevalência é de M.fortuitum. Diversas outras espécies de MCR têm sido identificadas: M.abscessus, M.bolletii, M.chelonae, M.smegmatis, M.wolinskyi e M.avium. Todas essas espécies são ambientais, excetuando M.avium (Brown-Elliott, Wallace, 2002; Falkinham, 2002). M.massiliense e M.bolletii são espécies descritas recentemente e anteriormente classificadas como M.abscessus (Adekambi et al., 2004, 2006).

M.wolinskyi pertence ao grupo M.smegmatis, que inclui M.smegmatis propriamente dito e duas outras espécies, descritas em 1999: M.goodii e M.wolinskyi (Brown et al., 1999), daí a importância de se efetuar a coleta de um ou mais material biológico, do sítio cirúrgico infectado, seguida de metodologia laboratorial adequada para confirmar a(s) espécies de MCR isoladas, devido características similares entre elas.

Oito casos de infecções causadas por M.wolinskyi foram relatadas na literatura (Wallace et al., 1998; Brown et al., 1999; Brown-Elliott, Wallace, 2002; Pulcini et al., 2006), com história clínica para sete deles. Brown et al. (1999) relatou três casos de infecção óssea do esterno - osteomielite, após cirurgia cardíaca, do pé e cotovelo decorrente de fratura aberta.

Nesta revisão integrativa, M.wolinskyi foi relatado pela primeira vez em uma prótese articular (E12-C1 - prótese total do quadril esquerdo), porém, a porta de entrada da micobactéria, na ISC do paciente, não ficou clara. Nenhum surto foi observado durante o período de hospitalização. Os autores (Pulcini et al., 2006), não excluiram, totalmente, a possibilidade de que a bactéria tinha sido introduzida durante a artrografia, apesar de não confirmada, uma vez que o paciente relatou dor, a partir de uma síndrome inflamatória moderada, com proteína $C$ - reativa aumentada e contagem de células brancas do sangue alterada, antes da artrografia ser realizada.

M.goodii identificado, como MCR do grupo da M.smegmatis (Brown et al., 1999), foi associado com casos esporádicos de celulites, osteomielites, infecção do sítio de inserção do marcapasso e pneumonia 
lipóide (microaspiração pulmonar) (Brown et al., 1999, 2002), no entanto, M.goodii não foi indicado como patógeno por Ferguson et al. (2004).

De acordo com Hamid et al. (1991), M.farcinogenes é o principal agente causador da farcino bovina, não havendo relatos anteriores de casos de infecção humana, por este micro-organismo.

Wong et al. (2005) relataram o primeiro caso de infecção por M.farcinogenes, em humano (artroplastia total de quadril esquerdo - E10C1). De acordo com os autores esta espécie é muito rara, mas é uma causa potencial de falha de implante cirúrgico, provocando a sua retirada. Embora o tratamento de infecção por MNT, após artroplastia total do quadril seja controverso, o caso apresentado obteve sucesso no tratamento, após os médicos terem consultado um microbiologista e terem feito outra cirurgia, além da prescrição de antimicrobianos, procedimentos considerados importantes na suspeita de infecção por MNT/MCR, particularmente quando os resultados de análises microbiológicas de rotina forem negativos, apesar da forte evidência clínica de infecção, após a colocação da prótese. A fonte da infecção por M.farcinogenes não foi encontrada. Não havendo histórico de contato de paciente ou cirurgiões, com animais, além de que nenhum outro paciente do hospital foi infectado pelo mesmo micro-organismo, na época.

Pring e Eckhoff (1996) descreveram o primeiro caso de infecção, após artroplastia total do joelho por M.chelonae. O paciente foi tratado com sucesso, após o debridamento, a remoção da prótese e a inserção de um espaçador de cimento, impregnado de antibiótico; a antibioticoterapia foi realizada por várias semanas, e houve implantação de uma nova prótese.

M.chelonae foi isolado de diversas amostras biológicas como pele de paciente, receptor de transplante hepático, córnea, sítio de inserção de cateter vascular, líquido sinovial, lavado bronco alveolar, sítio de marcapasso e sangue (Brasil, 2009b).

Booth et al. (1979) relataram o primeiro caso de infecção por MNT, após artroplastia total de joelho em 1979. O paciente foi infectado com M.fortuitum e após remoção da prótese e artrodese da articulação do joelho, teve boa recuperação funcional. 
Uma busca na base de dados MEDLINE (Portal PubMed) realizada por Wang et al. (2011) encontrou recentes periódicos sobre infecções protéticas em joelho, por MNT, num total de 16 casos, sendo 8 mulheres e 8 homens, com idade média de 65 anos (variando de 30 a 82 anos). Dos 16 casos analisados pelos autores - ISC's de próteses de joelho, em apenas um foi isolado mais de uma espécie de MNT, ou seja, eles relataram o primeiro caso de infecção protética multicolonizada por M.fortuitum e M.abscessus, em joelho (E21-C1). O paciente foi tratado, satisfatoriamente, por ressecção de artroplastia, uso prolongado de antibióticos e reimplantação de prótese. Co-infecção por diferentes espécies de MNT, em articulação de joelho protético, não tinha sido informada, até então. Porém, casos de ISC multicolonizadas por MNT e M.tuberculosis já tinham sido relatados em infecção pulmonar ou osteomielite (Khan et al., 2010; Lazzarini et al., 2002).

Em relação ao perfil de sensibilidade / resistência ( $S$ ou $R$ ) das diferentes espécies, isoladas nos estudos desta revisão, verificou-se que há possibilidade de comparação, com resultados de micobacterioses ortopédica ou não, somente para M.fortuitum, M.chelonae e M.abscessus, pois, as demais espécies relatadas foram testadas frente a pequeno número de agentes antimicrobianos.

As três espécies, citadas anteriormente, foram resistentes ao maior número de antibióticos, sendo consideradas multirresistentes, na maioria, de modo que concorda-se com Brown-Elliot e Wallace (2002), quando alerta que, dada à diversidade de espécies, aos diferentes perfis de sensibilidade observados para cada grupo de espécies, e ao número limitado de opções terapêuticas, o diagnóstico microbiológico, obtido por cultura específica para micobactérias, deve ser prioritário; além de que a escolha de um tratamento inicial, considerando-se a droga, o perfil do paciente e o padrão de resistência microbiológica, concorre para a melhoria dos resultados cirúrgicos; segundo Nicolau (2011), uma vez que não tem havido, ao longo do tempo, modificação expressiva dos agentes bacterianos, mas sim de sua resistência aos antimicrobianos, fato este que continua desafiando o cenário das infecções pós-operatórias (Torres, 2011). 
Infecção protética articular com MCR é uma ocorrência rara que requer a remoção da prótese e vários meses de tratamento com antibióticos (Wong et al., 2005; Degroote, Huit, 2006; Griffith et al., 2007; Miyasaka et al., 2007).

Há pouca informação de sensibilidade antimicrobiana de M.fortuitum. A sensibilidade in vitro de algumas cepas de M.fortuitum tem sido detectada frente à vancomicina, cefaloridina, tetraciclina, kanamicina, amicacina e claritromicina. A resistência foi relatada para cefalotina, penicilina G, meticilina, cabenicilina, ampicilina, rifampicina, eritromicina e ciprofloxacina (Booth et al., 1979; Saccente, 2005; Porat e Austin, 2008).

A técnica de micro-diluição em caldo é a recomendada pelo CSLI para determinar a sensibilidade das MCR. No entanto, um de seus inconvenientes é a dificuldade de realizar-la na maioria dos laboratórios que devem recorrer aos laboratórios de referência (García-Agudo et al., 2009).

Estudo que se propôs a verificar a sensibilidade de MCR aos antibimicrobianos pela técnica comercial E-test (AB Biodisk, Suécia), a partir de 54 cepas cultivadas em meio sólido de Löwenstein-Jensen, verificou que $100 \%$ das cepas de M.fortuitum, M.chelonae e M.abscessus foram sensíveis à amicacina e tigeciclina; quanto aos outros antimicrobianos as repostas foram variáveis entre as espécies. Apesar da técnica não ser recomendada pelo CSLI, os autores sugerem que ela é útil para determinar a sensibilidade das MCR, fácil de ser utilizada e acessível a qualquer laboratório (GarcíaAgudo et al 2009).

Dados retrospectivos sobre a sensibilidade antimicrobiana de 148 cepas isoladas de 2000 a 2008, em um centro de microbiologia indiano, testadas pelo método de Kirby Bauer, seguindo as orientações do CSLI, mostraram que $94 \%$ das M. abscessus eram sensíveis à amicacina e $100 \%$ resistente a tobramicina; a maioria das MCR era resistente às cefalosporinas que variou de $75-84 \%$ para o M.abscessus e $71-86 \%$ para a $M$. fortuitum e a resistência de ambas ao ceftriaxone girou em torno de $85 \%$ e para a cefaperozona foi de 78 e $86 \%$ respectivamente. Todas as M.foruitum se mostraram sensíveis à amicacina, seguidas por gatifloxacina (92\%), moxifloxacina (86\%), ciprofloxacina (86\%), norfloxacina (74\%) e azitromicina (64\%) (Gayathri 2010). 
Wang et al. (2011) em sua revisão de casos de micobacteriose protética concluiu que o tratamento prolongado com determinados antibióticos é necessário para completa erradicação da ISC, antes de realizar o reimplante da prótese, no entanto, o tempo adequado da antibioticoterapia ainda é desconhecido.

O caso de micobacteriose relatado por Wang et al. (2011) - E21-C1 - artroplastia de joelho direito ( + - 74 anos) início de sinais e sintomas, após 5 meses da cirurgia, com tempo de segmento médico até a cura da infecção correspondente a 2 anos e 8 meses, levou os autores a sugerirem que, devido à severidade da lesão ortopédica, pode ser necessário o uso de um marcador de inflamação (ESR - taxa de sedimentação de eritrócito), o qual foi usado para guiar a duração da antibioticoterapia, sendo que, no caso citado, a prescrição de eritromicina foi seguida, mostrando ser um marcador satisfatório para a cronometragem do reimplante.

Estudo que reviu 16 casos de ISC's por MCR, observou que a maioria dos pacientes que removeu a prótese, obteve a cura, após a antibióticoterapia, sem terem recaída. Embora dois pacientes tivessem sido curados, sem remoção da prótese, precisaram da utilização de antibióticos, a longo prazo, para mantêlos livres dos sintomas da infecção ortopédica (Wang et al., 2011).

Quanto ao resultado microbiológico dos diferentes materiais biológicos analisados nas ISC dos estudos E13-C2/C3; E15-C1 e E16-C1 (Tabela 5), em que se detectou a mesma espécie de MCR (M.fortuitum), caracterizando uma infecção monocolonizada, está de acordo com os dados observados na literatura consultada, que, também, detectaram ISC por uma única espécie de MCR (Schlossberg, Aaron, 1991; Yew et al., 1993). Em relação ao E21-C1, em que as análises microbiológicas de um só tipo de material detectaram a presença de duas espécies - M.fortuitum e M.abscessus, indicando uma ISC ortopédica multicolonizada, ou seja, infecção mista, comprova a importância da metodologia utilizada para identificar o(s) agente(s) etiológico(s), sendo que os autores (Wang et al., 2011) alertam que, quando a co-infecção por MNT não for identificada em infecções de articulações de joelho, a falha terapêutica, provavelmente, pode ocorrer devido à susceptibilidade de cada espécie a diferentes 
antimicrobianos, de modo que, várias amostras de material biológico da ISC devem ser coletadas, para a análise microbiológica e o antibiograma, possibilitando confirmar a caracterização de multicolonização por MNT.

Em diferentes estudos sobre MCR, a espécie M.abscessus demonstrou ser a mais resistente aos antibióticos entre as micobactérias (Wong et al., 2005; Degroote, Huitt, 2006; Miyasaka et al., 2007), resultado também comprovado nos estudos avaliados nesta revisão integrativa, tanto quanto para M.fortuitum.

M.abscessus e M.chelonae são, provavelmente as espécies mais resistentes aos antibióticos entre as MCR patogênicas, possivelmente pelas suas características moleculatres (Hinrichsen, 2007).

Yinkey et al. (2010) relataram o segundo caso de M.abscessus em infecção de prótese articular e o primeiro com sucesso no tratamento (E20C1 - $q$ - 40 anos / prótese total de quadril esquerdo), tendo como desfecho a cura da paciente. Em resumo, o seu curso de tratamento durou oito meses, envolvendo antibioticoterapia, com complicações por inúmeros efeitos adversos. Os autores demonstram a dificuldade no tratamento de infecções ortopédicas causadas por M.abscessus; relatam também, pela primeira vez, o uso de tigeciclina, para tratar uma infecção de prótese articular por MCR, e destacam o potencial uso desse antibiótico para infecções de próteses, além das dificuldades envolvidas em usá-lo, por um período de tempo prolongado, confirmando estudo feitos por Miyasaka et al. (2007), que relataram o papel em potencial da tigeciclina, no tratamento dessas infecções, e o de Wong et al. (2005), que alertaram para o fato de que estas infecções podiam ser curadas. Descrevem, também, a experiência com o uso de tigeciclina, em combinação com azitromicina e cefoxitina, após ter falhado a terapia com antibióticos de primeira linha, tais como amicacina, azitromicina, e cefoxitina, em combinação com a retirada da prótese.

Quanto às possíveis fontes de MCR, que causam ISC's protéticos, não foram confirmadas ou relatadas nos 21 estudos analisados nesta revisão. No entanto, acrescentamos algumas considerações encontradas na literatura sobre micobacteriose por MCR, de acordo com o seu habitat natural, principalmente. 
A fonte de contaminação por MCR é uma tarefa desafiadora, pois além das superfícies e dos materiais, normalmente considerados de risco, há também, soluções insuspeitas, como a violeta de genciana, a qual já foi identificada como fonte (Safranek, 1987).

$\mathrm{Na}$ maioria das vezes, as fontes de transmissão conhecidas são medicamentos injetáveis e colírios, solução de glutaraldeído contaminada, água não estéril (incluindo água potável), implante de contraceptivo, prótese mamária, fio de marcapasso/gerador, broncoscópios/endoscópios e videolaparoscópicos. Cabe salientar, a importância em fazer revisão de todas as etapas do processo de limpeza, lavagem adequada de todo o material, suas conexões e escovação de todas as pinças com os mais variados lumens. Artigos reprocessados fora da instituição deverão ser esterilizados na CME (Central de Material e Esterelização) da unidade de saúde, onde será realizado o procedimento cirúrgico, em relação a isso deve-se aumentar o controle da entrada destes artigos (Hinrichsen, 2007).

Cabe salientar que, no E2, o residente de ortopedia esteve na cirurgia de ambos pacientes. Culturas de M.fortuitum, de secreções respiratórias superiores, garganta e mãos foram negativas. Foi relatado, que o médico utilizava com frequência a hidromassagem de sua residência antes das cirurgias, e foi possível isolar, na água da hidromassagem M.fortuitum (Jeffrey et al., 1979).

A porta de entrada, em endocardites por M.chelonae, pode ser variada, há relatos de seu isolamento no líquido utilizado para o esfriamento da solução de cardioplegia, na máquina de gelo e até na água fornecida para o hospital. Em cinco dos seis pacientes (Jorge et al., 1994) submetidos à cirurgia cardíaca e contaminados por M.chelonae, a infecção se restringiu ao esterno e um apresentou endocardite infecciosa (subespécie M.abscessus). Para os autores, a provável fonte de contaminação foi o contato da enfermagem, anestesiologista ou cirurgião com a água não estéril contaminada. Esta, todavia, não é a única possibilidade de contaminação. No estudo de Jorge et al. (1994) teve crescimento de M.chelonae em material retirado da prótese no momento do implante em oito de 16 delas; a 
fonte de infecção, segundo os autores do estudo, foi a prótese contaminada (Jorge, et al., 1994).

Os achados obtidos da análise de 19 pacientes com infecção por M.fortuitum, submetidos à cirurgia cardíaca no Charlotte Memorial Hospital na Carolina do Norte (USA), sugerem que o cimento do osso e os enxertos, além da prótese, podem ser os responsáveis pela infecção (Robicsek et al., 1978). Nestes pacientes as manifestações clínicas apresentadas foram de infecção do esterno e sepse, sem relato de endocardite.

O resultado de um estudo prospectivo de cultura de 400 fragmentos retirados de 100 válvulas porcinas - já banhadas em solução de glutaraldeído a $0,625 \%$ - foi o crescimento de M.chelonae em $23 \%$ das amostras; assim como evidenciaram resistência destas bactérias a atuação do glutaraldeído. A eliminação completa só ocorreu após a utilização de formaldeído associado ao surfactante (Casagrande et al. 1986).

Descrição de uma série de ISC's por M.chelonae ocorridas em pacientes submetidos à cirurgia de videolaparoscopia em uma mesma unidade de saúde durante seis meses, identificou a água utilizada na etapa de rinsagem dos instrumentos que sofreram desinfecção como fonte de contaminação. A MCR sobrevivia e crescia no biofilme formado no fundo dos recipientes contendo os desinfetantes. Ao se substituir o processo de desinfecção pela esterilização em óxido de etileno, o surto se extinguiu (Vijayaraghavan et al. 2006).

Carson et al. (1988) detectaram MNT em abastecimentos de água de $95(83 \%)$ de 115 centros de diálise analisados. Nas saídas de torneiras, muitas MNT podem formar biofilme, em água destilada, em temperaturas variadas e cloradas (Wallace et al. 1998).

M. chelonae é encontrada em água potável, biofilmes em tubulações de sistemas de distribuição de água potável, piscinas, esgoto, solo e superfície de artigos hospitalares (Sampaio et al., 2006b; Brasil, 2009b).

Investigação utilizando cepas de MCR isoladas em surtos do CDC e cepas de MNT de crescimento lento estudou a formação de biofilmes por estas cepas considerando a presença de nutrientes (elevado ou reduzido) e o tipo de superfície (aço inoxidável ou policarbonato). Após $72 \mathrm{~h}$ de 
incubação observou-se que a formação de biofilme pelas MCR foi influenciada mais pela presença de nutrientes do que pelo tipo de superfície, embora ambos afetem o crescimento dos microrganismos. A estrutura de microcolônias mostrou que as MCR desenvolvem diferentes estruturas de biofilme em presença de elevada quantidade de nutrientes: pilares de várias formas (M. abscessus e M.fortuitum) e longos cordões (M.abscessus e M.chelonae). Apesar do crescimento lento no laboratório a M.avium desenvolveu mais biofilme em água potável após $72 \mathrm{~h}$ do que as MCR testadas, mostrando sua maior adaptação aos sistemas de água potável do que as condições de incubação no laboratório (Williams et al., 2009).

M.goodii não pôde ser isolada em pia ou água de qualquer espécie; no entanto a água como fonte deste micro-organismo não pôde ser excluída (Ferguson et al., 2004).

De acordo com Ingen et al. (2009), uma revisão sobre as fontes ambientais de MCR confirmou a presença de micobactérias em ambientes naturais de água (lagos, rios), solo, embora menos frequente, como fonte de infecção, e também em sistemas de água construídos pelo homem (sistemas de abastecimento, piscinas).

Também é descrito, que as MCR podem interagir com amebas de vida livre e protozoários presentes nos sistemas de água, que as protegem de ambientes hostis, podendo inclusive contribuir na seleção de organismos com maior capacidade de infectar o homem (Adekambi et al., 2006b)

Mycobacterium abscessus é encontrada em todos ambientes - no solo, poeira, pedras, bioaerossóis e água. A contaminação pode ocorrer por meio de equipamento contaminado, especialmente quando enxaguados com água contaminada (Degroote, Huitt, 2006). M.abscessus foi encontrada em infecções de tecidos mole, possivelmente decorrentes de contaminação direta por introdução de agulha contaminada ou outro corpo estranho (Degroote, Huitt, 2006; Griffith et al., 2007) e, também, em infecções associadas à vários tipos de próteses, cateteres de diálise, fios de marcapasso e outros dispositivos médicos invasivos (Cutay et al., 1998; Ellis et al., 2005; Wong et al., 2005; Eid et al., 2007). 
O ar ambiente, não é considerado, por si só, fator predisponente de ISC. Ele atua como veículo de micro-organismos liberados por outras fontes, como ar condicionado e outros equipamentos, além da pele da equipe cirúrgica; por isto mesmo, são necessários mecanismos que diminuam a concentração destes micro-organismos no ar, de maneira a evitar o contato, por queda gravitacional, no sítio cirúrgico aberto (Burgatti, 2007).

Desde o final da década de 80 têm-se relatado na literatura surtos de ceratite por MCR após cirurgia a laser (LASIK - laser in situ keratomieleusis) para correção de miopia, embora nem sempre se consiga identificar a fonte de contaminação. Surto ocorrido em 2000, envolvendo dez pacientes de uma mesma clínica em São Paulo (SP, Brasil), isolou o agente M. chelonae do filtro do ar condicionado da sala de cirurgia e da água do reservatório do vaporizador utilizado para a limpeza do cerátomo (Pitombo, 2009b).

A fonte de MCR em infecções de articulação de joelho protético é obscura. Provavelmente, o patógeno dessa infecção, seja decorrente de contaminação intraoperatória, por diferentes meios, ou veio da pele do paciente, devido a trauma secundário (McFarland, Kuritzkes, 1993; Brown et al., 2002; Kalita et al., 2005; Uslan et al., 2006).

De acordo com Eid et al., (2007) infecções de joelho protético são resultantes de contaminação intraoperatória por MCR, comumente encontradas em água de torneira ou na água utilizada durante a implantação de prótese, para o enxágue de instrumentos cirúrgicos. Cornelius et al. (2007), relatando infecções de articulação protética por M.fortuitum, confirmam a teoria de contaminação intraoperatoria.

Embora não haja evidências científicas na literatura da colonização no homem por MNT, estudo realizado para investigar resultados falsos positivos de testes tuberculínicos cutâneos em macacos (Callithrix jacchus) observou associação entre M.gordonae em fezes dos animais identificada por PCR e resultados suspeitos de testes tuberculínicos, o que indica colonização ou suscetibilidade instestinal à MNT (Wachtman et al., 2011)

Hospital de Nova lorque realizou uma análise retrospectiva de pacientes que apresentaram culturas positivas para MNT de 2000 a 2003. 
De uma amostra de 375 pacientes sem HIV com cultura positiva, 32\% apresentavam quadro clínico compatível com micobacteriose atípica, e dos pacientes com resultado positivo para MCR, $61 \%$ tinham sinais e sintomas para a afecção. Um quarto dos pacientes com doença por NMT não apresentaram fator de risco conhecido, o que sugere segundo os autores, suscetibilidade genética ou exposição ambiental (Bodle et al., 2008).

Segundo Wang et al. (2011), apesar do grande número de procedimentos de artroplastia de joelho executado, em poucos acontece a infecção por MNT; também não se pode afirmar que a contaminação acontece antes ou durante a substituição total de joelho do paciente, pois, de acordo com o estado imunológico dos pacientes, a inoculação direta de MCR, durante o pós-operatório, é a forma mais provável de infecção de articulação protética de joelho. Neste estudo (E21 - C1) realizado por eles, nenhuma fonte de micro-organismo advinda do ambiente foi confirmada.

O controle de variáveis externas ou de fatores intervenientes é fundamental, em investigações desta natureza. Elas constituem os demais fatores predisponentes à contaminação da ferida e de ocorrência de ISC. Para maior clareza, tais fatores foram classificados em extrínsecos (relacionados aos procedimentos e ambientes hospitalar) e intrínsecos (relacionados, principalmente ao paciente) (Burgatti, 2007).

Esclareça-se, contudo, que nos estudos que investigaram apenas a contaminação da ferida, os fatores intrínsecos perdem a sua força de representação de risco, uma vez que as condições específicas dos pacientes, apesar de contribuírem, fundamentalmente, para o desenvolvimento de ISC, não necessariamente implicam em maior ou menor contaminação da ferida (Burgatti, 2007).

A OMS e Universidade de Harvard efetuaram uma campanha mundial ("Cirurgia Segura Salva Vidas"), para reduzir taxas de infecção de sítio cirúrgico em $25,0 \%$, até 2020 , implicando, assim, numa queda na morbimortalidade. No contexto brasileiro, o país aderiu a esta aliança mundial em 2007, com o desafio proposto: "Uma assistência limpa é uma assistência mais segura", em que mobilizou profissionais de saúde, para o cuidado com 
a higienização das mãos, uma das medidas menos onerosas e eficazes, na prevenção de infecções hospitalares (Brasil, 2009c; Cabral, 2010).

Outro ponto, não menos importante, é a multirresistência bacteriana associada às ISC's. Diversos estudos reforçam a necessidade de vigilância e desenvolvimento de estratégias de controle, considerando-se a crescente resistência dos micro-organismos aos antimicrobianos disponíveis (Croft et al., 2007; Anderson et al., 2009; Alexiou et al., 2010; Weigelt et al., 2010; Wright, 2010; Torres, 2011).

Scotland (2008) ressalta que a utilização de antibioticoprofilaxia para a prevenção de ISC, não substitui a técnica e as boas práticas relacionadas aos procedimentos cirúrgicos, e que deve ser considerada apenas como um componente da política eficaz de prevenção das infecções.

Havendo, porém, reconhecimento de que a contaminação de ISC ocorre, predominantemente, por contato e que as fontes principais de microorganismos que causam ISC originam-se dos pacientes e dos profissionais, Burgatti (2007), considera que não há como duvidar da importância do uso de barreiras e de técnicas de anti-sepsia, que evitem a transferência de micro-organismos destas fontes para a ferida cirúrgica.

As evidencias demonstram que, nas áreas hospitalares onde estão mais claras as boas práticas, os profissionais devem se responsabilizar pelo cumprimento das estratégias que visam reduzir a infecção relacionada aos procedimentos cirúrgicos (Boscos et al., 2010).

Concorda-se com Cabral (2010), quando enfatiza a participação da enfermagem, na manutenção do ambiente biologicamente seguro. Se a infecção por micobactérias pode ser reduzida ou eliminada, esta ação passa diretamente pelas mãos dos profissionais de enfermagem, que, no cuidado direto e indireto à saúde, responsabiliza-se pela limpeza, desinfecção e esterilização dos instrumentais e equipamentos médicos. No entanto, é preciso que as instituições garantam recursos humanos e infra-estrutura.

Para Stefánsdóttir et al. (2009), o uso de um checklist, que contemple o momento adequado de administração da profilaxia e os procedimentos padrão de assepsia e anti-sepsia cirúrgica, pode contribuir para a redução de infecções em cirurgias ortopédicas de artroplastia. 
Desse modo, as estratégias de combate das micobacterioses ortopédicas, podem ser compartilhadas por profissionais de saúde, instituições e indústrias (Croft et al., 2007) e devem envolver várias esferas de atuação, quanto à adoção dos princípios de controle da infecção, associada à assistência, bem como do uso racional das drogas e do desenvolvimento de novos agentes contra patógenos multirresistentes (Rice, 2007), uma vez que infecções, de uma forma geral, têm um forte de impacto tanto na saúde quanto nos custos hospitalares para os países em desenvolvimento, indicando a necessidade de melhoria nas práticas de vigilância e controle (Allegranzi et al., 2011). 


\section{CONCLUSÕES}

A presente revisão não permitiu identificar a presença de um fator comum relacionado à ocorrência de ISC em ortopedia, mas as intervenções necessárias para a resolução da infecção tiveram uma trajetória semelhante. Em quase todos os estudos houve demora no isolamento de micobactérias, e em algumas situações, foi necessário recorrer a um laboratório de referência para a identificação da espécie.

Não foi possível compreender pelos estudos analisados porque houve uma moda de artigos publicados no ano de 2008 , Apenas $14,7 \%$ dos pacientes foram readmitidos no mesmo hospital da cirurgia anterior, o que dificultou qualquer possibilidade de se identificar a fonte de infecção. Nos casos em que houve uma investigação, apenas chegou-se a uma série de hipóteses sem confirmação. Poderia se concluir que o estudo com ISC por M.wolinskyi foi o que mais se aproximou da identificação de uma fonte de infecção, pois a micobactéria isolada da banheira do cirurgião pertencia à mesma espécie daquela responsável pela ISC.

A micobactéria mais prevalente nos estudos analisados foi a M.fortuitum presente em infecções pós-artroplastia de joelho e de quadril. Apesar de o tratamento com antimicrobianos em todos os pacientes, em metade deles foi preciso a remoção total da prótese. Nestes estudos, em particular, nem sempre se realizou o teste de sensibilidade antimicrobina e, quando realizado mostrou que a sensibilidde a amicacina, claritromicina e ciprofloxacina não é de $100 \%$. Fato preocupante, pois tanto a amicacina quanto a claritromicina estão no protocolo de tratamento das MCR. Constatou-se que quando do aparecimento das primeiras infecções por MCR em pacientes de cirurgia ortopédica, havia uma tendência de se iniciar o tratamento com os mesmos antimicrobianos utilizados no tratamento da M.tuberculosis.

Infecções pós-operatórias por MCR devem ser lembradas, especialmente em pacientes sem febre, com sinais inflamatórios no sítio cirúrgico após várias semanas do procedimento, associada à drenagem serosa. Quando há suspeita, o cirurgião deve procurar isolar tal 
micobactéria, pois os testes da susceptibilidade antimicrobiana ajudarão no tratamento medicamentoso. O material enviado para análise microbiológica pode ser o líquido da drenagem, mas preferencialmente o envio de tecido do sítio cirúrgico infectado é recomendado, pois o envio de swabs é pouco útil, apesar da facilidade da coleta.

Embora de crescimento rápido, as MCR crescem em torno de dias quando cultivadas em meio sólido, pelos dados obtidos na RI e, portanto, em casos de infecção com resultados de culturas negativas é importante considerar a possibilidade de uma micobacteriose e especificá-la no pedido de cultura para que o laboratório utilize os meios de crescimento e tempo de incubação adequados. O material biológico também pode ser encaminhado para laboratórios de referência dotados de protocolos de isolamento dos agentes, conduta esta utilizada em alguns estudos analisados da EUA e França, diante da dificuldade de isolamento do agente.

São necessárias discussões sobre as ISC em ortopedia quanto ao período de incubação das infecções por MCR, pois embora a maioria das ISC pudessem ser diagnsoticadas pelos critérios do CDC, houve situações em que o diagnóstico foi feito após muitos anos da cirurgia.

Uma vez que a assistência de enfermagem deve ser planejada para o controle de infecção, é de suma importância o conhecimento do enfermeiro sobre a infecção no sítio cirúrgico, para que haja o monitoramento e a implementação de cuidados de enfermagem nos períodos pré, trans e pósoperatório do paciente cirúrgico. Pode se afirmar que os índices de infecções associadas à assistência são importantes parâmetros da avaliação da qualidade do cuidado prestado ao paciente.

$\mathrm{O}$ uso de bundles tem-se mostrado eficaz na reduz de ICS, no entanto, o conjunto de medidas a serem adotadas devem se ajustar à necessidade de cada instituição. É importante uma mensuração das taxas de infecção antes de sua utilização, para que se possa mesnurar o efeito alcançado. 


\section{REFERÊNCIAS ${ }^{1}$}

Acklin YP, Widmer AF, Renner RM, Frei R, Gross T. Unexpectedly increased rate of surgical site infections following implant surgery for hip fractures: problem solution with the bundle approach. Injury. 2011;42:209-16.

Adekambi T, Drancourt M. Dissection of phylogenetic relationships among 19 rapidly growing Mycobacterium species by $16 \mathrm{~S}$ rRNA, $h s p 65$, sodA, recA and rpoB gene sequencing. Int. J. Syst. Evol. Microbiol. 2004;54:2095-105.

Adekambi T, Reynaud-Gaubert M, Greub G, Gevaudan MJ, Scola BL, Raoult D Drancourt M. Amoebal coculture of "Mycobacterium massiliense" sp. nov. from the sputum of a patient with hemoptoic pneumonia. J Clin Microbiol. 2004;42:5493-501.

Adekambi T, Ben Salah S, Khlif M, Raoult D, Drancourt M. Survival of environmental mycobacteria in Acanthamoeba polyphaga. Appl Environ Microbiol. 2006a;72:5974-5981.

Adekambi T, Berger P, Raoult D, Drancourt M. rpoB gene sequence-based characterization of emerging non-tuberculous mycobacteria with descriptions of Mycobacterium bolletii sp. nov., Mycobacterium phocaicum sp. nov. and Mycobacterium aubagnense sp. International Journal of Systematic and Evolutionary Microbiology. 2006b;(56):133-43.

Allegranzi B, Nejad SB, Combescure C, Graafmans W, Attar H, Donaldson L, Pittet D. Burden of endemic health-care-associated infection in developing countries: systematic review and meta-analysis. Lancet. 2011;377:228-41. Disponível em: http://www.ncbi.nlm.nih.gov/pubmed/21146207. Acesso em: 13 jan. 2011.

\footnotetext{
${ }^{1}$ De acordo com o Estilo Vancouver
} 
Alexiou VG, lerodiakonou V, Peppas G, Falagas ME. Antimicrobial prophylaxis in surgery: an international survey. Surg Infect (Larchmt). 2010;11(4):343-8.

Ahren P, Giese SB, Klausen J, Inglis NF. Two markers, IS901-IS902 and p40, identified by PCR and by using monoclonal antibodies in Mycobacterium avium strains. J Clin Microbiol. 1995;33:1049-53.

Ainscow DA, Denham RA. The risk of haematogenous infection in total joint replacements. J Bone Joint Surg Br. 1984;66: 580-582.

Almeida DV. et al. Genotipagem de micobactérias através da técnica PRA a partir de cepas isoladas de pacientes da rede pública do estado do Rio Grande do Sul. Anais do XXII Congresso Brasileiro de Microbiologia. Florianópolis (SC), 2003.

Anderson DJ, Kaye KS, Chen LF, Schmader KE, Choi Y, Sloane R, Sexton DJ. Clinical and financial outcomes due to methicillin resistant Staphylococcus aureus surgical site infection: a multi-center matched outcomes study. PLoS One;4(12):1-8, 2009.

Anderson DJ, Arduino JM, Reed SD, Sexton DJ, Kaie KS, Grussemeyer CA, Peter AS, Hardy C, Choi YI, Friedman JY, Fowler VGJr. Variation in the type and frequency of postoperative invasive Staphylococcus aureus infections according to type of surgical procedure. Infect Control Hosp Epidemiol. 2010 Jul; 31(7):701-9.

Andrade L. Micobactérias atípicas - micobacterioses. Etiopatogenia, diagnóstico, tratamento e epidemiologia. J Pneumologia. 1986;12(4):241-8.

Astagneau P, Hériteau LF. Surveillance of surgical-site infections: impact on quality of care and reporting dilemmas. Curr Opin Infect Dis. 2010;23(4):30610. 
ATS - American Thoracic Society. Diagnosis and treatment of disease caused by nontuberculous mycobacteria. Am J Respir Crit Care Med. 1997;156(2):S1-S25.

Bar TJ, Mishal J, Lewkowicz A, Nahlieli O. Osteomyelitis of the mandible due to Mycobacterium abscessus: a case report. J Oral Maxilofac Surg. 2005;(63):841-4.

Barnes Al, Rojo SY, Moretto $\mathrm{H}$. Prevalencia de micobacteriosis y de tuberculosis en pacientes de un hospital de referencia de la provincia de Córdoba. Revista argentina de microbiologia. [online]. 2004;36(4):170-3.

Barreto RASS. Problemas pós-operatórios de pacientes ortopédicos em sala de recuperação pós-anestésica Ribeirão Preto, 2002. Dissertação de Mestrado, apresentado à Escola de Enfermagem de Ribeirão Preto da Universidade de São Paulo.

Benefield, L.E. Implementing evidence-based practice in home care. Home Healthc Nurse 2003;21(12):804-11.

Blanco RM, Inumaru VTG, Conceição MM, Giampaglia CMS, Ueki SYM, Chimara E, Yoshida JTU, Telles MAS. Estratégias para a identificação de espécies do complexo Mycobacterium fortuitum. Rev Inst Adolfo Lutz. 2002;61(2):91-6.

Bodle EE, Cunningham JA, Della-Latta P, Schluger NW, Saiman L. Epidemiology of nontuberculous Mycobacteria in patients without HIV infection, New York City . Emerg Infect Dis. 2008;14(3):390-6.

Booth JE, Jacobson JA, Kurrus TA, Edwards, TW. Infection of prosthetic arthroplasty by Mycobacterium fortuitum: two case reports. The Journal of Bone and Joint Surgery. 1979;61:300-2. 
Borghaus JGA, Stanford JL. Mycobacterium chelonei in abscesses after injection of diphtheria-tetanus-polio vaccine. Am. Rev. Respir. Dis. 1973;107:1-8.

Bosco JA, Slover JD, Haas JP. Perioperative strategies for decreasing infection: a comprehensive evidence-based approach. Instr Course Lect. 2010; 59:619-28.

Brasil 1998. Ministério da Saúde. Portaria n. 2616 de 12 de maio de 1998. Brasília (DF): Ministério da Saúde; 1998.

Brasil, 2007a. Secretaria de estado da Saúde do Paraná - SESA. Superintendência de Vigilância à Saúde. Ocorrência de casos de infecções por MCR (Mycobacterium de crescimento rápido) pós videocirurgia. Nota Técnica n03/07 - SESA/SVS, de 28 de dezembro de 2007. Disponível em: <http://www.saude.pr.gov.br/modules/conteudo/print.php?conteudo=426>. Acesso em: 20 de maio de 2010.

Brasil, 2007b. Ministério da Saúde. Agência Nacional de Vigilância Sanitária (ANVISA). Medidas para a interrupção do surto de infecção por MCR e ações preventivas. Informe técnico $\mathrm{n}^{\circ} 2 / 07.2007$. Disponível em: http://www.saude.mt.gov.br/portal/controle-infeccoes/documento/doc/informe _tecnico_n_02_medidas_para_a_interrupcao_do_surto_de_infeccao_por_m cr_e_acoes_preventivas.pdf Acesso em: 20 de maio de 2010

Brasil, 2007c. Ministério da saúde. Secretaria de Vigilância em Saúde. Departamento de vigilância epidemiológica. Nota técnica $\mathrm{n}^{0} \quad 2$, DEVEP/SVS/MS. Ocorrência de surto de Infecção por Mycobacterium não tuberculosas pós cirurgias no Rio de Janeiro (RJ), 2007 [citado em 20 Junho 2007]. Disponível em: http:/portal.saude.gov.br/portal/saude.

Brasil, 2008. Agência Nacional de Vigilância Sanitária (ANVISA). Micobactérias. Nota Técnica de 08 de Agosto de 2008. Disponível em: http://www.anvisa.gov.br/divulga/noticias/2008/080808_NotaTecnica_Micoba cteria.pdf. Acesso em: 20 de maio de 2010. 
Brasil, 2009a. Ministério da Saúde. Agência Nacional de Vigilância Sanitária (ANVISA). Resolução RDC nº 8 de 27 de fevereiro de 2009. Dispõe sobre as medidas para redução da ocorrência de infecções por micobactérias de crescimento rápido - MCR em serviços de saúde. Diário Oficial da União, Brasília, DF, 02 de março de 2009. Disponível em: <http://elegis.anvisa. gov.br/leisref/public/showAct.php?id=35890\&word=esteriliza\%C3\%A7ao\%20 quimica\%20por\%20imersao>. Acesso em: 20 de maio de 2010.

Brasil, 2009b. Ministério da Saúde. Agência Nacional de Vigilância Sanitária (ANVISA). Infecções por micobactérias de crescimento rápido: fluxo de notificações, diagnósticos clínico, microbiológico e tratamento. Nota técnica conjunta $n^{\circ} 01 / 2009$ - SVS/MS e ANVISA. 2009. Disponível em: $<$ http://www.anvisa.gov.br/hotsite/hotsite_micobacteria/nota_tecnica_conjunt a.pdf> Acesso em: 20 de maio de 2010.

Brasil, 2009c. Ministério da Saúde. Agência Nacional de Vigilância Sanitária (ANVISA). Brasil se prepara para ter cirurgias mais seguras. 2009. Disponível em:<http://www.anvisa.gov.br/divulga/noticias/2009/100309_2.htm>. Acesso em: 20 de maio de 2010.

Brasil, 2009d - Agência Nacional de Vigilância Sanitária (ANVISA). Rede Nacional de Investigação de Surtos e Eventos Adversos em Serviços de Saúde - Reniss. Casos de Infecção por MNT notificadas. 2009. Disponível: http://www.anvisa.gov.br/hotsite/hotsite_micobacteria/notificados.pdf. Acesso em: 20 de maio de 2010.

Brasil 2009e - Ministério da Saúde. Agência Nacional de Vigilância Sanitária (BR). Segurança do Paciente em Serviços de Saúde: Higienização das Mãos. Brasília (DF): Ministério da Saúde; 2009. 105p. [acesso 13 out 2010]. Disponível em: http://www.anvisa.gov.br/servicossaude/manuais. 
Brasil, 2010. Secretaria de Estado da Saúde. Centro de Vigilância Epidemiológica. Casos de Infecção por micobactéria não tuberculosa de crescimento rápido (MCR), notificados ao Centro de Vigilância Epidemiológica CVE, dados acumulados de 2002 a 2010. Disponível em: htpp://www.cve.saude. sp.gov.br/htm/ih/pdf/IF10_MCR_REL2.pdf). Acesso em Fevereiro 2011.

Brasil, 2012. Secretaria de Estado de Saúde de Minas Gerais. Subsecretaria de Vigilância em Saúde. Superintendência de Vigilância Sanitária. Gerência de Vigilância em Estabelecimentos de Saúde. Alerta Técnico. Disponível em: http://www.saude.mg.gov.br/publicacoes/estatistica-e-informacao-em-saude/ alertas-tecnicos/Alerta\%20Tecnico\%20da\%20VISA\%20-\%20BH $\% 20$ e $\% 20$ SES.pdf . Acesso em Abril 2012.

Brown BA, Springer B, Steingrube VA, Wilson RW, Pfyffer GE, Garcia MJ, Menendez MC, Rodriguez-Salgado B, Jost KCJr, Chiu SH, Onyi GO, Böttger EC, Wallace RJJr. Mycobacterium wolinskyi sp. nov. and Mycobacterium goodii sp. nov., two new rapidly growing species related to Mycobacterium smegmatis and associated with human wound infections: a cooperative study from the International Working Group on Mycobacterial Taxonomy. Int. J. Syst. Bacteriol. 1999;49:1493-511.

Brown-Elliott BA, Wallace, R J Jr. 2002. Clinical and taxonomic status of pathogenic nonpigmented or late-pigmenting rapidly growing mycobacteria. Clin. Microbiol. Rev. 2002;15(4):716-46.

Brown-Elliott, B.A.; Griffith, D.E.; Wallace, R.J.Jr. Diagnosis of nontuberculous mycobacterial infections. Clinics in Laboratory Medicine. 2002;22:911-25.

Burgatti, JC. Revisão sistemática sobre o uso de aventais cirúrgicos, conforme o material de confecção, no controle da contaminação/infecção do sítio cirúrgico. São Paulo 2007. Dissertação de Mestrado, apresentada à Escola de Enfermagem da Universidade de São Paulo. 
Byrne AM, Morris S, McCarthy T, Quinlan W, O'Byrne JM. Outcome following deep wound contamination in cemented artroplasty. Int Orthop. 2007; 31:2731.

Cabral DB. Micobacérias não tuberculosa em cirurgias: desafio passível de enfrentamento no Brasil? Ribeirão preto, 2010. Dissertação de Mestrado, apresentado à Escola de Enfermagem de Ribeirão Preto da Universidade de São Paulo.

Carson LA, Bland LA, Cusick LB, Favero MS, Bolan GA, Reingold AL, Good RC. Prevalence of nontuberculous mycobacteria in water supplies of hemodialysis centers. Applied and Environmental Microbiology. 1988;54:3122-5.

Chadha R, Grover M, Sharma A, Lakshmy A, Deb M, Kumar A, Mehta G. An outbreak of post-surgical wound infections due to Mycobacterium abscessus. Pediatr Surg Int. 1998; 13:406-10.

Carvalho Júnior, LH; Perira, ML; Costa, LP; Gonçalves, MBJ; Soares, LFM; Santos, RL; Andrade, RP: Barbosa, EA. Trabalho realizado no Hospital Madre Teresa de Belo Horizonte (MG), Brasil. Infecção por micobactéria após videoartroscopia: o glutaraldeído pode ser o culpado? Estudo experimental in vitro*. Rev Bras Ortop. 2008;43(6):256-60.

Castella A, Argentero PA, Farina EC, Charrier L, Del Prever EM, Zotti CM. The Piemonte Nosocomial Infection Study Group. Incidence of surgical-site infections in orthopaedic surgery: a northern Italian experience. Epidemiol Infect. 2010 Jul;12:1-6.

Croft AC, D'Antoni AV, Terzulli SL. Update on the antibacterial resistance crisis. Med Sci Monit. 2007 Jun;13(6):RA103-18. 
Culver DH, Horan TC, Gaynes RP, Martone WJ, Jarvis WR, Emori TG, Banerjee SN, Edwards JR, Tolson JS, Henderson TS, et al. Surgical wound infection rates by wound class, operative procedure, and patient risk index. National Nosocomial Infections Surveillance System. Am J Med., 1991; 91(3B):152-7.

CDC - Centers for Disease Control and Prevention. Rapidly growing mycobacterial infection following liposuction and liposculputure - Caracas, Venezuela, 1996-1998. MMWR Morb Mortal Wkly Rep. v.47, n.49, p.1065-7, 1998.

CLSI - Clinical and Laboratory Standards Institute. Susceptibility testing of Mycobacteria, Nocardiae, and Other Aerobic Actinomycetes, Approved Standards Second Edition. M24-A2.

CVE - Centro de Vigilância Epidemiológica. "Prof. Alexandre Vranjac". Divisão de tuberculose. Secretaria Estadual da Saúde. Coordenadoria de Controle de Doença. Micobacterioses: recomendações para o diagnóstico e tratamento. São Paulo, 2005.

Collins CH, Grange JM, Yates MD. Tuberculosis Bacteriology - Organization and Practice. Butterworth-Heinemann, Oxford, 2nd ed.1997.

Cooper HM. Integrating Research: a guide for literature reviews. London SAGE publication, 2 ed. 1989;2;155.

Cornelius L, Reddix R, Burchett C, Bond G, Fader R. Cluster of Mycobacterium fortuitum prosthetic joint infections. Journal of Surgical ORTHOPAEDIC Advances. 2007;16:196-198.

Costa-Cruz JC. Mycobacterium fortuitum: um novo bacilo ácidoresistente patogênico para o homem (new acid fast bacillus pathogenic for man). Acta Med. 1938; 1:297-301. 
Cutay AM, Horowitz HW, Pooley RW, Van Horn K, Wormser GP. Infection of epicardial pacemaker wires due to Mycobacterium abscessus. Clin Infect Dis. 1998;26:520-1.

Dale H, Skråmm I, Løwer HL, Eriksen HM, Espehaug B, Furnes O, Skjeldestad FE, Havelin LI, Engesaeter. Infection after primary hip artroplasty: a comparison of 3 Norwegian registers. Acta Orthop 2011; 82(6): 646-54.

Davidson, P.T. The diagnosis and management of disease caused by M. avium complex, M. kansasii, and other mycobacteria. Clin. Chest. Med. 1989;10(3): 59-63.

Degroote MA, Huitt G. Infections due to rapidly growing mycobacteria. Clinical Infectious Diseases. 2006;42:1756-63.

Devi DR, Indumathi VA, Indira S, Babu PR, Sridharan D, Belwadi MR. Injection site abscess due to Mycobacterium fortuitum: a case report. Indian J Med Microbiol, v.21, n.2, p.133-4, 2003.

Díaz-Agero-Pérez C, Pita-López MJ, Robustillo-Rodela A, Figuerola-Tejerina A, Monge-Jodrá V. Grupo de Trabajo INCLIMECC de la Comunidad de Madrid. Assessment of the surgical site infection in 14 hospitals of the Madrid Region: na incidence study. Enferm Infecc Microbiol Clin. 2011;29(4):257-62.

Duarte RS, Lourenço MCS, Fonseca LS, Leão SC, Amorim ELT, Rocha ILL, Coelho FS, Viana-Niero C, Gomes KM, Silva MG, Lorena NOS, Pitombo MB, Ferreira RNC, Garcia MHO, Lupi O, Vilaça BR, Serradas LR, Chebabo A, Marques EA, Teixeira LM, Dalcolmo M, Senna SG, Sampaio JLM. An Epidemic of Post-Surgical Infections Caused by Mycobacterium massiliense. J Clin Microbiol. 2009;47(7):2149-55. 
Edwards JR, MStat, K D. Peterson, BBA, Mary L. Andrus, BA, RN, CIC, Margaret A. Dudeck, MPH, Daniel A. Pollock, MD, Teresa C. Horan, MPH. National Healthcare Safety Network (NHSN) Report, data summary for 2006 through 2007, issued November 2008. Am J Infect Control. 2008;36(9):60926.

Eid AJ, Berbari EF, Sia, IG, Wengenack NL, Osmon DR, Razonable RR. Prosthetic Joint Infection Due to Rapidly Growing Mycobacteria: Report of 8 Cases and Review of the Literature. Clinical Infectious Disesases. 2007;45:687-94.

Ellis EN, Schutze GE, Wheeler JG. Nontuberculous mycobacterial exit-site infection and abscess in a peritoneal dialysis patient. A case report and review of the literature. Pediatr Nephrol. 2005;20:1016-8.

Ercole FF, Chianca TCM. Infecção de sítio cirúrgico em pacientes submetidos à artroplastia de quadril. Rev. Latino-Am. Enfermagem. 2002;10(2):157-65.

Ercole FF, Chianca TCM, Duarte D, Starling CEF, Carneiro M. Infecção de sítio cirúrgico em pacientes submetidos a cirurgias ortopédicas: o índice de risco NNIS e predição de risco. Rev Latino-am Enferm. 2011a; 19(2): 269-76.

Ercole FF, Franco LMC, Macieira TGR, Wenceslau LCC, Resende HIN, Chianca TCM. Risco para infecção de sítio cirúrgico em pacientes submetidos a cirurgias ortopédicas. Rev Latino-am Enferm. 2011b; 19(6): 1362-8.

Falkinham, J.O. Epidemiology of infection by nontuberculous mycobacteria. Clinical Micorbiology Reviews. 1996;9(2):177-215.

Falkinham, J.O. Nontuberculous mycobacteria in the environment. Clinics in Chest Medicine. 2002;23:529-51. 
Fernandes AT, Fernandes MOV, Ribeiro Filho N. Infecção Hospitalar e suas interfaces na área da saúde. In: CAVALCANTE, N. J. F. Ética e controle de infecção hospitalar. São Paulo: Atheneu. 2000;2:1650-4.

Focaccia R, Veronesi R. Tratado de Infectologia. São Paulo: Atheneu. 2004.

Fontana RT. As Micobactérias de Crescimento Rápido e a infecção hospitalar: um problema de saúde pública. Universidade Regional Integrada do Alto Uruguai e das Missões. Curso de Enfermagem, Grupo de Estudo e Pesquisa em Enfermagem, Saúde e Educação. Santo Ângelo, RS. Rev Bras Enferm, Brasília. 2008;61(3):371-6.

Freitas D, Alvarenga L, Sampaio J, Mannis M, Sato E, Sousa L, Vieira L, Yu MC, Martins MC, Hoffling-Lima A, Belfort R Jr. An outbreak of mycobacterium chelonae infection after LASIK. Ophtalmology 2003, 110(2):276-285.

Galil K, Miller LA, Yakrus MA, Wallace RJJr, Mosley DG England B, Huitt G, Mcneil, MM, Perkins BA. Abscesses due to Mycobacterium abscessus linked to injection of unapproved alternative medication. emerg Infect Dis J.1999;5:681-7.

Galvão, C.M. Níveis de Evidência. Acta Paul Enferm. 2006;19(2):5-5.

García-Agudo L, García-Martos P, Jesús I, Rodriguez-lglesias M. Sensibilidad a los antimicrobianos de micobacterias de crecimiento rápido mediante el método E-test. Ver Méd Chile 2-9; 137:912-7.

Garner JS, Jarvis WR, Emori GT, Horan TC, Hughes JH. CDC definitions for nosocomial infections. American Journal of Infection Control. 1988; 16:12840. 
Gayathri R, Therese KL, Deepa P, Mangai S, Madhavan HN. Antibiotic susceptibility pattern of rapidly growing mycobacteria. J Postgrad Med. 2010; 56(2):76-8.

Graziano KU, Balsamo AC, Lopes CLBC, Zoteli MFM, Couto AT, Paschoal, MLH. Critérios para avaliação das dificuldades na limpeza de artigos de uso único. Rev Latino Am Enfermagem, 2006; 14(1):70-6.

Gravel D, Taylor G, Ofner M, Johnston L, Loeb M, Roth VR, Stegenga J, Bryce E. Point prevalence survey for healthcare-associated infections witin canadian adult acutecare hospitals. J Hosp Infec. 2007; 66(3):243-8.

Griffith DE, Aksamit T, Brown-Elliott BA, Catanzaro A, Daley C, Gordin F, Holland SM, Horsburgh R, Huitt G, Lademarco MF, Iseman M, Olivier K, Ruoss S, Von Reyn CF, Wallace RJJr, Winthrop K. An official ATS/IDSA statement: diagnosis, treatment, and prevention of nontuberculous mycobacterial diseases. American Journal of Respiratory and Critical Care Medicine. 2007;175:367-416, 2007.

Gusmão FA, Alvarenga L, Barbosa L, Sampaio J, Leão SC, Höfling-Lima AL, Freitas D. Deep stromal mycobacterial keratitis viable bacteria after six months of treatment: case report and literature review. Arq Bras Oftalmol. 2005;68(4):551-3.

Johnson LL, Shneider DA, Austin MD, Goodman FG, Bullock JM, DeBruin JA. Two per cent glutaraldehyde: a disinfectant in arthroscopy and arthroscopic surgery. J Bone Joint Surg Am. 1982;64(2):237-9.

Jorge Sdo C, Gondim FA, Arnoni AS, Zamorano MM, Garcia Dde O, Sousa JE. [Endocarditis due to Mycobacterium chelonei in a valvular prosthesis]. Arq Bras Cardiol. 1994;63(2):121-5. 
Hamid ME, Mohamed GE, Abu-Samra MT, el-Sanousi SM, Barri ME. Bovine farcy: a clinico-pathological study of the disease and its aetiological agent. $J$ Comp Pathol. 1991;105(3):287-301.

Hernández A, Martró E, Matas L, Jiménez A, Ausina V. Mycobactericidal and tuberculocidal activity of Korsolex AF, na amine detergent/disinfectant product. J. Hosp. Infect. 2005; 59(1):62-6.

Hernández A, Carrasco M, Ausina V. Mycobactericidal activity of chlorine dioxide wipes in a modified prEN 14563 test. J. Hosp. Infect, v.69, p.384-8, jul. 2008.

Hinrichsen SL. Micobactéria de crescimento rápido - MCR. Prática Hospitalar. 2007;53:106-11.

Hisbello SC. Manejo da doença micobacteriana não-tuberculosa. Bol. Pneumol. Sanit. 2000; 8(2): 39-50.

Hoffman PC, Fraser DW, Robiesek F, O'bar PR, Mauney CU. Two outbreaks of sternal wound infections due to organisms of the Mycobacterium fortuitum complex. J Infect Dis. 1981;143:533-42.

Huotari K, Lyytikäinen O. Impact of postdischarge surveillance on the rate of surgical site infection after orthopedic surgery. Infect Control Hosp Epidemiol. 2006; 27(12):1324-9.

Husted H, Otte KS, Kristensen BB, Orsnes T, Kehlet H. Readmissions after fast-track and knee asthroplasty. Arch Orthop Trauma Surg. 2010;130(9):1185-91.

Ingen J, Boeree M J, Dekhuijzen P N R, Soolingen D. Environmental sources of rapid growing nontuberculous mycobacteria causing disease in humans. Clin Microb Infect 2009;15: 888-93. 
Inman PM, Beck A, Brown AE, Fimlt, Libiol, Stanford JL. Outbreak of infection abscesses due to Mycobacterium. abscessus. Arch. Dermatol. 1969;100(2):141-47.

Kalita JB, Rahman H, Baruah KC. Delayed post-operative wound infections due to non-tuberculous Mycobacterium. The Indian Journal of Medical Research. 2005;122:535-9.

Katoch, V. Infections due to non-tuberculous mycobacteria (NTM). Indian J Med Res. 2004;10:290-304.

Khan MS, Rehman S, Ali MA, Sultan B, Sultan S. Infection in Orthopedic Implant Surgery, Its Risk Factors and Outcome. J Ayub Med Coll Abbottabad. 2008;20(1):23-5.

Khan Z, Miller A, Bachan M, Donath J. Mycobacterium avium Complex (MAC) lung disease in two inner city community hospitals: recognition, prevalence, co-infection with Mycobacterium tuberculosis (MTB) and pulmonary function (PF) improvements after treatment. The Open Respiratory Medicine Journal. 2010;4:76-81.

Knobben BAS, Van Horn JR, Van der Mei HC, Busscher HJ. Evaluation of measures to decrease intra-operative bacterial contamination in orthopaedic implant surgery. J Hosp Infect. 2006; 62: 174-80.

Koneman E, Stephen A. Diagnóstico Microbiológico - Texto e Atlas Colorido, 5a edição, 2001.

Lacerda RA, Egry EY. As infecções hospitalares e sua relação com o desenvolvimento da assistência hospitalar: reflexões para análise de suas práticas atuais de controle. Rev. Latinoamericana Enf. 1997; 5(4): 13-23. 
Lacerda RA. Controle de infecção em centro cirúrgico: fatos, mitos e controvérsias. Coordenação editorial Rúbia Aparecida Lacerda. Editora: Atheneu. São Paulo, p.10, 2003).

Lazzarini L, Amina S, Wang J, Calhoun JH, Mader JT. Mycobacterium tuberculosis and Mycobacterium fortuitum osteomyelitis of the foot and septic arthritis of the ankle in an immunocompetent patient. European Journal of Clinical Microbiology \& Infectious Diseases. 2002;21:468-70.

Leão SC, Tortoli E, Viana-Niero C, Ueki SY, Lima KV, Lopes M.L, Wubero J, Menendez MC, Garcia MJ. Characterization of mycobacteria from a major Brazilian outbreak suggests that revision of the taxonomic status of members of the Mycobacterium chelonae-M. abscessus group is needed.J Clin Microbiol. 2009;47(9):2691-8.

Leekha S, Sampathkumar P, Barry DJ, Thompson RL. Should national standards for reporting surgical site infections distinguish between primary and revision orthopedic surgeries? Infect Control Hosp Epidemiol 2010; 31(5): 503-8.

Lima JMMR, Leão SLPC. Formação de biofilmes de cepas de Mycobacterium massiliense, fenótipos liso e rugoso, isoladas de surtos e fontes ambientais. Dissertação de mestrado. UNIFESP, 2010.

Lopes, ML, Lima KVB, Leão SC, Sousa MS, Santi LQ, Loureiro ECB. NOTA PRÉVIA. Micobacterioses Associadas a Procedimentos Médicos Invasivos em Belém. BELÉM - PR, 2005.

Macedo, J.L.S.; Maierovitch, C.; Henriques, P. Infecções pós-operatórias por micobactérias de crescimento rápido no Brasil. Revista Brasileira de Cirurgia Plástica. 2009;24:544-51. 
Mangran AJ, Horan TC, Pearson ML, Silver CL, Jarvis WR, Jarvis WR. Hospital Infection Control Practices Advisory Committee. Guideline for prevention of surgical site infection. Infect Control Hosp Epidemiol. 1999;20 (4):97-134.

Martín-Casabona N, Bahrmand AR, Bennedsen J, Thomsen VO, Curcio M, Fauville-Dufaux M, Feldman K, Havelkova M, Katila ML, Köksalan K, Pereira MF, Rodrigues F, Pfyffer GE, Portaels F, Urgell JR, Rüsch-Gerdes S, Tortoli E, Vincent V, Watt B. Non-tuberculous mycobacteria: patterns of isolation. A multi-country retrospective survey. The International Journal of Tuberculosis and Lung Disease. 2004(10):1186-93.

McFarland EJ, Kuritzkes DR. Clinical features and treatment of infection due to Mycobacterium fortuitum/chelonae complex. Current Clinical Topics Infectious Diseases. 1993;13:188-202.

Mendes KDS, Silveira RCCP, Galvão CM. Revisão Integrativa: Método de Pesquisa para a Incorporação de Evidências na Saúde e na Enfermagem. Texto Contexto Enferm, Florianópolis, 2008 Out-Dez; 17(4): 758-64.

Meredith FT, Sexton DJ. Mycobacterium abscessus osteomyelitis following a plantar puncture wound. Clin Infect Dis. 1996;23:651-3.

Minnema B, Vearncombe M, Augustin A, Gollish J, Simor AE. Risk factor for surgical site infection following primary total hip artroplasty. Infect Control Hosp Epidemiol 2004; 25(6): 477-80.

Miyasaka T, Kunishima H, Komatsu M, Tamai K, Mitsutake K, Kanemitsu K, Ohisa $\mathrm{Y}$, Yanagisawa $\mathrm{H}$, Kaku $\mathrm{M}$. In vitro efficacy of imipenem in combination with six antimicrobial agents against Mycobacterium abscessus. The International Journal of Antimicrobial Agents. 2007;30:255-8.

Moyad TF, Thornhill T, Estok D. Evaluation and management of the infected total hip and knee. Orthopedics. 2008;31(6):581-8. 
Neut D, van der Mei HC, Bulstra SK, Busscher HJ. The role of small-colony variants in failure to diagnose and treat biofilm infections in orthopedics. Acta Orthopaedica. 2007; 78(3):299-308.

Nichols RL. Preventing surgical site infections. Clin Med Res. 2004;2(2):1158.

Nicolau DP. Current challenges in the management of the infected patient. Curr Opin Infect Dis. 2011;24 (1):S1-10.

Owen M, Smith A, Coultras J. Granulomatous lesions occurring at site of injections of vaccines and antibiotics. South. Med. J. 1963;56:949-52.

Pedersen AB, Svendsson JE, Johnsen SP, Riis A, Overgaard S. Risk factors for revision due to infection after primary total hip artroplasty. Acta Orthop 2010; 81(5): 542-7.

Padoveze MC, Assis DB, Freire MP, Madalosso G, Ferreira AS, Valente MG, Fortaleza CM. Surveillance Programme for Healthcare Associated Infections in the State of São Paulo, Brazil. Implementation and the first three years' results. J Hosp Infect. 2010 Dec; 76(4):311-5.

Peel TN, Dowsey MM, Daffy JR, Stanley PA, Choong PMF, Buising KL. Risk factors for prosthetic hip and knee infections according to arthroplasty site. J Hosp Infect 2011; 79: 129 - 33

Pérez CD, Rodela AR, Monge Jodrá V. Quality Control Indicator Working Group. The Spanish national health care-associated infection surveillance (INCLIMECC): data summary January 1997 through December 2006 adapted to the National Healthcare Safety Network Procedure-associated modules codes. Am J Infect Control. 2009; 37(10):806-12. 
Pitombo MB, Lupi O, Duarte RS. Infecções por micobactérias de crescimento rápido resistentes à desinfetantes: uma problemática nacional? Rev Bras Ginecol Obstet. 2009;31(11):529-33.

Polit, D.F.; Beck, C.T. Using research in evidence-based nursing practice. In: Polit DF, Beck CT, editor. Essentials of nursing research. Methods, appraisal and utilization.Philadelphia (USA): Lippincott Williams \& Wilkins; 2006. p. 457-94.

Porat MD, Austin MS. Bilateral Knee Periprosthetic Infection with Mycobacterium fortuitum. The Journal of Arthroplasty. 2008;23:787-9.

Poveda, V.B; Galvão, C.M; Hayashida, M. Análise do fatores de risco relacionados a incidência de infecção do sítio cirúrgico e gastrocirurgias. Revista de Escola de Enfermagem da USP, v37, n¹. março, 2003.

Prade et al. Estudo brasileiro da magnitude das infecções hospitalares em hospitais terciários. Rev Contr Infec Hosp. 1995; 2:11-24.

Prather EC, Bond JO, Hartwig EC, Bunbar FT. Preliminary Report: Epidemiology of Infections Due to the Atypical Acid-Fast Bacilli. Dis Chest 1961;39;129-139.

Pring M, Eckhoff DG. Mycobacterium chelonae infection following a total knee arthroplasty. The Journal of Arthroplasty. 1996;11:115-6.

Pruitt TC, Hughes LO, Blasier RD, McCarthy RE, Glasier CM, Roloson GJ. Atypical mycobacterial vertebral osteomyelitis in a steroid-dependent adolescent. A case report. Spine. 1993;18:2553-5.

Pulcini C, Vandenbussche E, Podglajen I, Sougakoff W, Truffot-Pernot C, Buu-Hoï A, Varon E, Mainardi J. Hip Prosthesis Infection Due to Mycobacterium wolinskyi. J Clin Microbiol. 2006;44(9):3463-4. 
Retta, S.M.; Sagripanti, J.L. Modeling the inactivation kinetics of bacillus spores by glutaraldehyde. Lett Appl Microbiol. 2008;46(5):568-74.

Rice LB. Emerging issues in the management of infections caused by multidrugresistant gram-negative bacteria. Cleve Clin $\mathrm{J}$ Med. 2007;74(4):S12-20.

Rivero-Olivera I, Guevara A, Escalona A, et al.: Enferm Infcc Microbiol Clin. 2006;24:302-6.

Robicsek F. Daugherty HK, Cook JW, Selle JG, Nasters TN, O'Bar PR, Fernandez CR, Mauney CU, Calhoun DM. Mycobacterium fortuitum epidemics after open heart surgery. J. Thorac. Cardiovasc. Surg.1978;75:916.

Roman AR, Friedlander MR. Revisão integrativa de pesquisa aplicada à enfermagem. Cogitare Enfermagem. 1998;3 (2):109-12.

Runyon EH. Anonymous mycobacteria in pulmonary disease. Med Clin North Am. 1959;43(1):273-90.

Rutala WA, Weber DJ. Guideline for Disinfection and Sterilization in Healthcare Facilities. Chapel Hill/North Carolina: The Healthcare Infection Control Practices Advisory Committee (HICPAC)/ University of North Carolina School of Medicine. 158p., 2008.

Ryu HJ, Kim WJ, Oh $\mathrm{CH}$, Song HJ. latrogenic mycobacterium abscessus infection associate with acupuncture: clinical manifestations and its treatment. Int J Dermatol. 2005;44(10);846-50.

Saccente M. Mycobacterium fortuitum group periprosthetic joint infection. Scandinavian Journal of Infectious Diseases. 2005;8:737-9. 
Sampaio JL, Chimara E, Ferrazoli L, da Silva Telles MA, Del Guercio VM, Jerico ZV, Miyashiro K, Fortaleza CM, Padoveze MC, Leao SC. Application of four molecular typing methods for analysis of Mycobacterium fortuitum group strains causing Post-Mammaplasty Infections. Clinical Microbiology And Infection. 2006a;12:142-9.

Sampaio JL, Viana-Niero C, de Freitas D, Hofling-Lima AL, Leao SC. Enterobacterial repetitive intergenic consensus PCR is a useful tool for typing Mycobacterium chelonae and Mycobacterium abscessus isolates. Diagnostic Microbiology and Infectious Disease. 2006b;55:107-18.

Seabra, F.P. et al. Ceratite por Micobacterium chelonae após laser in situ e histopatológico: relato de um caso. [resumo] Arq Bras Oftalmol 64(4 supl): P018 [Apresentado no $31^{\circ}$ Congresso Brasileiro de Oftalmologia; set 5-9; São Paulo, Brasil, 2001] Disponível em: <http://www.abonet.com.br/abo/ 644s/painel01.htm>

Schlossberg D, Aaron T. Aortitis caused by Mycobacterium fortuitum. Arch Intern Med. 1991;151:1010-1011.

Scotland. Scottish Intercollegiate Guidelines Network (SIGN). Antibiotic prophylaxis in surgery. A nacional clinical guideline. Edinburgh: SIGN; 2008. 97

Souza, M.T.S.; Silva, M.D.; Carvalho, R. Revisão integrativa: o que é e como fazer? Einstein, 2010;8(1):102-6.

Tang P, Walsh S, Murray C, Alterman C, Varia M, Broukhanski G, Chedore P, Dekoven J, Assaad D, Gold WL, Ghazarian D, Finkelstein M, Pritchard N, Yaffe B, Jamieson F, Henry B, Phillips E. Outbreak of acupunctureassociated cutaneous Mycobacterium abscessus infections. J Cutan Med Surg. 2006;10(4):166-9. 
Torres, LM. Readmissão por infecção de sítio cirúrgico em um hospital público de Belo Horizonte (MG). São Paulo 2011. Dissertação de Mestrado, apresentado à Escola de Enfermagem da Universidade de São Paulo.

Tortoli, E. Impact of genotypic studies on mycobacterial taxonomy: the new mycobacteria of the 1990s. Clin Microbiol Rev. 2003;16:319-54.

Trabulsi, L.R. Microbiologia, 3 ed., São Paulo: Editora Atheneu, p. 303-4, 2002.

Ueki SYM, Martins MC, Telles MAS. Micobactérias não tuberculosas: diversidade das espécies no estado de São Paulo. J Bras Patol Med Lab. 2005;41(1):1-8.

Urquhart DM, Hanna FS, Brennan SL, Wluka AE, Leder K, Cameron PA et al. Incidence and risk factors for deep surgical site infection after primary total hip arthroplasty: a systematic review. J Arthrop 2010; 25(8): 1216-22.

Ursi, E.S.; Galvão, C.M. Prevenção de lesões de pele no perioperatório: revisão integrativa da literatura. Rev. Latino-am Enfermagem, v.14, n.1, p.124-31, jan-fev, 2006.

Uslan DZ, Kowalski TJ, Wengenack NI, Virk A, Wilson JW. Skin and soft tissue infections due to rapidly growing mycobacteria: comparison of clinical features, treatment, and susceptibility. Archives of Dermatology. 2006;142:1287-92.

Vandepitte J, Dessmyter J, Gatti F. Mycobacteria, skins, and needles. Lancet. 1969;4:691.

Vijayaraghavan R, Chandrashekhar R, Sujatha Y, Belagavi CS. Hospital outbreak of atypical mycobacterial infection of port sites after laparoscopic surgery. J Hosp Infect. 2006;64(4):344-7. 
Wachtman LM, Milker AD, DongLing X, Curran EH, Mansfield KG. Colonization with nontuberculous mycobacteria is associated with positive tuberculin skin test reactions in the commom marmoset (Callithrix jacchus). Comparative Med 2011; 61(3): 278-54.

Wagner, D.; Young, L.S. Nontuberculous mycobacterial infections: a clinical review. Infection. 2004;32(5):257-70.

Wallace RJJr, Swenson JM, Silcox VA, Good RC, Tschen JA, Stone MS. Spectrum of disease due to rapidly growing mycobacteria. Rev Infect Dis. 1993a;5:657-79.

Wallace RJJr, Tranner D, Brennan PJ, Brow BA. Clinical trial of clarithromycin for cutaneous (disseminated) infection due to Mycobacterium chelonae. Annals of Internal Medicine. 1993b; 119:482-6.

Wallace RJJr, Brown BA, Griffith DE. Nosocomial outbreaks/pseudooutbreaks caused by nontuberculous mycobacteria. Annual Review of Microbiology. 1998;52:453-90.

Walsh SE, Maillard JY, Russell AD. Ortho-phthalaldehyde: a possible alternative to glutaraldehyde for high level disinfection. J Appl Microbiol. 1999;86(6):1039-46.

Wang SX, Yang CJ, Chen YC, Lay CJ, Tsai CC. Septic arthritis caused by Mycobacterium fortuitum and Mycobacterium abscessus in a prosthetic knee joint: case report and review of literature. Internal Medicine. 2011;50:222732.

Wayne LG, Kubica GP. The Mycobacteria. In Bergey's Manual of Systematic Bacteriology. Williams \& Wilkins, Baltimore, Sneath, P.H.A. (ed.). 1986;2:1435-57. 
Weigelt JA, Lipsky BA, Tabak YP, Derby KG, Kim M, Gupta V. Surgical site infections: Causative pathogens and associated outcomes. Am J Infect Control. 2010;38(2):112-20.

Whitehouse JD, Friedman ND, Kirkland KB, Richardson WJ, Sexton DJ. The impact of surgical site infection following orthopedic surgery at a community hospital and a university hospital: adverse quality of life, excess length of stay, and extra cost. Infect Control Hosp Epidemiol. 2002; 23(4):183-9.

Whittemore R, Knalf $\mathrm{K}$. The integrative review: updated methodology. Journal of Advanced Nursing. 2005;52(5):546-53.

Williams MM, Yakrus MA, Arduino MJ, Cooksey RC, Crane CB, Banerjee SN, Hilborn ED, Donlan RM. Structural analysis of biofilm formation by rapidly and slowly growing nontuberculous Mycobacteria. Appl Environ Microbiol 2009; 75(7):2091-8.

Winthrop, K.L. et al. Epidemic and sporadic cases of nontuberculous mycobacterial keratitis associated with laser in situ keratomileusis. Am J Ophthalmol 2003;135: 223-4.

Wright GD. Antibiotic resistance in the environment: a link to the clinic? Curr Opin Microbiol. 2010;13(5):589-94.

Wong TC, Chan WF, Tsang WI, Yeung SH, Ip Fk. Mycobacterium farcinogenes infection after total hip arthroplasty. The Journal of Arthroplasty. 2005;5:684-7.

Yew W, Wong P, Woo H, Yip C, Chan C, Cheng F. Characterization of Mycobacterium fortuitum isolates from sternotomy wounds by antimicrobial susceptibilities, plasmid profils, and ribosomal ribonucleic acid gene restriction patterns. Diagn Microbiol Infect Dis. 1993;17:111-117. 
Yinkey LM, Halsey ES, Lloyd BA. Successful Tigecycline Combination Therapy for Mycobacterium abscessus Infection of a Total Hip Arthroplasty. Infectious Diseases in Clinical Practice. 2010;18:269-70.

Zhibang, Y. et al. Large-scale outbreak of infection with Mycobacterium chelonae subsp. abcessus after injection Penicillin. J Clin. Microbiol. 2002;40(7):2626-28. 


\section{REFERÊNCIAS DOS ARTIGOS ANALISADOS}

Badelon, O.; David, H.; Meyer, L.; Radault, A.; Zucman, J. Suppurations à Mycobacterium fortuitum après prothèse totale de hanche. Revue de Chirurgie Orthopédique. 1979;6:39-43.

Bergogne-Berezin, E.; Nouhouayi, A.; Pierre, J. Suppuration sur prothèse de hanche a Mycobacatrium chelonei. Revue Française des Maladies Respiratories. 1976;4: 211-2.

Booth, J.E.; Jacobson, J.A.; Kurrus, T.A.; Edwards, T.W. Infection of prosthetic artroplasty by Mycobacterium fortuitum. The Journal of Bone and Joint Surgery. 1979;61: 300-2.

Cheung, I.; Wilson, A. Mycobacterium fortuitum infection following total knee arthroplasty: A case report and literature review. The Knee. 2008;15:61 - 3.

Cornelius, L.; Reddix, R.; Burchett, C.; Bond, G.; Fader, R. Cluster of Mycobacterium fortuitum prosthetic joint infections. Journal of Surgical Orthopaedic Advances. 2007;16:196-8.

Eid, A.J.; Berbari, E.F.; Sai, I.G.; Wengenack, N.L.; Osmon, D.R.; Razonable, R.R. Prosthetic Joint Infection Due to Rapidly Growing Mycobacteria: Report of 8 Cases and Review of the Literature. Clinical Infectious Diseases. 2007;45:687-94.

Ferguson, D.D.; Gershman, K.; Jensen, B.; Arduino, M.J.; Yakrus, M.A.; Cooksey, R.C.; Srinivasan, A. Mycobacterium goodi infections associated with surgical implants at Colorado hospital. Emerging Infectious Diseases. 2004;10:1868-71. 
Hasegawa, T.; Watanabe, R.; Hayashi, K.; Inufusa, A.; Nakagawa, H. Postoperative osteomyelitis due to Mycobacterium fortuitum. Archives Orthopaedic and Trauma Surgery. 1992;111:178-80.

Herold, R.C.; Lotke, P.A.; MacGregor, R.R. Prosthetic joint infections secondary to rapidly growing Mycobacterium fortuitum. Clinical Orthopaedics and Related Research. 1967;183-6.

Hetsroni, I.; Rosenberg, H.; Grimm, P.; Marx, R.G. Mycobacterium fortuitum infection following patellar tendon repair. Journal of Bone and Joint Surgery. 2010;92:1254-6.

Horadam, V.W,; Smilack, J.D.; Smith, E.C. Mycobacterium fortuitum infection after total hip replacement. South Medical Journal. 1982;75:244-6.

Jacoby, S.M.; Sivalingam, J.J.; Raikin, S.M. Mycobacterium fortuitum Infection Following Primary Achilles Tendon Debridement with Flexor Hallucis Longus Augmentation: A Case Report. 2008;29:538-41.

Moerman, J.; Vandepitte, J.; Corbeel, L.; Coppens, N.; Mannaerts, R.; Vanhandenhove, I.; Van den Broeck, H. latrogenic infections caused by the Mycobacterium fortuitum - chelonei complex. Acta Clinica Belgica. 1985;40:92-8.

Oh, H.L.; Chen, D.B.; Seeto, B.G.; Macdessi, S.J. Mycobacterium fortuitum infection after anterior cruciate ligament reconstruction using a polylactic acid bioabsorbable screw: Case report. 2009;211:203 - 33 .

Porat, M.D.; Austin, M.S. Bilateral Knee Periprosthetic Infection with Mycobacterium fortuitum. The Journal of Arthroplasty. 2008;23:787-9.

Pring M, Eckhoff DG. Mycobacterium chelonae infection following a total knee arthroplasty. The Journal of Arthroplasty. 1996;11:115-6. 
Pulcini, C.; Vandenbussche, E.; Podglajen, I.; Sougakoff, W.; Truffot-Pernot, C.; Buu-Hoï, A.; Varon, E.; Mainardi, J.L. Hip Prosthesis Infection Due to Mycobacterium wolinskyi. Journal of Clinical Microbiology. 2006;44:3463 - 4.

Saccente, M. Mycobacterium fortuitum group periprosthetic joint infection. Scandinavian Journal of Infectious Diseases. 2005;737-9.

Yinkey, L.M.; Halsey, E.S.; Lloyd, B.A. successful tigecycline combination therapy for Mycobacterium abscessus infection of a total hip arthroplasty. Infectious Diseases in Clinical Practice. 2010;18:269-70.

Wang, S.X.; Yang, C.J.; Chen, Y.C.; Lay, C.J.; Tsai, C.C. Septic arthritis caused by Mycobacterium fortuitum and Mycobacterium abscessus in a prosthetic knee joint: Case report and review of literature. Internal Medicine. 2011;50:2227-32.

Wong, T.C.; Chan, W.F.; Tsang, W.L.; Yeung, S.H.; Ip, F.K. Mycobacterium farcinogenes Infection After Total Hip Arthroplasty. The Journal of Arthroplasty. 2005;20:684-7. 


\section{APÊNDICES}

APÊNDICE A-

Quadro 1 - Instrumento para coleta de dados

1.Identificação do artigo original

\begin{tabular}{|l|l|}
\hline Título do artigo & \\
\hline Título do periódico & \\
\hline Autores & \\
\hline Revista & \\
\hline País & \\
\hline Idioma & \\
\hline Ano de publicação & \\
\hline Portal & \\
\hline
\end{tabular}

2.Características metodológicas do estudo

\begin{tabular}{|l|l|}
\hline 1. Tipo de estudo & ( ) coorte \\
& ( ) caso controle \\
& ( ) transversal \\
& ( ) estudo de caso \\
& ( ) revisão de literatura \\
( ) relato de experiência \\
( ) outros qual?
\end{tabular}




\begin{tabular}{|c|c|}
\hline & 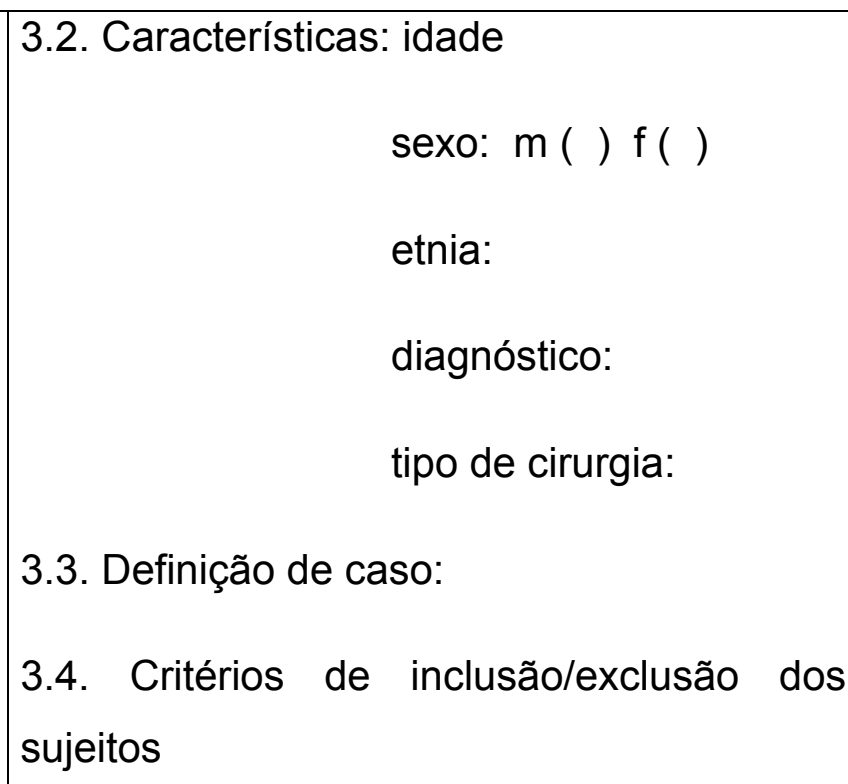 \\
\hline 4. Local do estudo & \\
\hline 5. Período do estudo & \\
\hline 6. Agente & $\begin{array}{l}\text { 6.1. Foi isolado ( ) sim ( ) não } \\
\text { 6.2. Formas de isolamento e identificação: } \\
\text { 6.3. Perfil de sensibilidade: }\end{array}$ \\
\hline 7. Classificação do agente & $\begin{array}{l}\text { ( ) potencialmente patogênico } \\
\text { ( ) raramente patogênico } \\
\text { ( ) crescimento lento } \\
\text { ( ) crescimento rápido }\end{array}$ \\
\hline 8. Característica das infecções & $\begin{array}{l}\text { 8.1. Sítio de infecção: } \\
\text { 8.2. Fatores de risco: }\end{array}$ \\
\hline $\begin{array}{|lcc|}9 . & \text { Fonte } & \text { presumível } \\
\text { infecção } & & \\
\end{array}$ & \\
\hline
\end{tabular}




\begin{tabular}{|c|c|}
\hline 10. Taxas de infecção & $\begin{array}{l}\text { ( ) prevalência ( ) incidência } \\
\text { Numerador: } \\
\text { Denominador: }\end{array}$ \\
\hline 11. Surto & ( ) sim ( ) não \\
\hline 12. Número de casos & \\
\hline 13. Tipo de procedimento & \\
\hline 14. Desfecho & Óbito ( ) sim ( ) não \\
\hline $\begin{array}{ll}15 . \quad \text { Análise } & \text { (quando } \\
\text { pertinente) } & \end{array}$ & $\begin{array}{l}\text { 13.1 Tratamento estatístico: } \\
\text { 13.2 Nível de significância: }\end{array}$ \\
\hline 16. Implicações & $\begin{array}{l}\text { 14.1. As conclusões são justificadas com } \\
\text { bases nos resultados: } \\
\text { 14.2. Quais são as recomendações dos } \\
\text { autores: }\end{array}$ \\
\hline 17. Particularidades & \\
\hline 18. Conclusão & \\
\hline
\end{tabular}




\section{APÊNDICE B-}

Quadro 1 - Síntese do Estudo 1 - Estudo de Caso. São Paulo, 2012.

\section{Estudo 1 - E1}

\section{TÍTULO DO ARTIGO:}

Supuração de prótese de quadril por Mycobacterium chelonae.

\section{AUTOR:}

Bergogne-Berezin, E.; Nouhouayi, A.; Pierre, J.

\section{PERIÓDICO:}

Revue Française des Maladies Respiratoires, v.4, p.211-2.

\begin{tabular}{l|l|l} 
ANO: 1976 & PAÍS: França & IDIOMA: Francês
\end{tabular}

\section{NÚMERO DE CASOS:}

Uma paciente de 62 anos de idade.

TIPO DE PROCEDIMENTO:

Artroplastia total do quadril direito.

\section{AGENTE ISOLADO:}

Mycobacterium chelonae.

\section{FONTES SUSPEITAS DA CONTAMINAÇÃO:}

Origem iatrogênica - não confirmada.

\section{OBJETIVO:}

Relatar um caso de supuração de prótese de quadril por Mycobacterium chelonae.

\section{CONCLUSÃO:}

A hipótese provável é de que M.chelonae é o agente da supuração podendo ter origem iatrogênica. 
Quadro 2 - Síntese do Estudo 2 - Estudo de Caso. São Paulo, 2012.

\begin{tabular}{|l|}
\hline \multicolumn{1}{|c|}{ Estudo 2 - E2 } \\
\hline TíTULO DO ARTIGO: \\
Infecção de artroplastia prostética por Mycobacterium fortuitum.
\end{tabular}

\section{AUTOR:}

Booth, J.E.; Jacobson, J.A.; Kurrus, T.A.; Edwards, T.W.

\section{PERIÓDICO:}

The Journal of Bone and Joint Surgery, v.61-A, n.2, p.300-2.

\begin{tabular}{|c|c|c|}
\hline ANO: 1979 & PAÍS: EUA & IDIOMA: Inglês \\
\hline \multicolumn{3}{|c|}{ NÚMERO DE CASOS: } \\
\hline
\end{tabular}

\section{TIPO DE PROCEDIMENTO:}

C1: Prótese de joelho direito.

C2: Prótese Silastic no trapézio do punho direito.

\section{AGENTE ISOLADO:}

Mycobacterium fortuitum.

\section{FONTES SUSPEITAS DA CONTAMINAÇÃO:}

Hábito do médico residente de ortopedia presente nas cirurgias de utilizar a hidromassagem antes de operar - não confirmada.

\section{OBJETIVO:}

Descrever o curso e tratamento dos pacientes, e uma investigação epidemiológica de uma possível fonte comum da infecção de artroplastia prostética por Mycobacterium fortuitum.

\section{CONCLUSÃO:}

Esses casos apontam uma patogenicidade potencial para M.fortuitum associada com implantes prostéticos e sugerem que quando há abscessos ou infecções associados com implantes de materiais estranhos, a pesquisa de BAAR deve ser realizada e o laboratório tem que estar alertar para possibilidade de ser infecção por micobactérias atípicas, particularmente quando o método de Gram falha em revelar um patógeno típico. 
Quadro 3 - Síntese do Estudo 3 - Estudo de Caso. São Paulo, 2012.

\section{Estudo 3 - E3}

\section{TÍTULO DO ARTIGO:}

Supurações por Mycobacterium fortuitum após artroplastia total do quadril.

\section{AUTOR:}

Badelon, o.; David, H.; Meyer, L.; Radault, A.; Zucman, J.

\section{PERIÓDICO:}

Revue de Chirurgie Orthopédique et Réparatrice de I' Appariel Moteur, v.65, n.1, p.39-43.

\begin{tabular}{|c|c|c|}
\hline ANO: 1979 & PAís: França & IDIOMA: Francês \\
\hline
\end{tabular}
e um homem com 70 (C3) anos de idade.

\section{TIPO DE PROCEDIMENTO:}

C1: Prótese total de quadril bilateral;

C2: Prótese total de quadril bilateral;

C3: Prótese total de quadril direito.

\section{AGENTE ISOLADO:}

Mycobacterium fortuitum.

\section{FONTES SUSPEITAS DA CONTAMINAÇÃO:}

Não Relatado.

\section{OBJETIVO:}

Relatar 3 casos de septicemia por M.fortuitum.

\section{CONCLUSÃO:}

São necessários pré-requisitos para a identificação de micro-organismos que crescem em meios de cultura especiais e que podem ser confundidos com Mycobacterium tuberculosis. Esta característica explica por que, em alguns casos, o micro-organismo não pode ser detectado. Os antibióticos foram ineficazes, mas a condição geral do paciente não foi muito afetada. 
Quadro 4 - Síntese do Estudo 4 - Estudo de Caso. São Paulo, 2012.

\section{Estudo 4 - E4}

\section{TÍTULO DO ARTIGO:}

Infecção por Mycobacterium fortuitum após artroplastia total do quadril.

\section{AUTOR:}

Horadam, V.W,; Smilack, J.D.; Smith, E.C.

\section{PERIÓDICO:}

Southern Medical Journal, v.75, n.2, p.244-6.

\begin{tabular}{l|l|l} 
ANO: 1982 & PAÍS: EUA & IDIOMA: Inglês
\end{tabular}

\section{NÚMERO DE CASOS:}

Uma paciente de 78 anos de idade.

\section{TIPO DE PROCEDIMENTO:}

Substituição total de prótese de quadril bilateral.

\section{AGENTE ISOLADO:}

Mycobacterium fortuitum

\section{POSSÍVEL FONTE DE INFECÇÃO:}

Componentes da a prótese metálica e o cimento metilmetacrilato - não confirmada.

\section{OBJETIVO:}

Reportar um caso de infecção por Mycobacterium fortuitum após artroplastia total do quadril.

\section{CONCLUSÃO:}

As dificuldades no reconhecimento da infecção por Mycobacterium fortuitum, e em seu tratamento, são enfatizadas. 
Quadro 5 - Síntese do Estudo 5 - Estudo de Caso. São Paulo, 2012.

\section{Estudo 5 - E5}

\section{TÍTULO DO ARTIGO:}

Infecções iatrogênicas causadas pelo complexo Mycobacterium fortuitumchelonae.

\section{AUTOR:}

Moerman, J.; Vandepitte, J.; Corbeel, L.; Coppens, N.; Mannaerts, R.; Vanhandenhove, I.; Van den Broeck, $\mathrm{H}$.

\section{PERIÓDICO:}

Acta Clinica Belgica, v.40, n.2, p.92-8.

\begin{tabular}{l|l|l} 
ANO: 1985 & PAÍS: Bélgica & IDIOMA: Inglês
\end{tabular}

\section{NÚMERO DE CASOS:}

Um paciente de 77 anos de idade.

\section{TIPO DE PROCEDIMENTO:}

Inserção de prótese total no quadril.

\section{AGENTE(s) ISOLADO:}

Mycobacterium fortuitum.

\section{POSSÍVEL FONTE DE INFECÇÃO:}

Origem iatrogênica - não confirmada.

\section{OBJETIVO:}

Descrever um caso de infecções iatrogênicas causadas pelo complexo Mycobacterium fortuitum-chelonae.

\section{CONCLUSÃO:}

Embora M.fortuitum se desenvolveu em agar sangue comum, geralmente dentro de $48 \mathrm{~h}$, as cepas devem ser incubadas por muito mais tempo, antes que o pus de abscessos, de injeção ou supurações pós-operatório, sejam considerados estéreis. Além disso, esses micro-organismos podem ser confundidos com difiteróides ou contaminantes de pele. Sempre que a infecção estiver associada a implante de material estranho, principalmente quando o resultado do Gram falhar na identificação de bactérias piogênicas clássica ou quando apenas revelar cepas de difiteróides. Análise microbiológica deve ser solicitada e o laboratório tem que ser alertado para uma possibilidade de micobacteriose atípica. 
Quadro 6 - Síntese do Estudo 6 - Estudo de Caso. São Paulo, 2012.

\begin{tabular}{|l|}
\hline \multicolumn{1}{|c|}{ Estudo 6 - E6 } \\
\hline \multicolumn{1}{|c|}{$\begin{array}{l}\text { TíTULO DO ARTIGO: } \\
\text { Infecções secundárias em próteses de articulação por Mycobacterium } \\
\text { fortuitum de crescimento rápido. }\end{array}$} \\
\hline $\begin{array}{l}\text { AUTOR: } \\
\text { Herold, R.C.; Lotke, P.A.; MacGregor, R.R. }\end{array}$ \\
\hline $\begin{array}{l}\text { PERIÓDICO: } \\
\text { Clinical Orthopaedics and Related Research, n.216, p.183-6. }\end{array}$
\end{tabular}

\begin{tabular}{l|l|l|}
\hline ANO: 1987 & PAÍS: EUA & IDIOMA: Inglês \\
\hline NÚMERO DE CASOS: \\
Uma paciente de 30 anos de idade.
\end{tabular}

\section{TIPO DE PROCEDIMENTO:}

Artroplastia total de joelho.

\section{AGENTE ISOLADO:}

Mycobacterium fortuitum

\section{POSSÍVEL FONTE DE INFECÇÃO:}

Injeções de cortisona - não confirmada.

\section{OBJETIVO:}

Reportar um caso de infecções secundárias em próteses de articulação por Mycobacterium fortuitum e discutir suas implicações terapêuticas, além de apresenta uma revisão da literatura.

\section{CONCLUSÃO:}

Quando a infecção ocorre na fixação da prótese articular, o tratamento combina remoção da prótese e longo tempo de antibioticoterapia, isso oferece a melhor esperança de cura. Subsequente revisão de prótese deve ser considerada com cautela e somente após com análise microbiológica negativa, realizar a suspensão da antibioticoterapia. 
Quadro 7 - Síntese do Estudo 7 - Estudo de Caso. São Paulo, 2012.

\section{Estudo 7 - E7}

\section{TÍTULO DO ARTIGO:}

Osteomielite pós-operatória por Mycobacterium fortuitum.

\section{AUTOR:}

Hasegawa, T.; Watanabe, R.; Hayashi, K.; Inufusa, A.; Nakagawa, H.

\section{PERIÓDICO:}

Archives Orthopaedic and Trauma Surgery, v.111, n.3, p.178-80.

\begin{tabular}{l|l|l} 
ANO: 1992 & PAÍS: Japão & IDIOMA: Inglês
\end{tabular}

\section{NÚMERO DE CASOS:}

Um paciente de 17 anos de idade.

\section{TIPO DE PROCEDIMENTO:}

Fixação intramedular por haste Kuntsher.

\section{AGENTE ISOLADO:}

Mycobacterium fortuitum.

\section{POSSÍVEL FONTE DE INFECÇÃO:}

Não Relatada.

\section{OBJETIVO:}

Reportar um caso raro de osteomielite pós-operatória por Mycobacterium fortuitum, que foi tratada com sucesso.

\section{CONCLUSÃO:}

Suspeita-se de infecção por micobacteria atípica quando uma ferida pósoperatório não consegue cicatrizar normalmente e quando as análises microbiológicas de rotina derem resultados negativos. Procedimentos cirúrgicos, tais como, extração de um implante e debridamento, deve continuar a ser o tratamento de escolha. Entretanto, a combinação de antibioticoterapia com a interleucina 2 (um modificador de resposta biológica), mostrou-se eficaz, neste caso. 
Quadro 8 - Síntese do Estudo 8 - Estudo de Caso. São Paulo, 2012.

\section{Estudo 8 - E8}

\section{TÍTULO DO ARTIGO:}

Infecção por Mycobacterium chelonae após uma artroplastia total de joelho.

\section{AUTOR:}

Pring, M.; Eckhoff, D.G.

\section{PERIÓDICO:}

The Journal of Arthroplasty, v.11, p.115-6.

\begin{tabular}{l|l|l} 
ANO: 1996 & PAÍS: EUA & IDIOMA: Inglês
\end{tabular}

\section{NÚMERO DE CASOS:}

Uma paciente de 66 anos de idade.

\section{TIPO DE PROCEDIMENTO:}

Artroplastia total de joelho.

\section{AGENTE ISOLADO:}

Mycobacterium chelonae.

\section{POSSÍVEL FONTE DE INFECÇÃO:}

Não Relatada

\section{OBJETIVO:}

Relatar detalhes do diagnóstico e do tratamento, do primeiro caso bem sucedido, de uma infecção por M.chelonae, após uma artroplastia total do joelho.

\section{CONCLUSÃO:}

Quando a infecção após artroplastia total do joelho é evidente, mas a análise microbiológica padrão der negativa, a infecção por micobactéria atípica deve ser considerada. Mycobacterium chelonae não se desenvolve no tempo de incubação normalmente colocado, assim resultados falsos negativos são comuns. Uma vez identificados, M.chelonae é difícil de tratar devido à sua resistência a terapias com antibióticos padrões. 
Quadro 9 - Síntese do Estudo 9 - Estudo de Caso. São Paulo, 2012.

\begin{tabular}{|l|}
\hline Estudo 9 - E9 \\
\hline
\end{tabular}

\section{TÍTULO DO ARTIGO:}

Infecções por Mycobacterium goodii associados com implantes cirúrgicos no hospital de Colorado.

\section{AUTOR:}

Ferguson, D.D.; Gershman, K.; Jensen, B.; Arduino, M.J.; Yakrus, M.A.; Cooksey, R.C.; Srinivasan, A.

\section{PERIÓDICO:}

Emerging Infectious Diseases, v.10, n.10, p.1868-71.

\begin{tabular}{l|l|l}
\hline ANO: 2004 & PAÍS: EUA & IDIOMA: Inglês \\
\hline NÚMERO DE CASOS: &
\end{tabular}

Dois casos, sendo um caso com um homem (C1) de 64 anos de idade e outro com uma mulher (C3) de 75 anos de idade.

\section{TIPO DE PROCEDIMENTO:}

C1 - Artroplastia total do quadril esquerdo.

C3 - Substituição total do joelho esquerdo.

\section{AGENTE ISOLADO:}

Mycobacterium goodii.

\section{POSSÍVEL FONTE DE INFECÇÃO:}

Não Relatada

\section{OBJETIVO:}

Relatar um resumo das investigações sobre o primeiro surto por M.goodii.

\section{CONCLUSÃO:}

Pesquisas são necessárias para determinar os antissépticos e desinfetantes efetivos contra M.goodii. Médicos deveriam estar cientes da associação de micobactéria não tuberculoses com infecção de sítio cirúrgico e considerar testes para miciobactérias, quando na técnica de Gram mostrar número considerável de leucócitos, mesmo que análises microbiológicas da ferida derem negativas. 
Quadro 10 - Síntese do Estudo 10 - Estudo de Caso. São Paulo, 2012.

\section{Estudo 10 - E10}

\section{TÍTULO DO ARTIGO:}

Infecção por Mycobacterium farcinogenes após artroplastia total do quadril.

\section{AUTOR:}

Wong, T.C.; Chan, W.F.; Tsang, W.L.; Yeung, S.H.; Ip, F.K.

\section{PERIÓDICO:}

The Journal of Arthroplasty, v.20, n.5, p.684-7.

\begin{tabular}{l|l|l} 
ANO: 2005 & PAÍS: China & IDIOMA: Inglês
\end{tabular}

\section{NÚMERO DE CASOS:}

Uma paciente de 67 anos de idade.

\section{TIPO DE PROCEDIMENTO:}

Artroplastia total de quadril esquerdo.

\section{AGENTE ISOLADO:}

Mycobacterium farcinogenes.

\section{POSSÍVEL FONTE DE INFECÇÃO:}

Não Relatada

\section{OBJETIVO:}

Relatar um caso bem sucedido no tratamento da infecção por Mycobacterium farcinogenes após artroplastia total do quadril.

\section{CONCLUSÃO:}

É importante manter um alto índice de suspeita de infecção por micobactéria atípica, particularmente quando os resultados de análises microbiológica padrão são negativas, apesar de fortes evidências clínicas de infecção da prótese. 
Quadro 11 - Síntese do Estudo 11 - Estudo de Caso. São Paulo, 2012.

\begin{tabular}{|l|}
\hline \multicolumn{1}{|c|}{ Estudo $11 \mathrm{E}-11$} \\
\hline $\begin{array}{l}\text { TíTULO DO ARTIGO: } \\
\text { Infecção articular periprostetica pelo grupo Mycobacterium fortuitum. }\end{array}$ \\
\hline $\begin{array}{l}\text { AUTOR: } \\
\text { Saccente, M. }\end{array}$
\end{tabular}

\section{PERIÓDICO:}

Scandinavian Journal of Infectious Diseases, v.38, n.8, p.737-9.

\begin{tabular}{l|l|l|} 
ANO: 2005 & PAÍS: EUA & IDIOMA: Inglês \\
\hline
\end{tabular}

NÚMERO DE CASOS:

Uma paciente com 44 anos de idade.

\section{TIPO DE PROCEDIMENTO:}

Artroplastia total bilateral de joelho.

\section{AGENTE ISOLADO:}

Mycobacterium fortuitum

\section{POSSÍVEL FONTE DE INFECÇÃO:}

Não Relatada

\section{OBJETIVO:}

Relatar o primeiro caso de Infecção articular periprostetica pelo grupo M.fortuitum que foi tratado com sucesso

\section{CONCLUSÃO:}

Infecção profunda de prótese articular é uma complicação infrequente, mas devastadora, de substituição total da articulação. O diagnóstico de infecção periprostética pelo grupo M.fortuitum foi tardia pois este micro-organismo patogênico incomum não foi considerado no início do curso da doença, apesar das análises microbioanas de rotina darem negativas e pela falta de resposta à terapia antibiótica empírica dirigido contra bactérias mais comuns. Depois da identificação do grupo M.fortuitum, a intervenção cirúrgica e terapêutica de combinação antimicrobiana baseada em dados de sensibilidade in vitro obteve a cura microbiologicamente comprovada. 
Quadro 12 - Síntese do Estudo 12 - Estudo de Caso. São Paulo, 2012.

\section{Estudo 12}

\section{TÍTULO DO ARTIGO:}

Infecção da prótese de quadril por Mycobacterium wolinskyi.

\section{AUTOR:}

Pulcini, C.; Vandenbussche, E.; Podglajen, I.; Sougakoff, W.; Truffot-Pernot, C.; Buu-Hoï, A.; Varon, E.; Mainardi, J.L.

\section{PERIÓDICO:}

Journal of Clinical Microbiology, v.44, n.9, p.3463-4.

\begin{tabular}{l|l|l}
\hline ANO: 2006 & PAÍS: França & IDIOMA: Inglês
\end{tabular}

\section{NÚMERO DE CASOS:}

Uma paciente de 83 anos de idade.

\section{TIPO DE PROCEDIMENTO:}

Artroplastia total de quadril.

\section{AGENTE ISOLADO:}

Mycobacterium wolinskyi.;

\section{POSSÍVEL FONTE DE INFECÇÃO:}

Não Relatada

\section{OBJETIVO:}

Apresentar o primeiro caso de infecção da prótese articular curada com a combinação de cirurgia e antibioticoterapia prolongada.

\section{CONCLUSÃO:}

Cirurgia combinada ao tratamento com antibiótico levou à cura da infecção. Em geral, curas de osteomielite, devido a MNT, tem sido alcançadas com drenagem cirúrgica e remoção da prótese, combinada com antibioticoterapia, por um período mínimo de 6 meses, de acordo com suscetibilidades in vitro do agente. De acordo com este caso, novas fluoroquinolonas, como a moxifloxacina, são promissoras para o tratamento deste tipo de infecção. 
Quadro 13 - Síntese do Estudo 13 - Estudo de Caso. São Paulo, 2012.

\begin{tabular}{|l|}
\hline \multicolumn{1}{|c|}{ Estudo 13 - E13 } \\
\hline $\begin{array}{l}\text { TÍTULO DO ARTIGO: } \\
\text { Infecção de articulação prostética por um aglomerado de Mycobacterium } \\
\text { fortuitum. }\end{array}$ \\
AUTOR: \\
Cornelius, L.; Reddix, R.; Burchett, C.; Bond, G.; Fader, R. \\
\hline $\begin{array}{l}\text { PERIÓDICO: } \\
\text { Journal of Surgical Orthopaedic Advances, v.16, n.4, p.196-8. }\end{array}$
\end{tabular}

\begin{tabular}{|l|l|l|}
\hline ANO: 2007 & PAÍS: EUA & IDIOMA: Inglês \\
\hline \multicolumn{2}{|l}{ NÚMERO DE CASOS: }
\end{tabular}

Um total de 3 pacientes, sendo todas mulheres, com idades de 70 (C1), 60 (C2) e 50 (C3).

\section{TIPO DE PROCEDIMENTO:}

C1 - Artroplastia total de joelho.

C2 - Artroplastia total de joelho.

C3 - Artroplastia total de quadril direito.

\section{AGENTE ISOLADO:}

Mycobacterium fortuitum

\section{POSSÍVEL FONTE DE INFECÇÃO:}

Sistema de ar condicionado da sala operatória e solução de imersão para enxague da prótese - não confirmadas.

\section{OBJETIVO:}

Reportar 3 casos de Infecção de articulação prostética por Mycobacterium fortuitum.

\section{CONCLUSÃO:}

Depois de se investigar o meio ambiente, nenhuma fonte comum foi revelada como sendo a origem de M.fortuitum, nestes casos. Mesmo as cepas (dos três casos) tendo o mesmo perfil genético, uma fonte comum não pôde ser identificada, o que indica a natureza esporádica e espontânea deste micro-organismo. 
Quadro 14 - Síntese do Estudo 14 - Estudo Retrospectivo. São Paulo, 2012.

\section{Estudo 14 - E14}

\section{TÍTULO DO ARTIGO:}

Infecção de articulação prostética por micobactérias de crescimento rápido: Relato de 8 casos e revisão da literatura

AUTOR:

Eid, A.J.; Berbari, E.F.; Sai, I.G.; Wengenack, N.L.; Osmon, D.R.; Razonable, R.R.

PERIÓDICO:

Clinical Infectious Diseases, v.45, p.687-94.

\begin{tabular}{l|l|l} 
ANO: 2007 & PAís: EUa & IDIOMA: Inglês
\end{tabular}

\section{NÚMERO DE CASOS:}

Um total de 8 pacientes sendo 4 homem e 4 mulheres, a idade média dos pacientes foi de 73 anos (faixa de 60-87 anos).

\section{TIPO DE PROCEDIMENTO:}

C1, C2, C3, C4, C5, C6, e C7 - Artroplastia total de joelho.

C8 - Artroplastia total de quadril.

C7 - Artroplastia de cotovelo.

\section{AGENTES ISOLADOS:}

Mycobacterium chelonae, Mycobacterium abscessus, Mycobacterium fortuitum e Mycobacterium smegmatis.

\section{POSSÍVEL FONTE DE INFECÇÃO:}

Não Relatada

\section{OBJETIVO:}

Fornecer informações adicionais sobre as características e resultados de Infecção de articulação prostética por micobactérias de crescimento rápido e relatar um estudo grande de pessoas que foram tratados em nossa instituição e os casos de revisão da literatura.

\section{CONCLUSÃO:}

Micobactérias de crescimento rápido são uma causa rara de Infecção de articulação prostética, que deve ser suspeitada em pacientes com resultados negativos, na análise microbiológica de rotina. A combinação de artroplastia de ressecção e terapia antimicrobiana é a abordagem preferida. No entanto, em casos que envolvam remoção de componentes prostéticos, a infecção por micobactérias de crescimento rápido pode ser suprimida ao longo da vida com uso de antibioticoterapia eficaz. 
Quadro 15 - Síntese do Estudo 15 - Estudo de Caso. São Paulo, 2012.

\section{Estudo 15 - E15}

\section{TÍTULO DO ARTIGO:}

Infecção periprostetica bilateral de joelho por Mycobacterium fortuitum.

\section{AUTOR:}

Porat, M.D.; Austin, M.S.

\section{PERIÓDICO:}

The Journal of Arthroplasty, v.23, n.5, p.787-9.

\begin{tabular}{l|l|l|} 
ANO: 2008 & PAÍS: EUA & IDIOMA: Inglês \\
\hline NÚMERO DE CASOS: &
\end{tabular}

Um paciente de 68 anos de idade.

\section{TIPO DE PROCEDIMENTO:}

Cirurgia de joelho, quadril e cotovelo

\section{AGENTE ISOLADO:}

Mycobacterium fortuitum.

\section{POSSÍVEL FONTE DE INFECÇÃO:}

Não Relatada

\section{OBJETIVO:}

Relatar o primeiro caso conhecido de infecção bilateral envolvendo Mycobacterium fortuitum, após a artroplastia total do joelho.

\section{CONCLUSÃO:}

O diagnóstico de infecção periprostética por micobactéria deve ser considerado em pacientes imunocomprometidos e em pacientes com análise microbiológica negativas, apesar da evidência clínica de infecção. Uma vez diagnosticado, a conduta padrão é a ressecção da artroplastia e o tratamento com antibiótico por longo tempo. Este caso demonstra, que infecção por M.fortuitum pode ser tratado com sucesso, em curto prazo, com terapia supressiva crônica de antibióticos em um paciente cirúrgico debilitado. Os critérios aceitos para antibioticoterapia supressiva crônica (microorganismo com baixa virulência que é suscetível a um agente com toxicidade relativamente baixa em um paciente com alto risco cirúrgico) devem ser rigorosamente respeitados. O paciente deveria ser seguido de perto para sinais sistêmicos de bacteriemia ou complicações dos antibióticos, por um infectologista. 
Quadro 16 - Síntese do Estudo 16 - Estudo de Caso. São Paulo, 2012.

\begin{tabular}{|c|c|c|}
\hline \multicolumn{3}{|c|}{ Estudo 16 - E16 } \\
\hline \multicolumn{3}{|c|}{$\begin{array}{l}\text { TíTULO DO ARTIGO: } \\
\text { Infecção por Mycobacterium fortuitum após artroplastia total de joelho: } \\
\text { Um relato de caso e revisão da literatura. }\end{array}$} \\
\hline \multicolumn{3}{|c|}{ AUTOR: } \\
\hline \multicolumn{3}{|c|}{$\begin{array}{l}\text { PERIÓDICO: } \\
\text { The Knee, v.15, p.61-3. }\end{array}$} \\
\hline ANO: 2008 & PAÍS: Autrália & IDIOMA: Inglês \\
\hline \multicolumn{3}{|c|}{$\begin{array}{l}\text { NÚMERO DE CASOS: } \\
\text { Um paciente de } 68 \text { anos de idade. }\end{array}$} \\
\hline \multicolumn{3}{|c|}{$\begin{array}{l}\text { TIPO DE PROCEDIMENTO: } \\
\text { Artroplastia total de joelho }\end{array}$} \\
\hline \multicolumn{3}{|c|}{$\begin{array}{l}\text { AGENTE ISOLADO: } \\
\text { Mycobacterium fortuitum. }\end{array}$} \\
\hline \multicolumn{3}{|c|}{$\begin{array}{l}\text { POSSÍVEL FONTE DE INFECÇÃO: } \\
\text { Não Relatada }\end{array}$} \\
\hline \multicolumn{3}{|c|}{$\begin{array}{l}\text { OBJETIVO: } \\
\text { Relatar um caso de infecção por Mycobacterium fortuitum após artroplastia } \\
\text { total de joelho e seu tratamento. }\end{array}$} \\
\hline \multicolumn{3}{|c|}{$\begin{array}{l}\text { CONCLUSÃO: } \\
\text { A atividade in vivo de meropenem e moxifloxacina é clinicamente eficaz } \\
\text { contra M.fortuitum após artroplastia total de joelho, quando combinados com } \\
\text { tratamento cirúrgico. }\end{array}$} \\
\hline
\end{tabular}


Quadro 17 - Síntese do Estudo 17 - Estudo de Caso. São Paulo, 2012.

\section{Estudo 17 - E17}

\section{TÍTULO DO ARTIGO:}

Infecção por Mycobacterium fortuitum após debridamento primário do tendão de Aquiles com aumento do flexor longo do hálux: Relato de Caso

\section{AUTOR:}

Jacoby, S.M.; Sivalingam, J.J.; Raikin, S.M.

\section{PERIÓDICO:}

Foot \& Ankle International, v.29, n.5, p.538-41.

\begin{tabular}{l|l|l|} 
ANO: 2008 & PAÍS: EUA & IDIOMA: Inglês
\end{tabular}

\section{NÚMERO DE CASOS:}

Um paciente de 55 anos de idade.

\section{TIPO DE PROCEDIMENTO:}

Correção cirúrgica, que incluía debridamento do tendão de Aquiles, flexor longo do hálux, com transferência do tendão do calcâneo e ostectomia.

\section{AGENTE ISOLADO:}

Mycobacterium fortuitum.

\section{POSSÍVEL FONTE DE INFECÇÃO:}

Sabão na água para a imersão do pé - não confirmada.

\section{OBJETIVO:}

Apresentar um caso raro de infecção por Mycobacterium fortuitum após uma cirurgia no tendão de Aquiles em um paciente não-imunocomprometidos.

\section{CONCLUSÃO:}

Fundamental para a identificação e tratamento final deste patógeno, em particular, é a utilização de análises microbiológicas apropriadas no intraoperatório. Além disso, repitir os procedimentos de irrigação e debridamento, juntamente com a remoção de materiais estranhos e o uso adequado de antibioticoterapia prolongada podem resultar em um tratamento a longo prazo, bem sucedido. 
Quadro 18 - Síntese do Estudo 18 - Estudo de Caso. São Paulo, 2012.

\section{Estudo 18 - E18}

\section{TÍTULO DO ARTIGO:}

Infecção por Mycobacterium fortuitum após a reconstrução do ligamento cruzado anterior usando um parafuso de ácido polilático bioabsorvível: Relato de caso.

\section{AUTOR:}

Oh, H.L.; Chen, D.B.; Seeto, B.G.; Macdessi, S.J.

\section{PERIÓDICO:}

The Knee, v.17, n.2, p.176-8.

\begin{tabular}{l|l|l} 
ANO: 2010 & PAÍS: Autrália & IDIOMA: Inglês \\
\hline
\end{tabular}

\section{NÚMERO DE CASOS:}

Uma paciente de 15 anos de idade.

\section{TIPO DE PROCEDIMENTO:}

Reconstrução do ligamento cruzado anterior.

\section{AGENTE ISOLADO:}

Mycobacterium fortuitum.

\section{POSSÍVEL FONTE DE INFECÇÃO:}

Parafuso bioabsorvível utilizado na cirurgia - não confirmada.

\section{OBJETIVO:}

Destacar a apresentação clínica deste caso e enfatizar a necessidade de excluir a infecção periprostetica por micobactérias.

\section{CONCLUSÃO:}

Em todos os casos de feridas e abcessos, associados com implantes bioabsorvíveis, as amostras devem ser enviadas para a análise micobacteriana, em adição à análise microbiológica de rotina. As alterações inflamatórias com análise microbiológica negativas, só devem ser atribuída à reação ao parafuso bioabsorvível, se a infecção por micobacterias atípica também for excluída. 
Quadro 19 - Síntese do Estudo 19 - Estudo de Caso. São Paulo, 2012.

\section{Estudo 19 - E19}

\section{TÍTULO DO ARTIGO:}

Infecção por Mycobacterium fortuitum após o reparo do tendão patelar.

\section{AUTOR:}

Hetsroni, I.; Rosenberg, H.; Grimm, P.; Marx, R.G.

\section{PERIÓDICO:}

Journal of Bone and Joint Surgery, v.92, n.5, p.1254-6.

\begin{tabular}{l|l|l} 
ANO: 2010 & PAÍS: EUA & IDIOMA: Inglês
\end{tabular}

\section{NÚMERO DE CASOS:}

Um paciente de 40 anos de idade.

\section{TIPO DE PROCEDIMENTO:}

Reparo do tendão patelar

\section{AGENTE ISOLADO:}

Mycobacterium fortuitum.

\section{POSSÍVEL FONTE DE INFECÇÃO:}

Não Relatada

\section{OBJETIVO:}

Relatar o caso de um homem saudável que foi submetido ao reparo do tendão patelar que foi complicada pela infecção por Mycobacterium fortuitum.

\section{CONCLUSÃO:}

Importância da consciência do cirurgião sobre este patógeno, a fim de facilitar o diagnóstico preciso e tratamento adequado. 
Quadro 20 - Síntese do Estudo 20 - Estudo de Caso. São Paulo, 2012.

\begin{tabular}{|l|}
\hline \multicolumn{1}{|c|}{ Estudo 20 - E20 } \\
\hline $\begin{array}{l}\text { TÍTULO DO ARTIGO: } \\
\text { Tratamento bem sucedido com tigeciclina combinada para infecção de } \\
\text { artroplastia total do quadril por Mycobacterium abscessus. }\end{array}$ \\
AUTOR: \\
Yinkey, L.M.; Halsey, E.S.; Lloyd, B.A. \\
\hline $\begin{array}{l}\text { PERIÓDICO: } \\
\text { Infectious Diseases in Clinical Practice, v.18, n.4 p.269-70. }\end{array}$
\end{tabular}

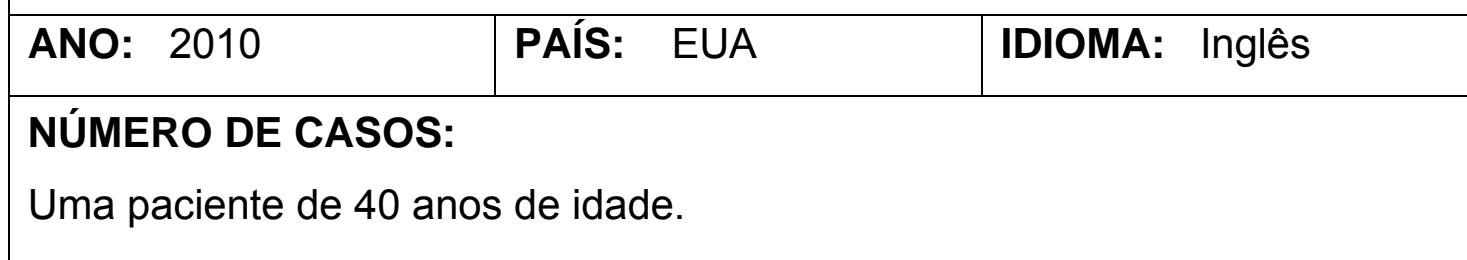

\section{TIPO DE PROCEDIMENTO:}

Artroplastia total de quadril esquerdo.

\section{AGENTE ISOLADO:}

Mycobacterium abscessus.

\section{POSSÍVEL FONTE DE INFECÇÃO:}

Não Relatada

\section{OBJETIVO:}

Apresentar o primeiro caso que utilizou a tigeciclina combinada para o tratamento da bactéria de crescimento rápido em infecções de prótese de quadril.

\section{CONCLUSÃO:}

Este caso reporta o primeiro tratamento bem sucedido de infecção prostética articular por Mycobacterium abscessus, com utilização de tigeciclina. Embora a tigeciclina não seja o único responsável pelo sucesso da erradicação do M.abscessus, acredita-se que é um componente importante do tratamento. 
Quadro 21 - Síntese do Estudo 21 - Estudo de Caso. São Paulo, 2012.

\section{Estudo 21 - E21}

\section{TÍTULO DO ARTIGO:}

Artrite séptica causada por Mycobacterium abscessus e Mycobacterium fortuitum em prótese de joelho: Relato de Caso e Revisão da Literatura

\section{AUTOR:}

Wang, S.X.; Yang, C.J.; Chen, Y.C.; Lay, C.J.; Tsai, C.C.

\section{PERIÓDICO:}

Internal Medicine, v.50, p. 2227-32.

\begin{tabular}{l|l|l} 
ANO: 2011 & PAÍS: Taiwan & IDIOMA: Inglês
\end{tabular}

\section{NÚMERO DE CASOS:}

Uma paciente com 72 anos de idade.

\section{TIPO DE PROCEDIMENTO:}

Artroplastia total de joelho direito.

\section{AGENTES ISOLADOS:}

Mycobacterium abscessus e Mycobacterium fortuitum.

\section{POSSÍVEL FONTE DE INFECÇÃO:}

Injeções intra-articulares de dexametasona - não confirmadas.

\section{OBJETIVO:}

Relatar a experiência clínica e uma revisão da literatura sobre infecção prostética articular por NTM.

\section{CONCLUSÃO:}

Em conclusão, MNT deveriam ser consideradas para a lista de patógenos possíveis para infecção de prótese articular do joelho. Co-infecção com dois tipos de Micobactéria de crescimento rápido é possível. Análises microbiológicas específicas para micobactérias são necessárias para o diagnóstico e repetidas análises devem ser feitas para afastar co-infecção por outras espécies de MNT, evitando evolução desfavorável do tratamento. Remoção da prótese e prolongado tratamento com antibióticos adequados antes de reimplantar a prótese são os pontos-chave para o tratamento de infecção de prótese articular no joelho por MNT. 